\title{
Resource Evaluation and Site Selection for Microalgae Production Systems
}

\author{
Eugene L. Maxwell \\ A. Gray Folger \\ Susan E. Hogg
}

May 1985

Prepared under Task Nos. 3337.86 and 1028.01

Solar Energy Research Institute

A Division of Midwest Research Institute

1617 Cole Boulevard

Golden, Colorado 80401

Prepared for the

U.S. Department of Energy

Contract No. DE-AC02-83CH10093 


\section{PREFACE}

This report describes the procedures used and the results of an evaluation of land, climate, and water resources in the Southwest and their impact on the siting of microalgae biomass production systems. Proper use of the "suitability" maps prepared under this project requires a knowledge of the data used and the compositing procedures. Providing that knowledge along with guidance to the potential user is the primary objective of this report. The current maps can be used to identify large regions which are probably more suitable than others. Selection of specific sites within these "suitable" regions will require the collection of more data and the employment of finer resolution for analysis and display purposes.

The authors wish to express their appreciation for the support received from the Biomass Program and specifically from Larry Raymond and Mike Lowenstein. Technical guidance was provided by many people, too numerous to list. Special recognition is given to Bill Larson (Colo. State Univ.) for the photointerpretation of over 100 Landsat images and to David Hildbold (Colo. State Univ.) and Keith Turner (Geometronics International) for their part in the onerous manipulation of map data in the original and digital formats, respectively.

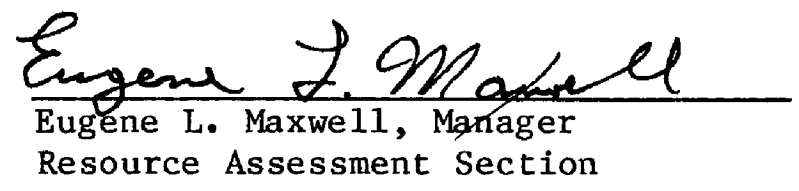

Approved for

SOLAR ENERGY RESEARCH INSTITUTE

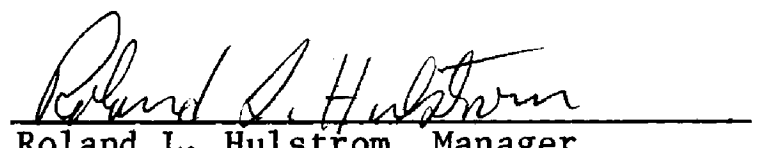

Roland L. Hulstrom, Manager

Resource Assessment \& Instrumentation Branch

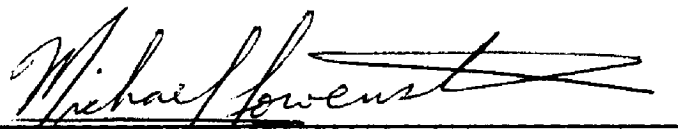

Michael Loxfenstein, Coordinator Biomass Program

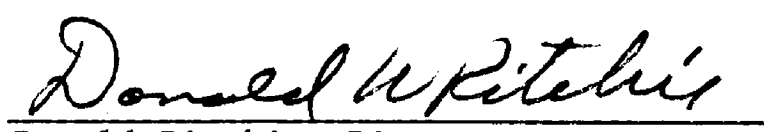

Donald Ritchie, Director

Solar Electric Conversion Research Division

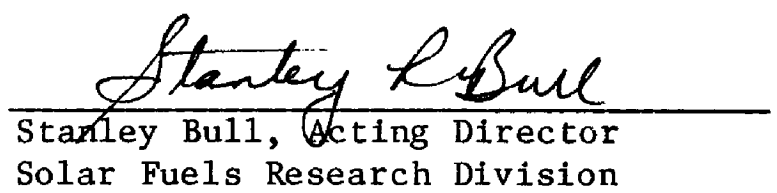




\section{SUMMARY}

Climate, 1and, and water resource requirements of microalgae production systems (MPS) were examined relative to construction costs, operating costs, and biomass productivity. The results of these system considerations were used to guide the stratification of the Southwest into zones of relative suitability for microalgae production. The resource study was conducted in the Southwest because of known high levels of insolation, the availability of saline water resources, and the existence of vast acreages of relatively low valued land. The results of the study are summarized below.

\section{Resource Relationships}

The relationships between microalgae production systems and climate, water, and land resources are briefly defined below. Reference to Figures 2-2, 3-1, 4-2, 5-1, and 5-2 in the main body of the report will further clarify these relationships.

\section{Climate}

Under the general category of climate, one finds that insolation and temperature (length of growing season) directly affect productivity whereas evaporation, precipitation, and severe storms represent environmental constraints. Annual evaporation and precipitation combine to determine the makeup water which must be supplied to the ponds. This represents a significant operating cost and will restrict the location of such systems to regions having adequate water supplies. Severe storms (thunderstorms, hail, high winds) could seriously damage covered systems. Even for an uncovered system, the introduction of contaminants from high winds and the damage that would be incurred from hail storms and tornados represent serious constraints.

\section{Water}

The four parameters found under water resources include supply/demand and location which represent resources of interest, and salinity and chemistry which generally represent constraining factors that could limit the availability and/or the usefulness of the water resources. Allocation involves the complexities of water law and water distribution systems in the southwestern United States and will almost surely present one of the most difficult and limiting problems.

\section{Land}

The primary land resource of interest can be described as the available acreage at locations suitable for the construction of microalgae production systems. Land use and land cover will constrain the installation of aquatic biomass production systems for a number of reasons. Certain land uses may give the land such a high value that converting the land to the production of 
biomass for energy would be economically infeasible. Other land uses represent very sensitive environmental or political constraints which will eliminate such lands from consideration. These include national parks, designated wilderness areas, and certain military reservations.

Land ownership is important in the Southwest because of the large holdings of the federal and state governments. Indian reservations also comprise a significant proportion of the land. In effect, land ownership represents political constraints on land availability.

Topography will be a limiting factor for these systems since the installation of large shallow ponds requires relatively flat terrain. As a first approximation, lands having a slope greater than $10 \%$ will be designated as unsuitable or limiting for these systems. These slope limitations will be refined at a later date when more design information is available.

\section{Critical Resource Issues}

The critical resource issues relative to microalgae production in the Southwest are itemized below:

- Annual insolation

- Length of growing season

- Land and water stewardship

- Legal and political constraints on 1and availability

- Environmental constraints on land and water availability

- Water law constraints on water availability

- Sustainable water yields

- Development of an infrastructure to supply nutrients.

These issues can be directly related to data requirements and needed research which must be undertaken in the near future.

\section{The Initial Stratification of the Southwest}

The southwestern United States was chosen as the focus of this resource assessment study primarily on the basis of the region's characteristically high levels of insolation. The presumed availability of relatively inexpensive desert land and saline groundwater resources was also influential in the decision. The region of study, which includes the panhandle of Oklahoma, west Texas, New Mexico, Colorado, Utah, Arizona, Nevada, and southern California, is characterized by diverse terrain and a generally arid or semi-arid climate.

The objective of this effort was not to select specific sites for microalgae production, but rather to stratify the southwestern United States into zones of varying suitability for such systems. Actual site selection was ruled out because of the many system-dependent considerations involved. Future work 
will examine the areas or zones of greatest suitability for the selection of specific sites.

\section{Stratification Process}

The geographic stratification process was performed in four steps:

$$
\begin{aligned}
& \text { Step } 1 \text { - Application/Resource Systems Study } \\
& \text { Step } 2 \text {-- Overlay Map Production } \\
& \text { Step } 3 \text { - Digitization of Maps } \\
& \text { Step } 4 \text { - Preparation of Composite Maps }
\end{aligned}
$$

The systems study under Step 1 established the dependency of micralgae production on natural resources and served to identify resource needs and environmental relationships. Specifically, Step 1 identified the resources and environmental parameters of interest and defined the data and maps that will be needed to accomplish the task at hand. The results of the studies of microalgae production systems are summarized in Section 2.0 of this report.

Step 2 was conducted in response to Step 1 and entailed data collection and the making of maps.

Step 3 saw the conversion of the resource data from map formats to a digital form which could be read by a computer.

Step 4, the preparation of composite maps, was itself a multi-step process that contained the following steps:

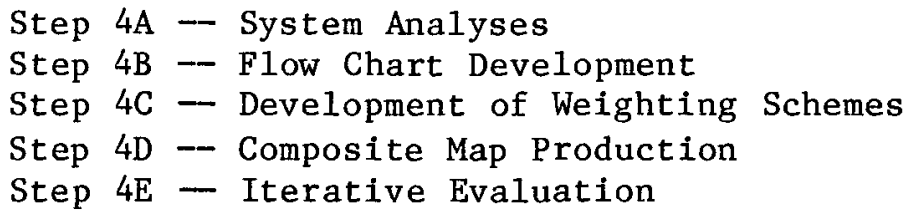

The systems analyses conducted at this point were designed to develop functional relationships between resource parameters and construction costs, operating costs, and biomass productivity. The actual procedures employed and the results of Steps 1 through $4 \mathrm{E}$, as carried out for the stratification of the Southwest, are described 1ater.

\section{Climate Maps}

The climate maps generated were:

- Global Horizontal Insolation (Figure 6-4)

- Freeze-Free Period (Figure 6-5)

- Precipitation (Figure 6-6)

- Evaporation (Figure 6-7)

- Thunderstorm Days (Figure 6-8) 
These annual maps were obtained from the "Solar Radiation Energy Resource Atlas of the United States" and the "Climatic Atlas of the United States." The originals were at a scale of $1: 10,000,000$.

\section{Land Resource Maps}

The land resource maps generated were:

- Ten Percent Slope (Figure 6-9)

- Land Use/Cover (Figure 6-10)

- Land Ownership (Figure 6-12)

Slope maps were not available for most of the Southwest. The only practical means for generating slope maps for this project was the manual interpretation of elevation contour lines on topographic maps. State maps at a scale of 1:500,000 were selected for reasons of economy. Land use/cover maps were not available for most of the Southwest. Approximately 130 Landsat color transparencies, at a scale of 1:1,000,000, were photointerpreted using a modified classification scheme developed by Anderson et a1. (1976).

Land ownership maps were obtained from the BLM for all states except Texas and Oklahoma. These BLM "Land Status Maps" were created in 1979 at a scale of 1:500,000 and a resolution of 120 acres, two orders of magnitude better than the 12,455 acre cell created by the digitization process used on this project.

\section{Water Resource Maps}

The only readily available, compatible map data for mineralized groundwater resources of the Southwest was that prepared by Feth et al. (1965). This nationwide compilation of data came from many sources in 34 states. The largest single contributor was the U.S. Geological Survey.

The character, reliability, and usefulness of the data displayed on Feth's maps can be summarized by the following statements:

- On1y the uppermost zone of mineralized water was mapped according to its occurence at depths of $0-500 \mathrm{ft}, 500-1000 \mathrm{ft}$, and greater than $1000 \mathrm{ft}$.

- The available data were grouped into the following categories of mineral concentrations :

$$
\begin{array}{r}
1,000-3,000 \mathrm{ppm} \\
3,000-10,000 \mathrm{ppm} \\
10,000-35,000 \mathrm{ppm} \\
>35,000 \mathrm{ppm}
\end{array}
$$

- The information was derived primarily from data of opportunity, obtained from wells being drilled for purposes other than exploration for mineralized water. Thus, the sampling was not statistically designed. 
Overall one must conclude that water resource information is seriously deficient and represents a major weakness in this attempt to stratify the Southwest into zones of suitability for microalgae production. Figure 6-13 shows the polygon map of saline water resources for the Southwest.

\section{Development of Suitability Maps}

Based on the results of the systems analysis, the flow chart shown in Figure 6-19 was developed to guide the compositing process. The first step in the process involved the development of a relative productivity map from the composite of insolation and freeze-free period and the development of a makeup water map from the composite of precipitation and evaporation.

The second step in the compositing process called for the development of individual climate, water, and land suitability maps. These intermediate results are useful for several reasons. First, each of the resultant maps provide informative and very different kinds of suitability data of value to the future development of microalgae systems. Furthermore, the quality and reliability of the climate, water, and land data were quite different, making it desirable to present the resultant composite maps separately.

Two final or combined composites were prepared: the first was formed by combining land and climate suitability maps. Water was excluded from the first because of the questions surrounding the water resource data. In particular, the sparsity of the data and its "data of opportunity" character make one hesitate to give the water suitability map much weight. Therefore, the climate/land suitability composite is probably more significant than the overall suitability map, which included water suitability.

The results of the compositing process are shown in Figures 6-20 through 6-26. They clearly have achieved the stratification of the Southwest into zones of relative suitability, which will guide future resource studies and site selection efforts.

\section{Plans for Future Assessments, Stratification, and Site Selection}

Plans for future work should be developed with the following important considerations in mind.

1. The saline groundwater data for the southwestern United States must be considered as lacking in geographic coverage, inadequate regarding aquifer yield and water salinity data, deficient regarding supporting geologic strata information, and generally suspect and inadequate for the design and siting of aquatic biomass production systems.

2. The slope information generated under this project is based on an arbitrary suitability boundary, established for a slope of $10 \%$. A range of slopes should be mapped prior to the refinement of the stratification process and prior to site selections. Both the vertical and horizontal resolutions of the $1: 500,000$ scale maps used to generate the slope map are inadequate for site selection. 
3. The climate data, though of good quality, relate directly to the growth of plants above the surface of the earth. Models must be developed to relate available climatological and meteorological data to the growth environment of shallow ponds containing microalgae cultures. Furthermore, the national resolution of the climate data is inadequate for site selection purposes. State and county level data must be obtained where available and if such data are not available measurement programs will be required.

4. In order to complete the initial stratification within the time and monies alloted, land ownership and land use classes were combined into broad general categories. Furthermore, the digitization employed resulted in a 10:1 degradation in the spatial resolution of the original data. In this instance, the original work was done at scales of $1: 500,000$ and $1: 1,000,000$. A11 of the original information has been retained for future work.

5. Water law and environmental law could easily become the dominant factors detering or prohibiting the construction and operation of large-scale aquatic biomass production systems. 


\section{TABLE OF CONTENTS}

Page

1.0 Introduction $\ldots \ldots \ldots \ldots \ldots \ldots \ldots \ldots \ldots \ldots \ldots \ldots \ldots \ldots \ldots \ldots \ldots \ldots \ldots \ldots \ldots \ldots$

2.0 Microalgae Systems, Natural Resources, and the Environment........ 3

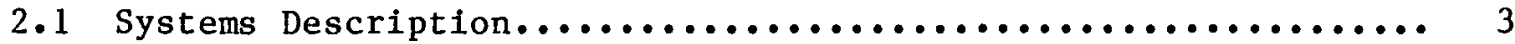

2.2 Critical Resource Issues........................... 5

2.2.1 Climate Constraints........................... 6

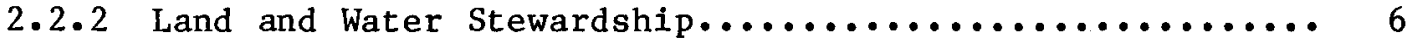

2.2.3 Land and Water Availability..................... 6

2.2 .4 Nutrient Supplies............................ 7

2.2.5 Summary of Critical Resource Issues................ 7

3.0 Climate Resources................................. 8

3.1 Climate Controls.................................. 8

3.2 Climate Data and Data Sources........................ 9

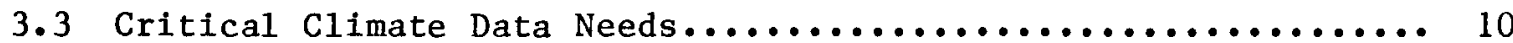

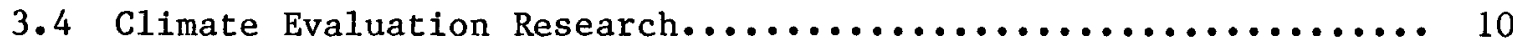

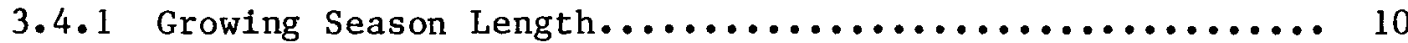

3.4 .2 Propagation of Light into Ponds.................. 11

3.4.3 Wind and Particle Transportation.................. 11

4.0 Water Resources................................... 12

4.1 Water Controls.................................. 12

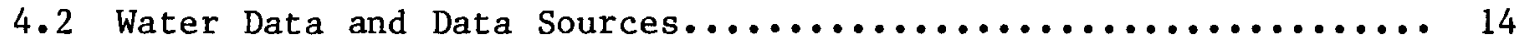

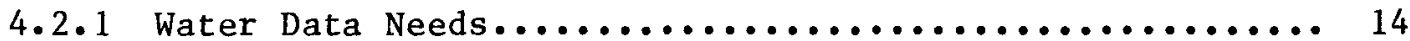

4.2.2 Water Data Sources............................. 14

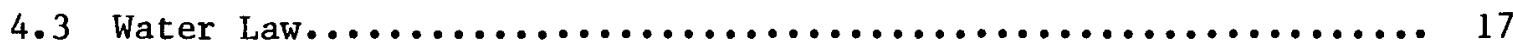

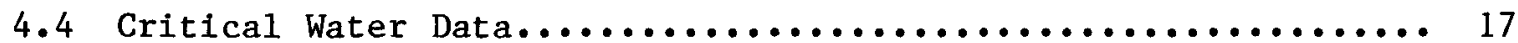

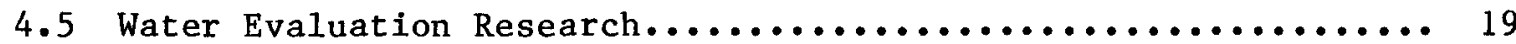

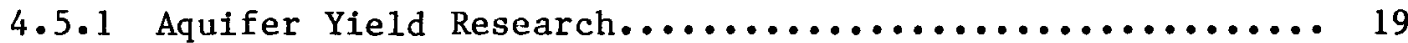

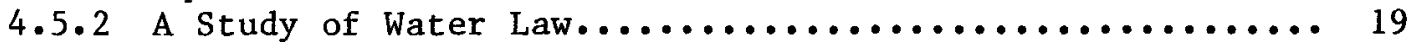

4.5.3 Environmental Impact Research.................... 20

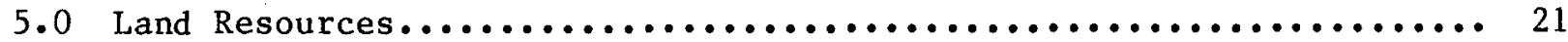

5.1 Land Controls................................... 21

5.2 Land Resource Data and Data Sources.................... 23

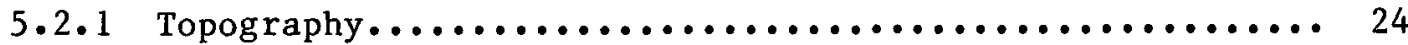

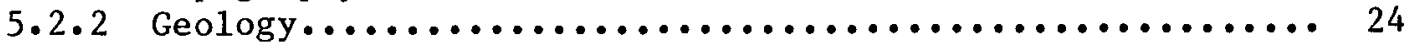

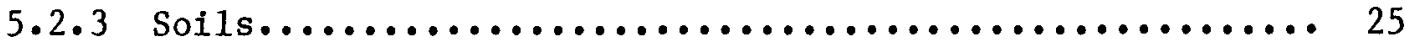

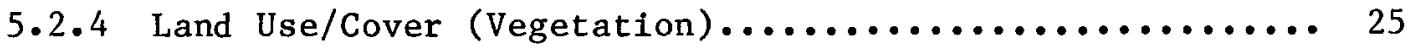

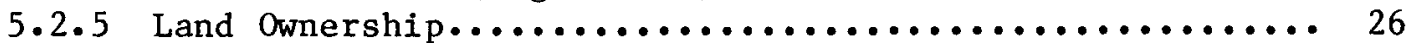

5.3 Critical Land Data.............................. 27

5.3 .1 Topography................................... 27

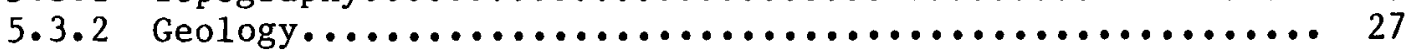

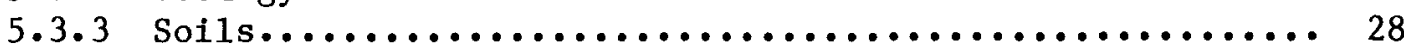

5.4 Land Resources Research........................... 28 


\section{TABLE OP CONTENTS (Concluded)}

$\underline{\text { Page }}$

6.0 Initial Stratification of the Southwest.................... 29

6.1 Stratification Process............................. 29

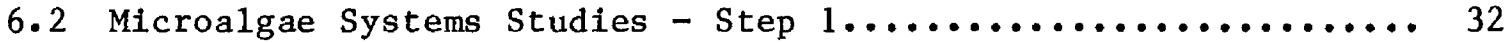

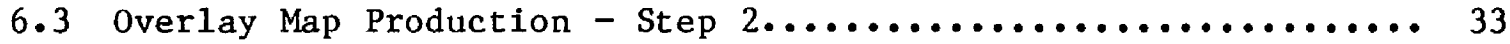

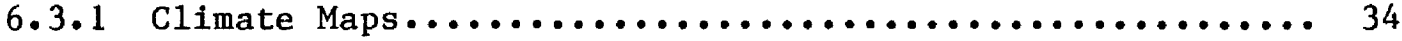

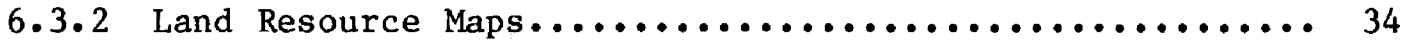

6.3 .3 Water Resource Maps.......................... 43

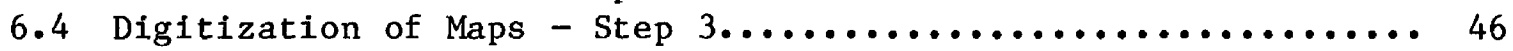

6.4 .1 Climate Maps............................... 46

6.4 .2 Land Resource Maps.......................... 46

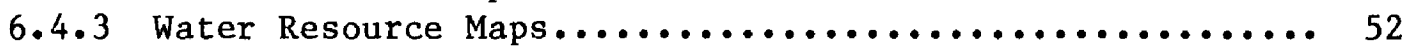

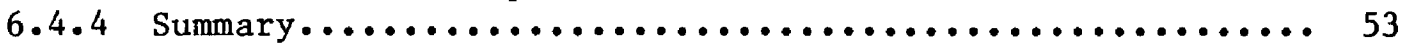

6.5 Compositing the Maps for the Southwest - Step 4........... 53

6.5 .1 Systems Analyses - Step 4A.................... 53

6.5 .2 Flow Chart Development - Step 4B................. 60

6.5.3 Development of Weighting Schemes - Step 4C........... 62

6.5 .4 Composite Map Production - Steps 4D and 4E.......... 62

6.5 .5 Climate Suitability Composite................... 63

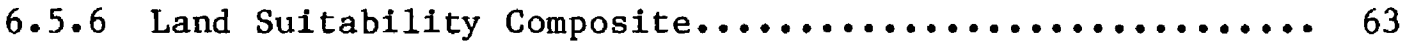

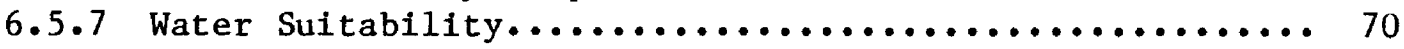

6.5 .8 Overall Suitability Composites................. 70

7.0 Plans for Future Assessments, Stratification, and Site Selection.... 80

8.0 References...................................... 82 


\section{LIST OF FIGURES}

$\underline{\text { Page }}$

2-1 Artist's Concept of a Microalgae Biomass Production System........ 4

2-2 Typical Microalgae Biomass Production System and Significant Conversion Parameters....................... 4

3-1 Climate Controls on Water Demand and Aquatic Biomass Production.... 8

4-1 The Hydrologic Cycle, Including Processes that Control the Availability of Water Resources...................... 13

4-2 Factors and Processes that Control Water Yield from a Groundwater Reservoir............................... 13

4-3 U.S. Water Resource Regions Based on Physiographic and Water Resource Features................................. 15

4-4 Sources of Information on Water Resources Indicating Data Formats Generally Available........................... 15

4-5 Data Sources for the National Water Data Exchange (NAWDEX) System......................................... 16

4-6 Controls Imposed by Regulations and Competition on the Use of Groundwater and Procedures to Gain Continued Access to Groundwater........................................

5-1 Factors that Influence the Availability of Land for Microalgae Production Systems.................................. 21

5-2 Sequence of Controls that Define Land Available for Microalgae Production...............................

6-1 Overlay of Possible Land Ownership and Land Use Patterns in the Western United States that Can Be Simulated in a Computer Geographic Information System................... 30

6-2 Overlay Concept of Figure 6-1 with the Addition of Climate and Water Resource Parameters for Resource Stratification........ 31

6-3 Region Included in the Stratification of our Study Area.......... 33

6-4 Annual Average of the Daily Total Global Horizontal Insolation for the Study Area in $\mathrm{kWh} / \mathrm{m}^{2}$ day................ 35

6-5 Annual Freeze-Free Period for the Study Area in Days........... 35

6-6 Annual Precipitation for the Study Area in Inches.............. 36 


\section{LIST OF FIGURES (Continued)}

$\underline{\text { Page }}$

6-7 Annual Pan [Evaporation for the Study Area in Inches] $\ldots \ldots \ldots \ldots$

6-8 Annual Thunderstorm Days for the Study Area................. 37

6-9 Portion of Study Area with a Slope of $10 \%$ or More............ 38

6-10 Land Use Map of New Mexico Generated by Photointerpretation of $1: 1,000,000$ Scale False Color Composites of Landsat Images....... 41

6-11 Portion of the BLM Land Status Map of New Mexico Showing the Checkerboard Patterns of Public, State, and Private Ownership..... 42

6-12 Polygon Map of Land Ownership Patterns in New Mexico.......... 44

6-13 A Saline Groundwater Map of the Study Area Based on Data of Opportunity from Feth et al. (1965)................ 45

6-14 Polygon and Digital (Line Printer) Versions of the Freeze-Free Period Maps for the Study Area.......................... 47

6-15 Polygon and Digital (Line Printer) Versions of the $10 \%$ Slope Map for the Study Area................................ 48

6-16 Digital Version of the Land Use Map of the Study Area.......... 50

6-17 Progressive Loss of Information Illustrated by Original, Polygon, and Digital Land Ownership Maps for a Small

Region in Southern New Mexico......................... 51

6-18 Digital (Line Printer) Map of Land Ownership for the Study Area.... 52

6-19 The Map Compositing Process Used to Stratify the Southwest into Zones of Relative Suitability for Microalgae Production of

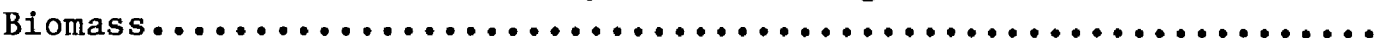

6-20a Estimated Relative Productivity of Shallow Pond Microalgae Production Systems in the Study Area...................... 64

6-20b Computations Performed in the Compositing of Insolation and Freeze-Free Period Maps to Generate the Relative Productivity Map; A1so Bar Graph with Relative Productivity Proportionate Occurrence of Each Class............................. 65

6-21a Estimated Make-Up Water Required to Maintain a Constant Water Leve1 in Shallow, Uncovered Ponds in the Study Area............ 66 


\section{LIST OF FIGURES (Concluded)}

6-21b Computations Performed in the Compositing of Precipitation and Evaporation Maps to Generate the Make-Up Water Map; Also Bar Graph Depicting the Proportionate Occurrence of Each Make-Up

Water Class......................................

6-22a Zones of Relative Suitability for Microalgae Biomass

Production Based on Climate Factors........................ 68

6-22b Process Employed to Combine Relative Productivity, Make-Up

Water, and Thunderstorm Day Maps to Generate the Climate

Suitability Map; Also Bar Graph of Relative Suitability

and Proportionate Occurrence of Each Class....................

6-23a Zones of Relative Suitability for Microalgae Biomass Production

Based on the Availability and Suitability of Land Resources...... 72

6-23b Process Employed to Combine Land Use, Land Ownership, and

Gradient (10\% Slope) Maps to Generate the Land Suitability

Map; Also Bar Graph Defining Types of Land Parcels and

Proportionate Occurrence of Each Class.................... 7

6-24a Zones of Relative Suitability for Microalgae Biomass

Production Based on the Depth to Saline Groundwater............ 74

6-24b Assignment of Each Depth Class to a Suitability Class and the Proportionate Distribution of Each Class................ 75

6-25a Zones of Relative Suitability for Microalgae Biomass Production Based on a Compositing of the Climate and Land Suitability Maps.... 76

6-25b Process Employed to Combine Land and Climate Suitability Maps to Generate the Climate/Land Suitability Map; Also Bar Graph Showing Relative Suitability and Proportionate Occurrence of Each Class.....................................

6-26a Zones of Relative Suitability for Microalgae Biomass Production Based on a Compositing of Climate, Land, and Water Suitability Maps..........................................

6-26b Process Employed to Combine Climate, Land, and Water Suitability Maps to Generate the Overall Suitability Map; Also Bar Graph Depicting the Total Suitability and Proportionate Occurrence of Each Class. 


\section{LIST OF TABLES}

Page

5-1 Land Resource Data Requirements.......................... 23

6-1 Land Use/Cover Classes................................ 39

$6-2$ Land Ownership Classes............................... 43

6-3 Land Use/Cover Classes Used for Digital Map.................. 49

6-4 Land Ownership Classes for Digital Map.................... 50 
S=P굴 
SECTION 1.0

\section{INTRODUCTION}

This report is about aquatic biomass production systems and their potential use as renewable sources of chemicals, food, and fuels. More specifically, this report addresses the interactive impact of land, water, and climate on the siting, design, construction, and operation of microalgae systems. This report was prepared for R\&D program administrators and research scientists at DOE, SERI, and other laboratories involved in aquatic species research. Therefore, little background is presented about microalgae production systems and required microalgae culture conditions.

One objective of this report is to translate the knowledge of culture requirements gained from laboratory and small pond research into the resource demands and environmental constraints of large operational systems. The initial concept of a large microalgae system, in the eyes of a laboratory scientist, is often on the order of a few acres. However, if such systems are to become significant sources of energy on a national scale, one must think in terms of hundreds of square miles of algae pond systems. This is given proper perspective when microalgae systems are compared with other biomass production systems, such as the more than 1000 center-pivot irrigation systems operated in Colorado alone, which collectively cover over 250 square miles and represent an equipment investment on the order of $\$ 40 \mathrm{~K}$ each. The millions of acres of rice paddies around the world provide another comparison.

Eventual investors in large microalgae systems must have the answers to questions such as these:

- Why is this a cost-effective use of these resources at this location? Why not some other location? Why not some other use of resources?

- Will needed resources (water, $\mathrm{CO}_{2}$, etc.) be available at acceptable costs for the expected lifetime of the system?

- What are the legal/political constraints on resource availability and environmental impact?

- How accurate and reliable are the available resource and environmental data? Are available data adequate? If not, how should one obtain needed data?

The answers to these questions will not be found in the laboratory or in this report. However, this report does provide insight into resource issues and evaluates the suitability of the southwestern United States for large-scale microalgae production. In the process of evaluating resources of the Southwest, critical resource issues, data requirements, and research needs have been identified. In general, these factors are pervaded by climate and water, which will probably dictate the siting of large-scale, outdoor microalgae production systems.

The study reported herein concentrated on the southwestern United States which is characterized by an arid to semiarid climate and varying topography. 
Readily available resource data were collected for the Southwest and used to stratify the entire region into zones of varying suitability for large-scale microalgae production. This initial stratification provides estimates of the total acreage judged suitable for microalgae production in the Southwest. It also identifies prime regions for the location of experimental ponds and associated test facilites. 


\section{SECTION 2.0}

\section{MICROALGAE SYSTEMS, NATURAL RESOURCES, AND THE ENVIRONMENT}

\subsection{SYSTEMS DESCRIPTION}

Existing microalgae production systems (MPS) have been reviewed and described by Goldman (1979) and by Benemann and Raymond (1981). Many systems are also described in the conference papers which were edited and compiled by Shelef and Soeder (1980). While a great variety of MPS have been described, they tend to fall into one or more of the following categories: (1) bench-scale or pilot-scale systems of research laboratories; (2) waste treatment oxidation ponds; or (3) adaptations of existing natural water bodies. A few commercially operated systems exist, but most have been designed and operated for R\&D purposes.

Large-scale land-based culture facilities for commercial microalgae production for energy have not been developed. In fact, except for the 2000-acre modular units described by Benemann, Pursoff, and Oswald (CSO International 1978), there has been very little development of concepts and designs for such facilities. Lacking appropriate design specifications, it is difficult to accurately determine system demands on natural resources and the environment. The approach used in this investigation, therefore, has been to extrapolate from the technology as it currently exists to form preliminary judgments on natural resource suitability and the environmental impacts of large-scale systems in the southwestern United States.

Figure 2-1 shows an artist's rendition of a commercia1-scale MPS under the conditions of the Southwest. While much technical detail has obviously been omitted, the figure portrays the interactive relationships that would exist between microalgae systems, natural resources, and the environment. Further, the illustration suggests that "large-scale" systems do not necessarily entail extremely large ponds but could instead be engineered as interconnected arrays of smaller site-adapted ponds.

The system is shown installed on essentially flat or gently rolling terrain over, or very close to, a subsurface saline water supply. The great majority of the land surface within the region will be covered by shallow ponds or channels which themselves may be covered with a transparent plastic material. The covering of the ponds or channels may not be reciuired, but in the Southwestern climate, covering will reduce evaporation and the introduction of contaminants from wind-blown materials.

A concept of these systems is depicted in Figure 2-2, which shows basic inputs, processes, and products of microalgae production. Figure 2-2 also shows the major resource and environmental parameters that pertain to the inputs of climate, water, and land. These parameters were selected because of their importance to siting, design, production efficiency, and costs. For each parameter, a variety of conditions may be more or less favorable to costeffective siting and operation of MPS. 


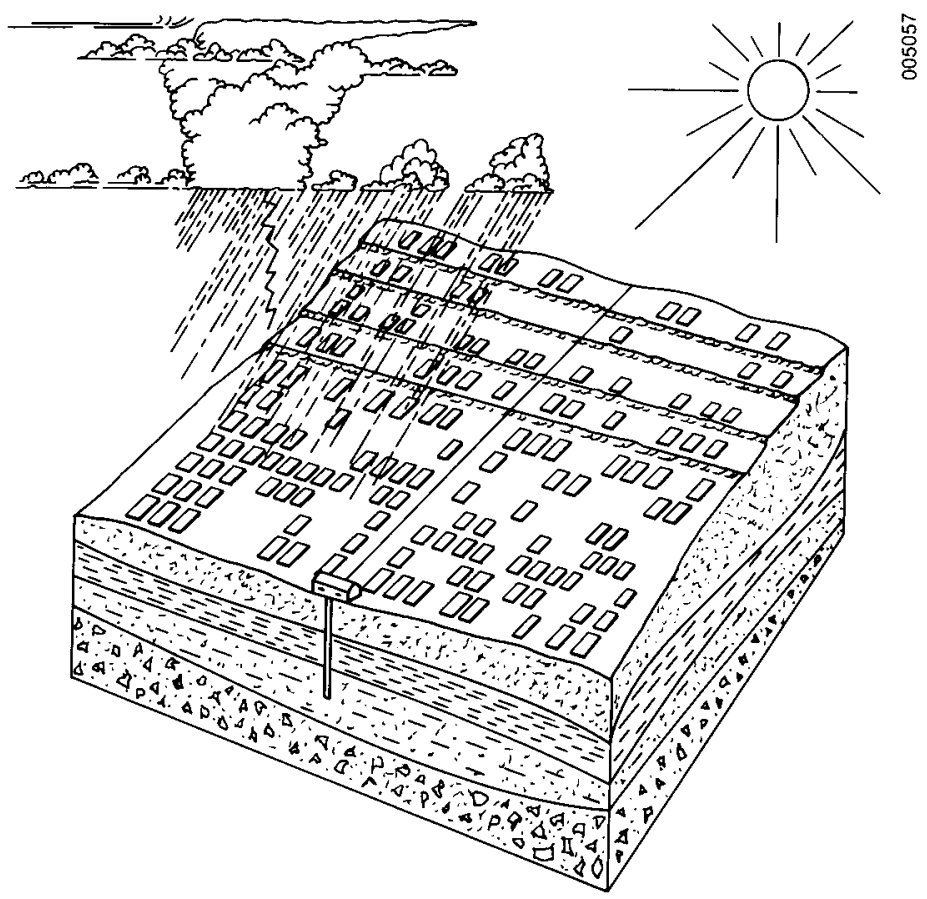

Figure 2-1. Artist's Concept of a Microalgae Biomass Production System

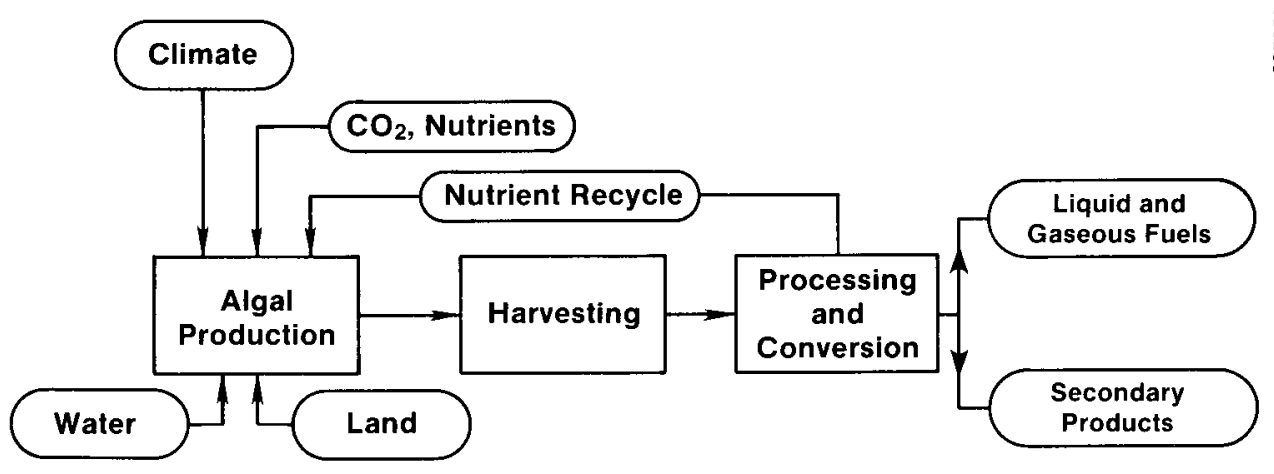

\section{Resource and Environmental Parameters}

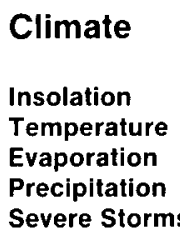

Water
Location
Supply/Demand
Salinity
Chemistry
Allocation

Land

Figure 2-2. Typical Microalgae Biomass Production System and Significant Conversion Parameters 
Under the general category of climate, insolation and temperature (length of growing season) directly affect productivity, whereas evaporation, precipitation, and severe storms represent environmental constraints. Annual evaporation and precipitation combine to determine how much makeup water must be supplied to the ponds. This represents a significant operating cost and will restrict the location of such systems to regions having adequate water supplies. Severe storms (thunderstorms, hail, high winds) could seriously damage covered systems. Even for an uncovered system, the introduction of contaminants from high winds and the damage caused by hail storms and tornados represent serious constraints.

The four parameters under the general category of water resources include supply/demand and location, which represent resources of interest, and salinity and chemistry, which generally represent constraining factors that could limit the availability and the usefulness of the water resources. Allocation involves the complexities of water law and water distribution systems in the southwestern United States and will probably be one of the most difficult and limiting problems.

The primary land resource of interest can be simply described as the available acreage at locations suitable for the construction of microalgae production systems. With the exception of geology, therefore, the parameters in Figure 2-2 under land represent constraints that will limit the total acreage available for this application.

Land use and land cover will constrain the installation of aquatic biomass production systems for a number of reasons. Certain land uses may give the land such a high value that converting the land to the production of biomass for energy would be economically infeasible. Other land uses represent very sensitive environmental or political constraints that will eliminate such lands from consideration. These include national parks, designated wilderness areas, and certain military reservations.

Topography will be a limiting factor for these systems since the installation of large shallow ponds requires relatively flat terrain. As a first approximation, lands having a slope greater than $10 \%$ will be designated as unsuitable or limiting for these systems. These slope limitations will be refined at a later date when more design information is available.

Soils also represent a constraint on aquatic production systems. A minimum soil depth will be required in order to construct a pond at a reasonable cost. The porosity, permeability, and compactibility of the soils will be important relative to the effectiveness of efforts to seal ponds to reduce water losses to an acceptable value. The microalgae provide some natural sealing, depending on soil characteristics.

\subsection{CRITICAL RESOURCE ISSUES}

Critical resource issues are those issues that will determine the practicality and economic feasibility of microalgae biomass production systems. These issues are based on our current understanding of microalgae production systems, and one must recognize that a critical issue today might become less so in the future and vice versa. 


\subsubsection{Climate Constraints}

An obvious prerequisite to high production of biomass is a high annual level of insolation. Achieving a high efficiency in the conversion of solar energy to stored chemical energy further requires favorable temperature, moisture, and nutrients essential to the photosynthetic processes. The various species of microalgae grow under a wide range of temperatures and, therefore, temperature per se will not likely be critical. High annual production for a given species, however, will require that suitable climatic conditions exist for a major part of the year. The critical climate issues, therefore, are annual insolation and length of growing season.

\subsubsection{Land and Water Stewardship}

Microalgae production systems could be established upon almost any flat surface, and various species of microalgae will grow efficiently in almost any degree of salinity from fresh water to almost saturated brine. It might seem, therefore, that land and water should not present any critical resource issues. Because of the need for conservation of land and water resources and the increasing demands for these resources, this is not the case. Because microalgae production systems are less demanding than many other uses of our land and water resources, good stewardship requires the selection of species and the design of systems that will function efficiently using land and water for which there is currently little demand. It is primarily for these reasons that the arid lands of the Southwest and the saline groundwater that underlies them are receiving heavy consideration for these systems.

One must not make the mistake, however, of considering these lands and water resources to be useless. Our desert ecosystems are important to many plants, animals, and people, and the saline water resources are an integral part of the overall hydrological system in the desert Southwest.

\subsubsection{Land and Water Availability}

The developers of the race track MX missile system made the mistake of initially assuming seemingly barren desert lands are unwanted or basically undesirable. In many instances this is really not correct and even in those situations where the lands are essentially unused, there may be restrictions imposed by existing land ownership such as Indian treaties, designation of areas for preservation as wilderness, and complex legal and political problems surrounding the actual availability of the lands. Add to this the potential environmental impact of any large system, and one quickly realizes that the practical availability of land will ultimately be an important resource issue.

The complexity of western water law places the availability of water resources in a similar critical position. The establishment of water rights that will guarantee the availability of water over the lifetime of a microalgae production system will likely be one of the most critical issues. Added to the legal question is the technical difficulty encountered when one tries to define long-term sustainable water yields from an aquifer. This will be the subject of future research. 


\subsubsection{Nutrient Supplies}

There is little question of adequate supply when one considers natural sources of nutrients such as carbon dioxide, phosphates, nitrogen, etc., as well as the generation of such nutrients as by-products of power plants and other industrial operations. The critical issue will become the development of an infrastructure to economically supply the required nutrients. Whereas the agricultural industry has built up a very reliable infrastructure for supplying liquid and dry pelletized fertilizer for efficient delivery to individual farms, no system exists for supplying gaseous $\mathrm{CO}_{2}$ to a $100-\mathrm{mi}^{2}$ system of microalgae ponds.

\subsubsection{Summary of Critical Resource Issues}

The critical resource issues are summarized as follows:

- Annual insolation

- Length of growing season

- Land and water stewardship

- Legal and political constraints on land availability

- Environmental constraints on land and water availability

- Water law constraints on water availability

- Sustainable water yields

- Development of an infrastructure to supp1y nutrients.

These issues can be directly related to data requirements and needed research which must be undertaken in the near future. These topics will be discussed in the following sections under the separate treatments of climate, water, and land resources. 


\section{SECTION 3.0}

\section{CLIMATE RESOURCES}

The impact of climate on microalgae production systems is comparable to the impact of climate on any agricultural system, but there are some unique aspects which result from photosynthetic production within a water body rather than within the air. As shown in Figure 3-1, solar radiation is still the basic source of energy, but the radiation must penetrate beneath the surface of the water to irradiate the plants. The controls that the climate imposes on aquatic biomass production are illustrated in Figure 3-1, and are discussed in the following subsection.

\subsection{CLIMATE CONTROLS}

Figure 3-1 is a systems diagram developed specifically to illustrate climate controls on water demand and aquatic biomass production. The arrows represent both inputs and outputs to and from the system. The valve symbols ( $\triangleleft$ ) represent any factor or process that controls flow into and out of the system.

The water which must be supplied to the pond is controlled by precipitation and evaporation. In turn, precipitation is controlled by cloud cover. This is a very simplistic representation of precipitation controls, since factors other than the presence or absence of clouds are operating. The controls on evaporation are air temperature, surface temperature, wind, humidity, and surface insolation.

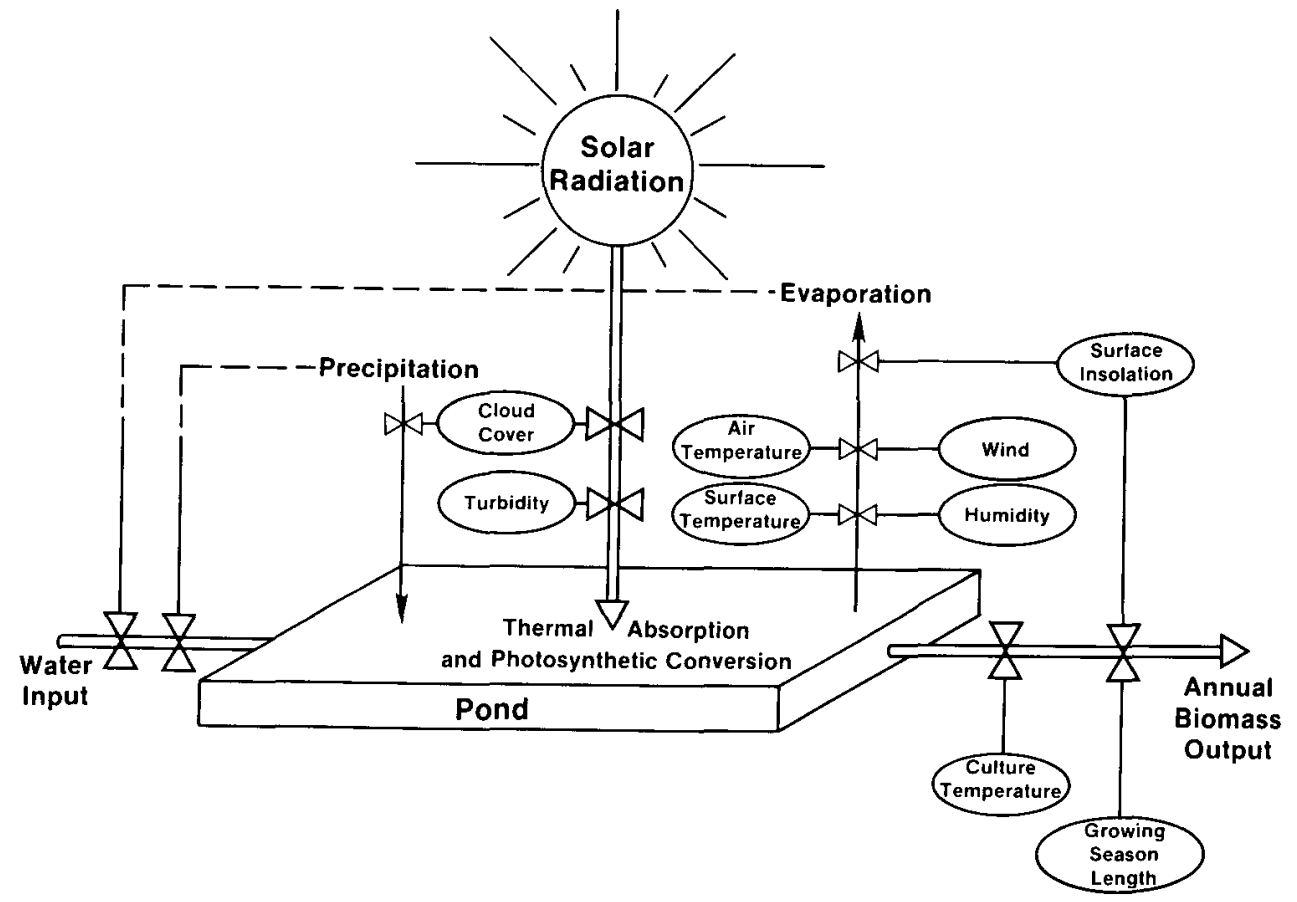

Figure 3-1. Climate Controls on Water Demand and Aquatic Biomass Production. (Valves indicate controlling processes or factors.) 
The solar radiation incident upon the pond is controlled by cloud cover and atmospheric turbidity. Time of day and season also affect the incident solar radiation, but these were not considered as climate controls. The climate itself is directly controlled by latitude, which in turn determines the length of the day and the solar elevation. The thermal absorption and photosynthetic conversion of the incident solar radiation directly affect the water temperature and the primary production of biomass within the pond.

The annual primary production, or biomass output obtained from the aquatic production system, is directly related to the surface insolation, the culture temperature, and the growing season length.

Since microalgae are known to be capable of surviving, if not thriving, under an extremely wide range of environmental conditions, climatic controls are not likely to totally eliminate a site from consideration for aquatic biomass production. Instead of being geographically limiting, climate parameters are likely to affect production efficiency and operating costs. The use of models to estimate production costs and production efficiency for an aquatic biomass system requires data for the parameters shown in Figure 3-1.

\subsection{ClIMATE DATA AND DATA SOURCES}

The specific data needed for each of the general climate parameters shown in Figure 3-1 are listed below. Pond temperature, though not a climate parameter per se, is included because it is controlled to a great extent by the climate and is closely linked to the length of the growing season.

- Solar radiation

- Average global horizontal insolation (monthly and annual)

- Direct normal insolation as a function of solar elevation

- Spectral characteristics of the radiation

- Air temperature

- Maximum, minimum and average daily temperature (monthly)

- Pond temperature

- Diurnal and seasonal variations as a function of insolation, air temperature, winds, pond depth, and culture density.

- Growing season length

- Freeze free period (annual average)

- Growing degree-days (annua1 average)

- Precipitation and evaporation

- Average rainfall and snowfall (monthly and annual)

- Average evaporation (monthly and annual)

- Maximum probable precipitation in 6- and 24-hour periods 
- Severe storms

- Thunderstorm days (monthly and annual)

- Hail occurrence (days per month or year and hail size)

- Tornado occurrence (days per month or year)

- Wind

- Wind velocities at the site (monthly and annual average)

- Peak velocities at the site (monthly and annual maxima)

- Regional wind fields.

Most of the climate data required can be obtained from the National Climatic Center in Asheville, N.C. Climatological summaries and the Climatic Atlas of the United States are published by the U.S. Department of Commerce (1977). More detailed, higher resolution data at the state level are generally available from the offices of state climatologists. Finally, national scale radiation data are available from the Solar Radiation Energy Resource Atlas of the United States (SERI 1981). Not only are climate data generally available, but these data are usually of high quality and provide the accuracy and reliability needed for evaluating regional suitability for biomass production.

However, not all of the data required for evaluating climate suitability for microalgae production systems are available. Some of the unique needs of these systems are discussed in Section 3.3. Furthermore, the unique data needs and system characteristics generate a need for research which is briefly described in Section 3.4 .

\subsection{CRITICAL CLIMATE DATA NEEDS}

Annual insolation is a critical resource, but it does not represent a critical data requirement since reasonable data for insolation are available. The most critical climate data requirements are those required to define the length of the growing season. Essentially, this becomes a need for data for the temperature of shallow ponds containing algae cultures. Such data are virtually nonexistent. IThe potential for contamination of microalgae cultures raises a concern over the transportation of biotic and abiotic materials by wind. Wind data are generally available from weather station operations, but information on the transportation of fine particle materials is generally not available. This could be particurlarly critical in the desert Southwest because of the general lack of vegetative cover to provide stabilization of soils.

\subsection{Climate EVALUATION RESEARCH}

\subsubsection{Growing Season Length}

The greatest uncertainties regarding the impact of climate on aquatic production systems center on a lack of data for shallow ponds. Growing degree-days or frost-free periods are directly applicable only to plants growing above the 
surface of the earth. An acceptable or at least survivable environment will exist in a pond for some time after the first frost. It is also likely that an acceptable growth environment will exist before the last frost in most regions. Hence, research needs to be conducted to develop a model that will reliably extrapolate above ground climate and weather data to the environment of covered or uncovered ponds. This study will develop relationships between pond temperatures and the surrounding physical environment and microclimate which can then be used to estimate the length of the growing season.

\subsubsection{Propagation of Light into Ponds}

There is also a lack of information regarding the penetration of solar radiation beneath the surface of a pond being used for the aquatic production of biomass. Data are available for estimating the propagation of light through clear or even muddy water, but very little information is available regarding the propagation of light through aerated or turbulent water or a dense culture of microalgae. Hence, a research program is needed to study the propagation of electromagnetic energy through cultures of aquatic plants.

\subsubsection{Wind and Particle Transportation}

Dust storms transport both biotic and abiotic materials which may pose a major threat to the survival of an MPS. In the desert Southwest, dust storms occur frequently due to the lack of vegetative cover. Little quantitative information is available, however, on material transported via these aeolian erosion processes. Needed studies include:

- The frequency and severity of dust storms in the Southwest

- Analysis of potential particle transport in the Southwest based on available wind data, surface materials, vegetative cover, and the regional geomorphology

- The feasibility of characterizing areas according to their location within the aeolian phases of entrainment, transport, and settling

- Mitigation methods, such as fences of the type used for trapping snow, that cause settling of particles outside the areas of concern

- Effects on uncovered and covered systems (culture contamination, reduction of light penetration, abrasion of covering materials, etc.). 


\section{SECTION 4.0}

\section{WATER RESOURCES}

Any biomass production system requires water resources. Aquatic plants are unique in that the water is the medium in which the plant grows. This requires more water in the system at any point in time but this does not necessarily imply a higher rate of water use if losses to the atmosphere and lithosphere can be controlled. Thus the stewardship of the water resources becomes a critical issue.

\subsection{WATER CONTROLS}

To ensure that prudent stewardship of the groundwater resource is undertaken, the entire hydrologic cycle (Figure 4-1) must be considered. The groundwater reservoir is the lithosphere portion of the hydrologic cycle. It must be emphasized that this reservoir is part of a dynamic interacting system and is not a static entity with clearly defined boundaries. The connections between the groundwater system and other parts of the hydrologic cycle can create serious environmental problems during development of the resource.

Furthermore, the most promising source of water for microalgae pond systems appears to be saline groundwater. Because saline water has the potential for degrading fresh water supplies, it is even more important that interactions and connections between the various hydrologic system components be recognized and carefully evaluated.

Basic controls on water yield from an aquifer are illustrated in Figure 4-2. These controls include recharge rate, storage, transmissivity, evapotranspiration, and well spacing. Water entering the aquifer from outside the lithosphere is called recharge and includes available precipitation plus irrigation return flow from agriculture and any water spread on the ground for artificial recharge purposes. The amount of recharge determines the 1ong-term sustained yield of an aquifer, since pumping from the aquifer at rates greater than recharge will result in depletion. We are concerned with aquifer yield over the life of the project.

In order to calculate aquifer yield, knowledge of the total amount of water in storage is required. Furthermore, the aquifer connections to other hydraulic systems (surface lakes and streams, other aquifers, etc.) must be determined in order to understand the real extent of the aquifer. Transmissivity indicates the capacity of an aquifer to transmit water through its entire thickness and therefore represents an upper limit to the pumping rate from the aquifer. The transmissivity of an aquifer is a function of the aquifer gradient (slope of the water surface), the lithology, and whether the aquifer is confined (surrounded by impermeable or relatively less permeable strata) or unconfined (surrounded by strata of equal permeability). Proper spacing of wells is also an important control on aquifer yield. We1ls placed too close will induce excessive drawdown or lowering of the water table. Another less significant control on well yield is the amount of evapotranspiration losses 


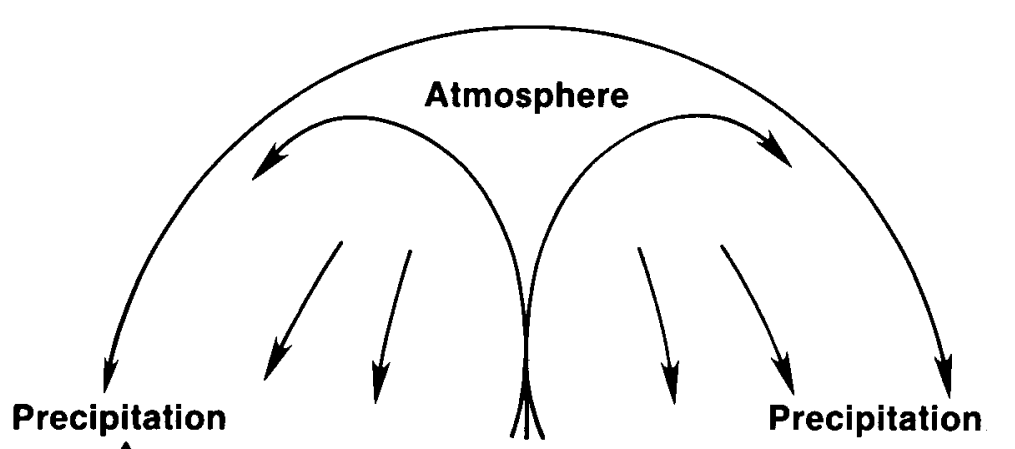

吕

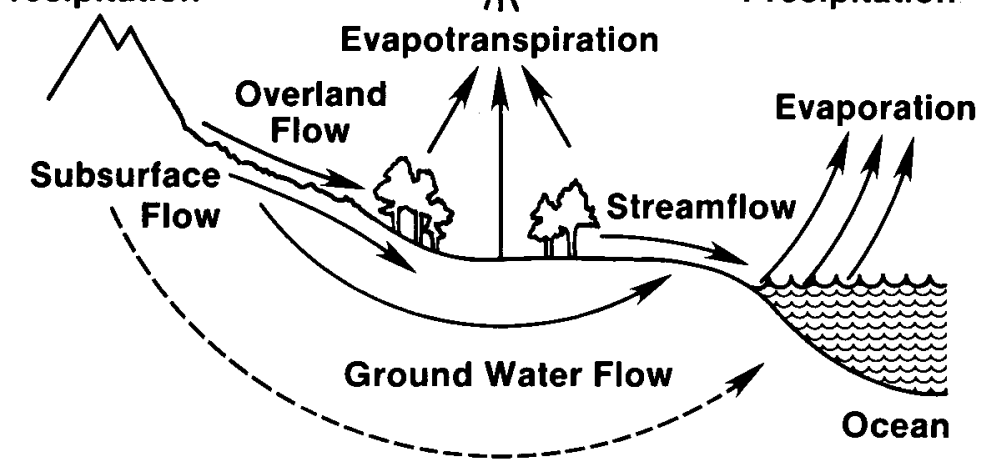

Figure 4-1. The Hydrologic Cycle, Including Processes that Control the Availability of Water Resources

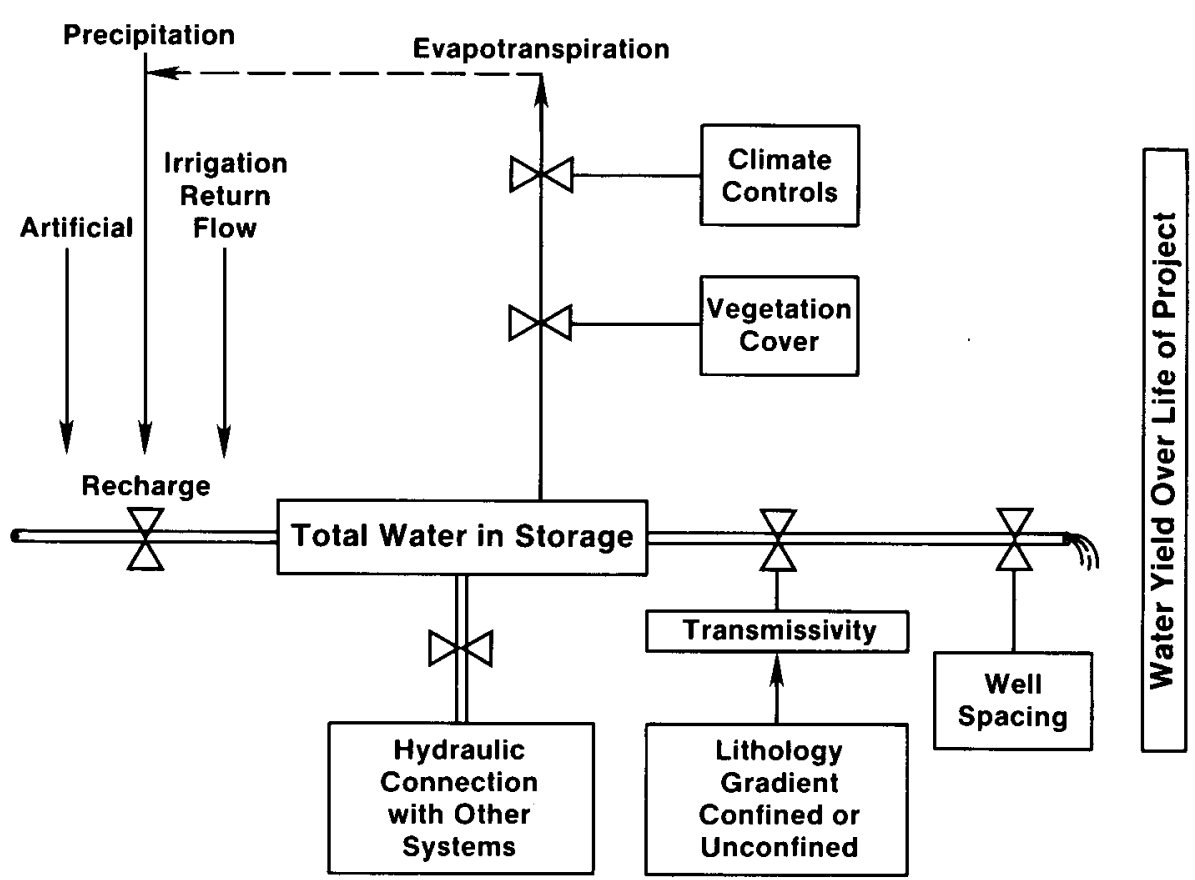

Figure 4-2. Factors and Processes that Control Water Yield from a Groundwater Reservoir 
from the aquifer. Evapotranspiration is a function of various climate controls (solar radiation, humidity, wind, advection, etc.) and also the nature and extent of the vegetative cover.

\subsection{WATER DATA AND DATA SOURCES}

\subsubsection{Water Data Needs}

The most useful information initially is data indicating the location and potential yield of aquifers. Ideal data should reflect spacing of wells to account for the cone-of-depression effects (drawdown) of pumping. If such information is not already available, other data (hydraulic conductivity, porosity, and compressibility--or the derived aquifer parameters of transmissivity and storativity) allow use of standard formulas to calculate drawdown associated with well development. Such data are generally not available for saline groundwater resources.

Pertinent to the economics of resource development is the depth of the water from the surface. Along with geological data, depth information determines the cost of drilling a well in a given location.

Furthermore, information on water quality is required to evaluate water resource suitability. Primarily, data on the salinity or total dissolved solids (milligrams or grams per liter) are necessary. Data on the specific ion concentrations, $\mathrm{pH}$, and temperature of the water wil1 influence species selection and system engineering. Data on the presence of toxic substances such as various trace metals are also desired since these substances influence the economics of operating the system.

Data on current and potentially competing uses of the saline water resource are necessary to assess the real availability of the resource. Water allocation information for each state is required to determine priority of use, present allocations in both perfected and inchoate status, pending permit allocations, ownership of water rights, and purchasing options.

\subsubsection{Water Data Sources}

The United States Water Resources Council established water resource regions in the United States based on physiographic and water resource boundaries (Figure 4-3). Data files are generally organized according to these regions, and coordination of the activities of various government and private agencies involved with water resources also tends to follow these regional designations.

The primary agency involved in the collection and dissemination of data and information on water resources is the United States Geological Survey (USGS). The major sources of information on water resources are shown in Figure 4-4. The largest of these sources is the National Water Data Exchange (NAWDEX) system, which references approximately $70 \%$ of all water resource information in the country. The dissemination of NAWDEX information is the 


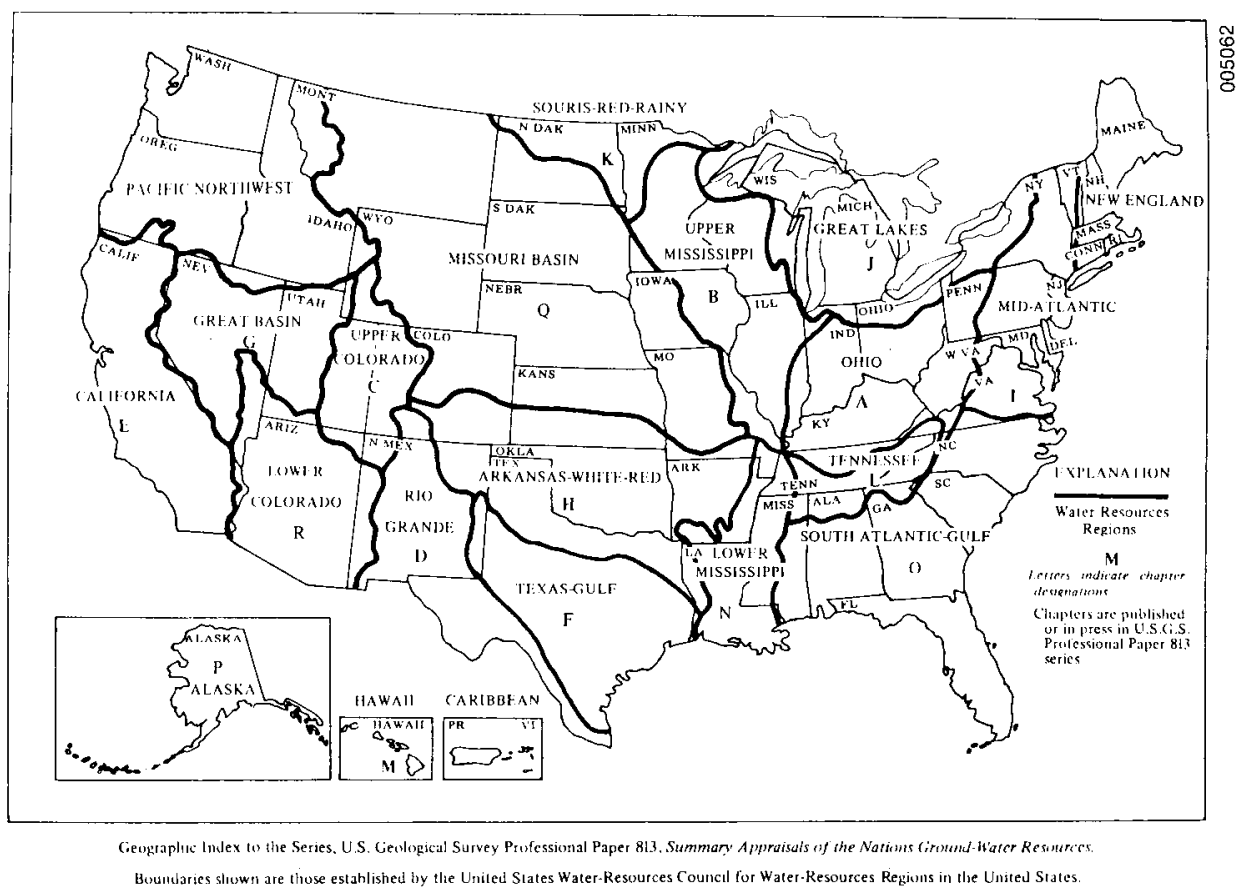

Figure 4-3. U.S. Water Resource Regions Based on Physiographic and Water Resource Features

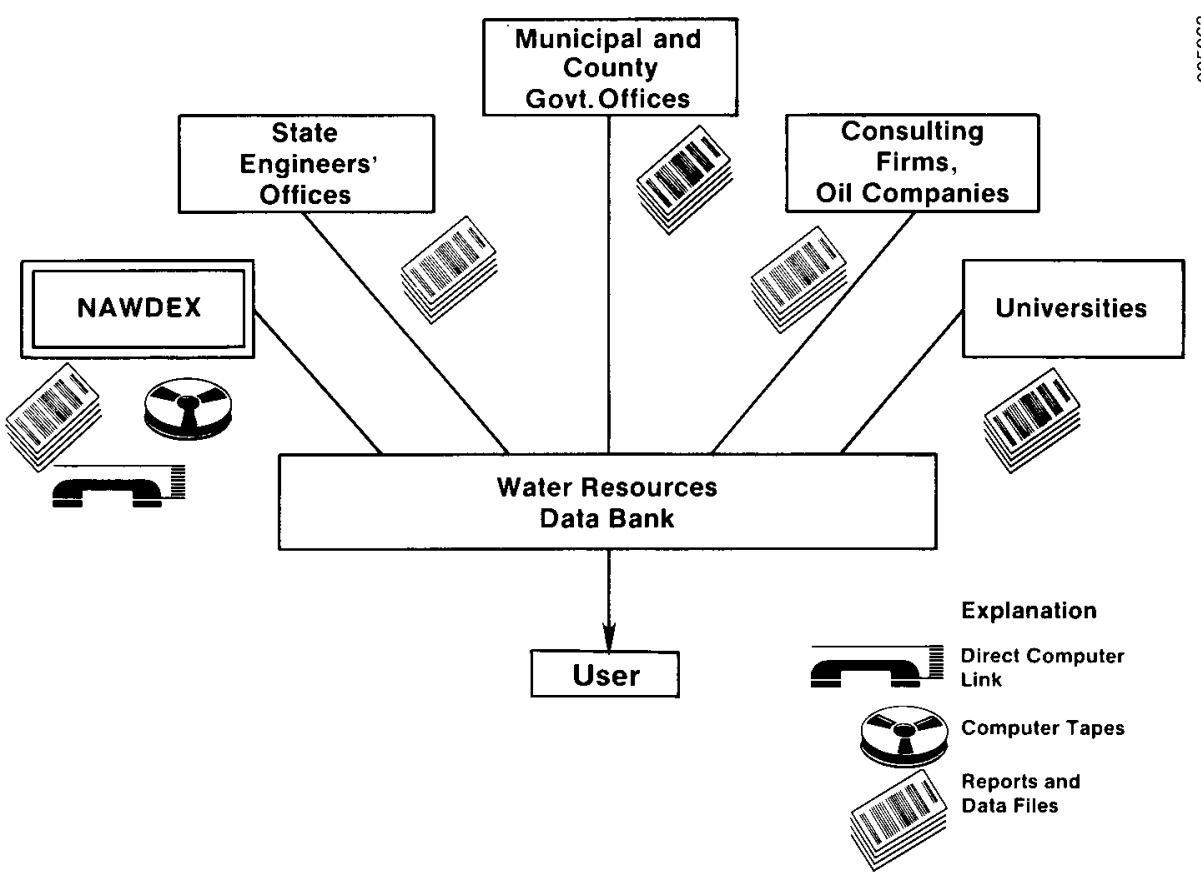

Figure 4-4. Sources of Information on Water Resources Indicating Data Formats Genera11y Available 
responsibility of the Office of Water Data Coordination of the USGS, which publishes the Catalog of Information on Water Data. This catalog provides a guide to data located in state engineers' offices, municipal and county government offices, private consulting firms, oil companies, and universities.

Within the NAWDEX system information is stored in two major files: the Master Water Data Index (indexes types of data) and Water Data Sources Directory (contains information on organizations holding water data) (Figure 4-5). Through reciprocal agreements, several sources supply information to the NAWDEX system. Included are the Water Data Storage and Retrieval System (WATSTORE) maintained by the USGS; the Storage and Retrieval System (STORET) of the Environmental Protection Agency (EPA); the bibliographic data base of the Water Resources Scientific Information Center (WRSIC) of the Department of Interior's Office of Water Research and Technology; the Environmental Data and Information Service (EDIS) and Environmental Data Index (ENDEX) of the National Oceanic and Atmospheric Administration (NOAA); various interstate and regional organizations; state agencies such as the Texas Natural Resources Information System (TNRIS); the Water Resources Document Reference Centre (WATDOC) of the Canadian Department of the Environment; a variety of private organizations; and some research universities. WATSTORE is the most extensive source of data and includes a groundwater site-inventory file (including quality and quantity data) as well as surface water data. STORET contains much data relating to both surface and subsurface water quality. These data pertain primarily to low salinity, potable water.

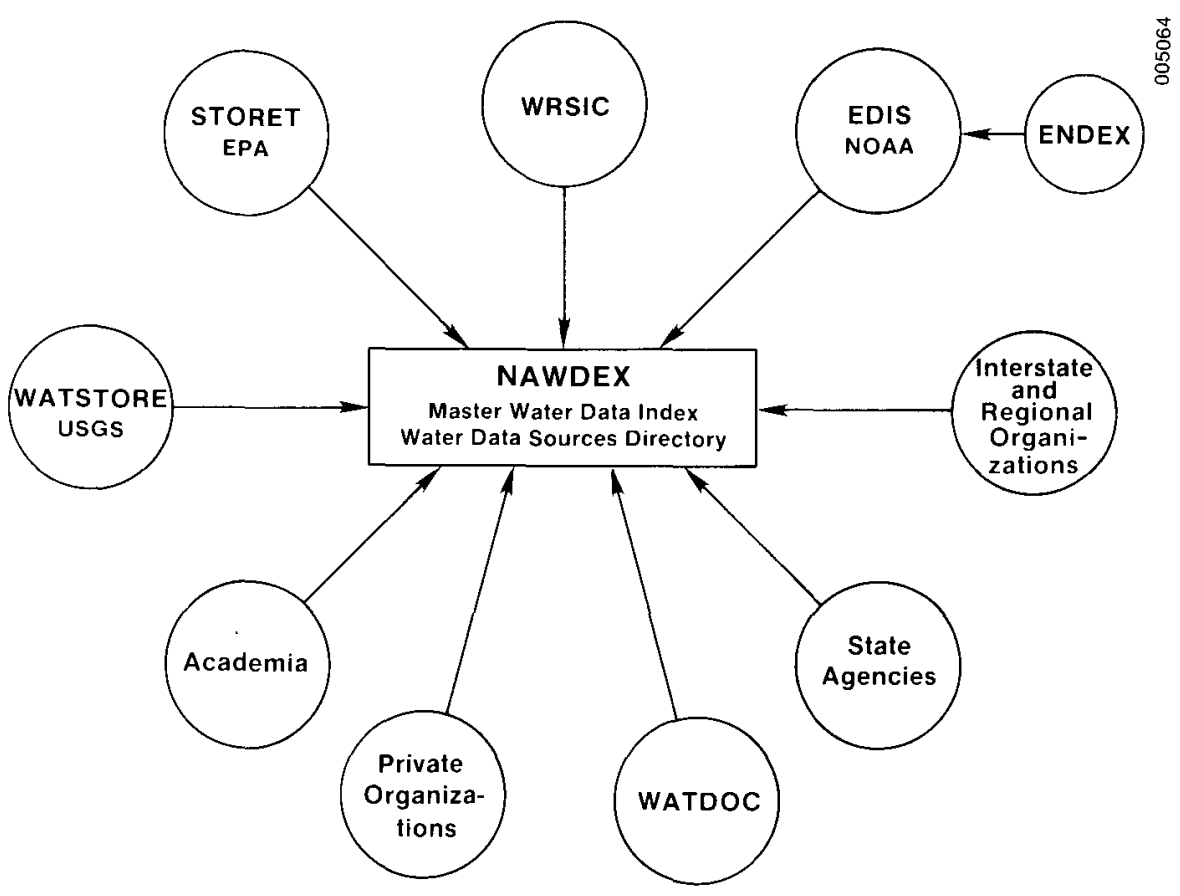

Figure 4-5. Data Sources for the National Water Data Exchange (NAWDEX) System 


\subsection{WATER LAW}

Because of the semiarid nature of the Southwest and the increasing population of the area, competition for water in the region has become intense. Legal complexities of developing saline groundwater should not be underestimated and may in fact constitute a "make or break" situation regarding the development of MPS.

Throughout the western states, water is normally acquired through the principle of "first in time, first in right," known as the Prior Appropriation Rule. In the Southwest, all surface waters are under the legal doctrine of the Prior Appropriation Rule. This is not true of groundwater. Some states distinguish between ground and surface waters and some do not. Some states recognize the connection between ground and surface waters and some do not. Consequently the exact legal status of groundwater must be evaluated on a state-by-state basis.

Legal procedures to be followed by a potential developer of saline groundwater are illustrated in Figure 4-6. The Federal Reserve Doctrine and a number of other federal laws may override state regulations on federal lands within a state. These legal requirements must be fully researched to insure proper compliance. Where there is competition for groundwater (which occurs throughout the Southwest), the developer must follow one the pathways illustrated in Figure 4-6 depending on whether or not any groundwater law currently exists in the state. If groundwater law does exist, then water rights must be obtained. The developer has two options: either to go through the application process or to purchase existing water rights on the open market. In areas considered to be fully appropriated, the only option is outright purchase of existing rights.

In areas where no groundwater law exists, the developer simply begins pumping. He must, however, take precautions to protect his long-term interest in and use of that water. New legislation may be required to protect longterm rights on saline groundwater. No legal distinction is made between saline and fresh groundwater. Since no large-scale development of saline groundwater has yet occurred in the Southwest, it is difficult to predict the legal status of such water.

\subsection{CRITICAL WATER DATA}

Since water stewardship and economic considerations are encouraging the use of saline water resources, data on these resources become critical. In general, the demand for saline water up to the present time has been quite low, and very few data on these resources have been collected. For the most part, these data are available at those locations where holes have been drilled for oil, fresh water, minerals exploration, etc. In many instances, therefore, the actual data collected on saline water resources are very sparse and of questionable accuracy. The magnitude and cost of the efforts required to obtain needed water data are probably greater than that for any of the other resources of concern. In fact, the most critical aspect of saline groundwater data is its absence. 


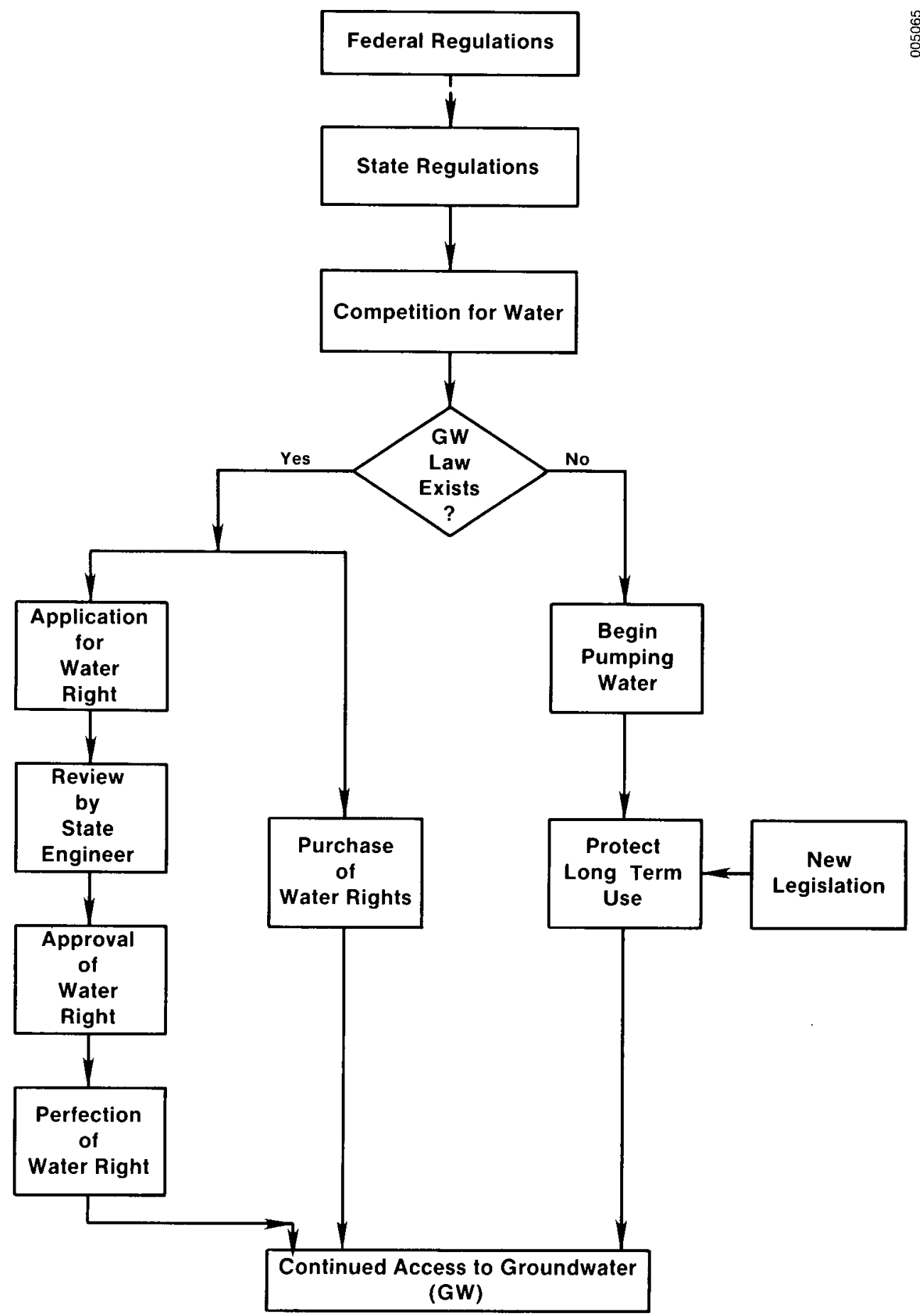

Figure 4-6. Controls Imposed by Regulations and Competition on the Use of Groundwater and Procedures to Gain Continued Access to Groundwater 
A great deal of water resource data must be collected before much confidence can be given to any statements about water resources available for aquatic production systems. A systematic program should be established to assess vast areas in the Southwest for which no information is available. It will not be necessary, however, to undertake water resource assessments for the entire region. C1imate and land suitability factors, discussed elsewhere in this report, can be used to eliminate large regions from further consideration. The remaining regions should be subjected to further water assessment efforts. This work could begin in those areas having the highest potential and proceed to lower priority regions as the demand for information dictates.

\subsection{WATER EVALUATION RESEARCH}

Much of the research described in this section concerns the broadest search for and expansion of information. This research must take place prior to the development of an aquatic biomass production system.

\subsubsection{Aquifer Yield Research}

Currently, long-term sustainable yield is obtained from the data collected by users of groundwater. In other words, yield is calculated from data collected as farmers and municipalities withdraw water from the aquifers. Over a period of years, rather accurate estimates of yield are developed. The kinds of systems being considered for aquatic biomass production do not lend themselves to this approach since the commitment of large capital investments is required prior to the initiation of water use. In order to improve estimates of sustainable water yield from aquifers, a major research effort must be undertaken. This effort should begin with the evaluation of existing groundwater yield models such as those of Prickett and Lonnquist (1971) or the U.S. Geological Survey (Trescott et al. 1976). The model or models selected for further development will be improved relative to the treatment of multilayer geologic strata, the interaction between aquifer systems, and the interaction with surface water systems.

\subsubsection{A Study of Water Law}

Since biomass production systems may be pioneering large-scale use of saline water resources, it is highly probable that the developers of these systems will also be pioneering saline water law. Some preliminary investigations into the current status of groundwater law in the southwestern United States and any other area of interest could greatly reduce the time required to obtain water rights for an operational system. This study should undertake state-by-state clarification of water law, particularly as it pertains to groundwater and saline groundwater. The procedures and time required to obtain water rights should be established and the possibility of introducing new legislation should be examined. It will also be necessary to clarify Indian and certain federal water rights on the extensive federal land holdings in the Southwest. 


\subsubsection{Environmental Impact Research}

Many environmental impact studies will be required prior to the construction of the first large-scale aquatic biomass production system. Advance research is recommended in particular for two potential problems unique to these aquatic production systems. First, large-scale withdrawal of saline water from aquifers has the potential of affecting fresh water aquifers and/or fresh water surface supplies. Therefore, even if the saline water resources are uncontested, the interaction of these aquifers with fresh water systems could limit use of the saline water resource. A study of aquifer interactions and the development of techniques for monitoring them will probably be required prior to large-scale use of saline groundwater resources.

Second, it is recommended that an initial study be undertaken of the potential environmental impacts of large, open ponds. The covering of tens to hundreds of square miles of previously dry desert terrain with uncovered ponds could significantly alter the climate of the immediate region. Preliminary research would seek to determine if such an effect is likely and if the changes will be significant. The impact of land use changes and the destruction of wildife habitat must also be considered. 


\section{SECTION 5.0}

\section{LAND RESOURCES}

The vast and seemingly useless land of the arid Southwest actually has characteristics, values, uses, and use constraints that warrant careful examination for sound development of microalgae production systems (MPS). Southwestern ecosystems, though diverse, can be generally characterized as both tough and fragile; they are sustained under severe climatic conditions but are also easily damaged and slow to recover. The region is valued by many inhabitants and visitors alike for its scenic, recreational, and other aesthetic qualities. More practical cultural uses and values include rangeland grazing, agriculture, forestry, and urban/industrial development. Much of the land in the region is owned by various public agencies, with variable restrictions and requirements regarding land use. Clearly, the development of MPS in the Southwest should incorporate an ethic of land stewardship that places importance on minimizing the impacts of development through planning, design, siting, and operation of microalgae systems in an environmentally compatible manner.

\subsection{LAND CONTROLS}

The potential availability and use of land for microalgae systems involve a variety of physical, economic, legal, and political factors. The major influences and controls on land availability are presented in Figures 5-1 and $5-2$, respective1y.

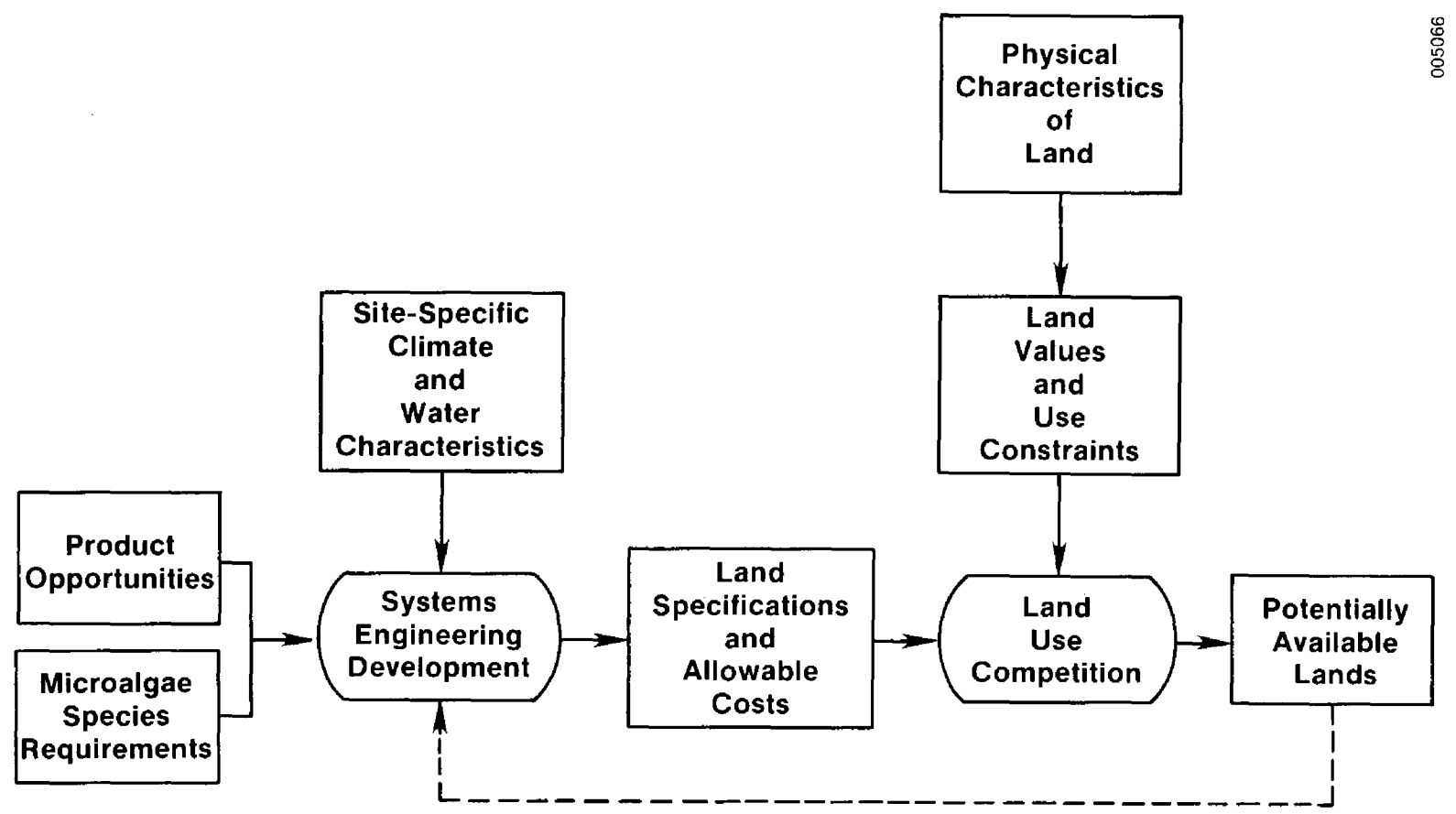

Figure 5-1. Factors that Influence the Availability of Land for Microalgae Production Systems 


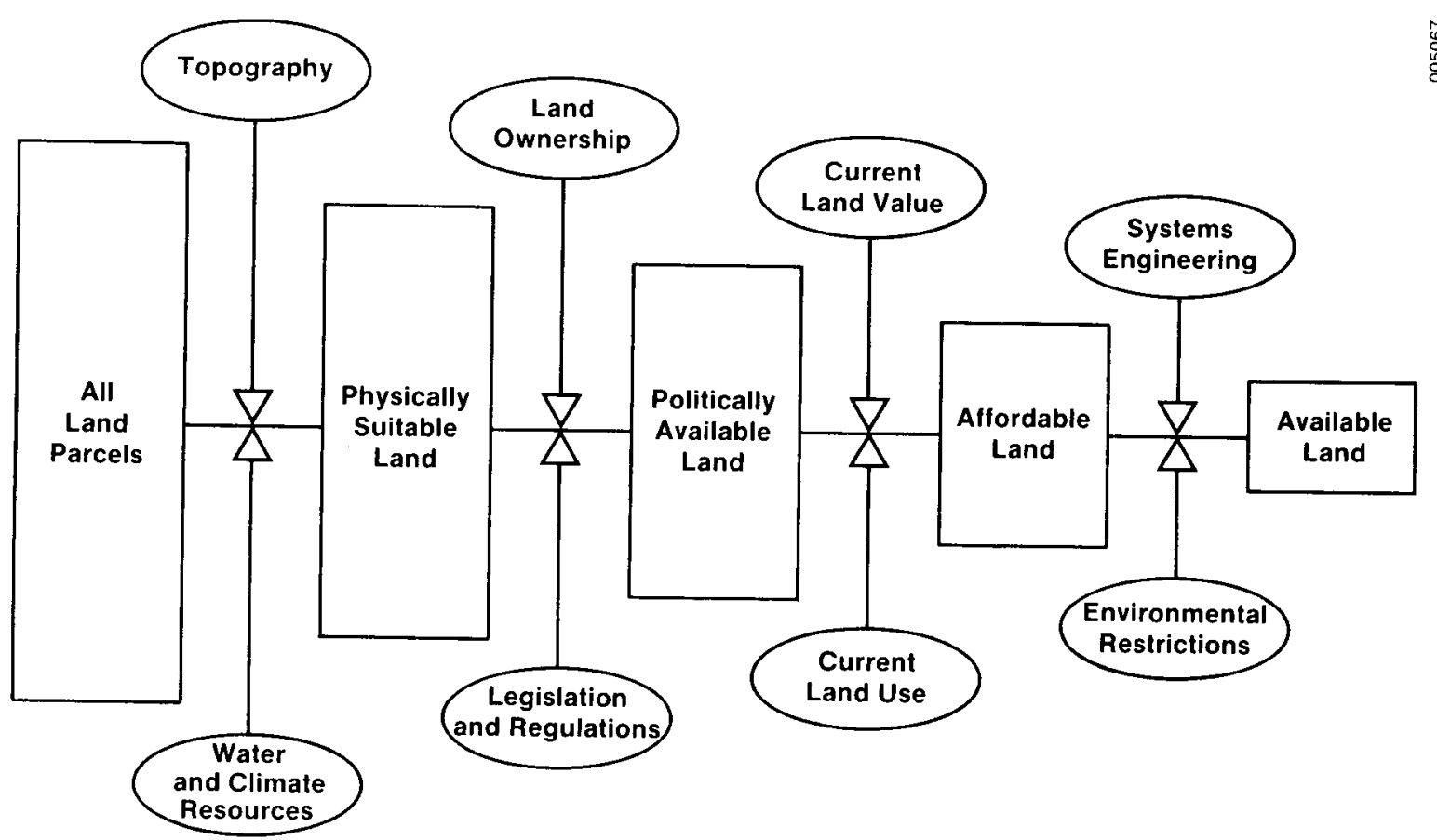

\section{Figure 5-2. Sequence of Controls that Define Land Available for Microalgae Production}

As shown in Figure 5-1, "potentially available 1ands" are determined by economic and political processes of land use competition. Physical land specifications and allowable land costs can be derived from system engineering design. Engineering design is dictated by microalgae culture and processing requirements for optimizing production of valuable materials in accordance with site-specific climate and water conditions. In turn, system design variables will influence land specifications. For example, the interrelated system engineering variables of pond area and depth, growth period, pond lining and covering, and harvesting--and their associated economies of scale-directly affect the areal and qualitative requirements for land. Once the physical land requirements and allowable land costs are determined, then land that fulfills these criteria and is not precluded by higher value uses or legal restrictions is potentially available.

An alternative means of displaying the relationships among factors controlling land availability is presented as Figure 5-2. Potentially available land is physically suitable, politically available, and economically affordable. Political availability is considered important in the Southwest due to the large areas of publicly owned land; some areas are more amenable to developmental use than others. As suggested in the diagram, the area of land that is potentially both suitable and available for MPS is likely to be only a fraction of the total land area. Determining a reliable estimate of the available land will require (1) an evaluation of physical suitability factors in con-junction with microalgae system engineering development and (2) an investigation of policies and procedures for gaining use of public domain land. The environmental impact statement requirements of the latter will encourage the development of environmentally compatible systems. 


\subsection{LAND RESOURCE DATA AND DATA SOURCES}

Two general kinds of land resource information are required for an adequate evaluation of land suitability and availability for MPS. Data pertaining to physical or natural characteristics of land (e.g., topography, geology, soils, and vegetation) are needed to determine physical suitability and to assess potential environmental impacts. Second, information is required concerning institutional aspects of the same land (e.g., ownership, use) to evaluate prospective policy, regulatory, and cost constraints on land availability.

Examples of the kinds of data required for each of the land resource parameters are 1isted in Table 5-1. Both physical and institutional aspects of land suitability and availability are included. These information requirements are, however, illustrative and preliminary. As site requirements and system engineering become better defined, more specific data requirements can be identified.

Mapped land information is available at several scales with concomitant differences of resolution or detail. The resolution of land resource data should

Table 5-1. Land Resource Data Requirements

\begin{tabular}{|c|c|}
\hline $\begin{array}{l}\text { Resource } \\
\text { Parameter }\end{array}$ & Information Required \\
\hline Topography & $\begin{array}{l}\text { Slope configuraton } \\
\text { Elevation } \\
\text { Dry or shallow lake beds } \\
\text { Salt flats }\end{array}$ \\
\hline Geology & $\begin{array}{l}\text { Aquifer lithology } \\
\text { Surface rippability } \\
\text { Seismicity } \\
\text { Minerals occurrence }\end{array}$ \\
\hline Soils & $\begin{array}{l}\text { Porosity/permeability } \\
\text { Agricultural quality }\end{array}$ \\
\hline Vegetation & $\begin{array}{l}\text { Cover type } \\
\text { Cover density } \\
\text { Habitat type }\end{array}$ \\
\hline Use & $\begin{array}{l}\text { Categories } \\
\text { Location } \\
\text { Area } \\
\text { Value }\end{array}$ \\
\hline Ownership & $\begin{array}{l}\text { Categories } \\
\text { Location } \\
\text { Area } \\
\text { Market value } \\
\text { Leasing policies and costs } \\
\text { Mineral rights } \\
\text { Management policies }\end{array}$ \\
\hline
\end{tabular}


be consistent with the size of the area under investigation. Data at a gross resolution are acceptable and appropriate for a region-wide evaluation. Finer resolution data become necessary as the evaluation focuses on specific sites. In the sections that follow, map sources for land information are described with reference to scale so distinctions between information available for regional versus site evaluations can be recognized.

\subsubsection{Topography}

Information on slope, elevation, and the occurrence of particular landforms are of interest for identifying areas with high potential for siting MPS. Excavation and pond construction costs can be expected to increase with increasing slope. Thus the parameter of interest is actually the area of land within a given slope increment (e.g., $0 \%-5 \%, 5 \%-10 \%$, etc.).

Topographic maps showing the shape and elevation of terrain are produced primarily by the National Mapping Division of the USGS. Other agencies involved in topographic mapping are the Defense Mapping Agency (DMA) and the U.S. Forest Service. Virtually all of the publicly available topographic map products can be obtained through the National Cartographic Information Center (NCIC) of the USGS.

Topographic maps are available at scales of $1: 24,000\left(7.5^{\prime} \times 7.5^{\prime}\right), 1: 62,500$ $\left(15^{\prime} \times 15^{\prime}\right)$, and $1: 250,000\left(1^{\circ} \times 2^{\circ}\right)$ for most of the United States. Topographic maps are available for each individual state at a scale of 1:500,000 and for the United States as a whole, in the International Maps of the World Series, at a scale of 1:1,000,000. The USGS publishes indexes of available topographic maps, and maps in preparation, to indicate the status and geographic coverage of the various map series.

Slope maps, which show zones of slope ranges, can be produced from topographic data upon request by either the NCIC or a few private firms, but at a considerable cost. Each map costs approximately $\$ 225$ for one slope zone and $\$ 115$ for each additional zone. Needed slope zone increments can be specified-expressed as a percentage, a gradient ratio, or as degree of inclination.

\subsubsection{Geology}

Information on surficial and subsurface geology is of interest to the development of MPS primarily from the standpoint of siting restrictions and, to some extent, for the effects on construction costs. The geological data requirements identified in Table 5-1 represent potential constraints on siting microalgae systems. The occurrence, depth, storativity, and transmissivity of aquifers, and thus the water supply to MPS, are directly related to the lithology of permeable and impermeable formations. Grading and excavation will be encumbered by rock outcrops and hard bedrock near the surface, depending upon pond depth and area specifications. Seismically active areas near fault zones should be avoided due to the sensitivity of pond flow to a level or a deliberately inclined grade. 
Geological information in the form of maps, charts, diagrams, and reports is available primarily from the USGS, the U.S. Bureau of Mines, state geological and mining agencies, and state universities. A useful initial source on surficial geology is the geological highway map series published by the American Association of Petroleum Geologists.

The USGS provides primary sources of geological information and references contained in both USGS and non-USGS publications. A variety of thematic maps are published for distribution by the USGS that range from smal1-scale geologic, fossil fuel, and mineralogic maps of the United States to state geologic maps to larger-scale geologic quadrangles and maps from geophysical, hydrologic, coal, mineral, and oil and gas investigations.

\subsection{3 $\underline{\text { Soils }}$}

As with the geological requirements, information on soils is most important for actual site selection within a general zone of suitability. In addition to siting, the porosity/permeability characteristics affect the construction costs and design of MPS by virtue of the need for pond lining or sealing.

The major source of soils information is the Soil Conservation Service (SCS) of the U.S. Department of Agriculture. The SCS, in cooperation with state agricultural experiment stations and other federal and state agencies, conducts and publishes soil surveys for counties having a significant agricultural economy. Published soll surveys contain maps at scales of 1:24,000, $1: 20,000$, or $1: 15,840$. These maps generally include descriptions and interpretations of each kind of soil in the particular area. A list of soil surveys is published periodically by the SCS. For state, regional, and national appraisals of soils characteristics, the SCS prepares and publishes state maps of major soil associations and national maps of generalized soils and major land resource areas.

Soils are also classified for engineering purposes. Two systems for engineering classification of soils are the American Association of State Highway and Transportation Officials (AASHTO) system and the unified soil classification. Both are oriented to field analysis and emphasize textural and plasticity properties of soils.

\subsubsection{Land Use/Cover (Vegetation)}

Information on land use bears directly on the relative regional availability of land for MPS. Mapped information is needed on the types, location, and areal extent of land uses from which the value of the land can be derived and evaluated for MPS. Vegetation cover of the land is generally correlated with land use and thus these attributes are often combined.

The NCIC of the USGS has land use/land cover maps at scales of $1: 100,000$ and $1: 250,000$ for portions of the United States, either from open-file holdings or as published maps. However, only a small portion of the Southwest has been mapped. The status of map coverage is described in a NCIC/USGS publication entitled "Index to Land Use and Land Cover and Associated Maps." The maps are 
being compiled using nine general Level I categories which are further subdivided to 37 Level II categories, based on the classification system proposed by Anderson et a1. (1976), as illustrated in Table 6-1. The 1and use and land cover maps are currently being digitized, edited, and incorporated into a digital base and will be available in both graphic and digital formats (Fegeas et a1. 1983).

\subsubsection{Land Ownership}

Information on land ownership and controls on land use is needed to determine the relative availability and costs of land for MPS. Various kinds of publicly and privately held lands are subject to quite variable use, lease, and purchase requirements. Ownership rights and use restrictions are frequently split between surface and subsurface estates. Much of the land in the western United States is government owned. Developmental use of public domain land requires environmental assessments and/or environmental impact statements as a major component of approval procedures. Many states also have environmental impact assessment requirements. Information obtained on land ownership and land use requirements is described briefly in the paragraphs that follow. However, more detailed information will be needed in this area for a realistic appraisal of microalgae resource potential and for timely development of the technology.

Mapped information on public land (by types) versus private land ownership is available for most of the region at scales suitable for state, county, and site analysis. The major source of land ownership maps is the Bureau of Land Management (BLM) of the U.S. Department of Interior. Since 1976, the BLM has published "land status" maps of surface ownership for Colorado, Utah, Nevada, Arizona, and New Mexico at a scale of 1:500,000 and for California at a scale of 1:750,000. Two series of larger-scale maps $(1: 126,720)$ are being generated by BLM to depict surface and subsurface ownership, respectively. There are, for example, 88 such maps in each series for Colorado. More detailed, precise, and current information on federal land ownership can be obtained from the Master Title Plat records at BLM district offices. Comparable information on private lands is contained in county deed records.

The primary objective for the BLM land status maps is to show the location and distribution of public domain land in states with substantial federal government land holdings as required by the Federal Land Policy and Management Act of 1976 and ensuing regulations. However, there is some lack of uniformity in the mapped land ownership information for the study region. The states of Texas and Oklahoma, with virtually no public domain land remaining, are not mapped by BLM for surface ownership. Subsurface ownership is being mapped as needed in 0klahoma. Among the states that are mapped, there are inconsistencies in the definition and representation of land ownership categories. For example, the map of Colorado omits Department of Defense lands, state lands, and designated wilderness areas. 


\subsection{CRITICAL LAND DATA}

This subject will be addressed by reference to the land resource parameters listed in Table 5-1. The first three parameters (topography, geology, and soils) generate almost all of the critical data needs, whereas the last two (use and ownership) create a need for research, which is addressed in the next subsection.

\subsubsection{Topography}

Topographic information is readily available in the form of USGS map series at scales from $1: 24,000$ to $1: 500,000$. The conversion of the elevation data on these maps to slope information is a critical data need since slope directly affects the cost and practicality of constructing systems of shallow ponds. Very limited slope data are available.

An initial study conducted under this task revealed the necessity of using 1:24,000 scale topographic maps for slope calculations. The smaller scale $1: 250,000$ and 1:500,000 maps can overestimate the areas having low relief (low slopes) by as much as $25 \%$ and $40 \%$, respectively, because the large increments between elevation contours (200 feet for 1:250,000 scale maps) smooth sma11 terrain features like gullies and ridges. The small-scale maps can be used for preliminary estimates of flat terrain for large-size regions or states, as long as one remembers that the acreages are likely to be overestimated.

The Defense Mapping Agency, previously known as the Army Map Service, has digitized their 1:250,000 scale maps; these computer compatible tapes can be used to calculate slope areas for regional surveys. The USGS is in the process of digitizing 7.5' topographic quadrangle maps $(1: 24,000$ scale), but this task is not completed at this time. Until the 1:24,000 digital maps are readily available (many years from now), slope data will be difficult and costly to obtain. Hence, slope information will remain a critical land resource need.

\subsubsection{Geology}

Geological data needed for all the purposes indicated on Table 5-1 are not readily available at the detail and resolution required. This kind of information may exist or be inferred from $7.5^{\prime}$ geologic quadrangle maps, depending on the purpose for which the maps were prepared. The geologic quadrangle maps vary in scale, coverage, and content depending on the purpose of the investigation. It is unlikely, therefore, that all the kinds of geological data required will be readily available for areas under consideration for MPS use.

Data on aquifers relate directly to water resources and represent the most critical geological data need. Surface rippability will directly affect construction costs and could eliminate some areas with shallow soils from further consideration. 


\subsubsection{Soils}

The porosity/permeability of the soils will determine the need for special measures to seal the bottom of MPS ponds, thereby limiting water loss and contamination of underlying strata. This kind of information is usually not available and, therefore, it becomes a critical data need.

\subsection{LAND RESOURCES RESEARCH}

The land resources in the Southwest can be characterized by their highly variable and federal dominated ownership (except for Texas and California). Checkerboard mixes of state, federal, and private ownership are common. Spanish land grants and large Indian reservations further complicate the situation. Federal ownership or control is distributed among several departments and agencies, including the Bureau of Land Management, the National Park Service, and the Bureau of Indian Affairs of the Department of the Interior; the Forest Service of the Department of Agriculture; the Department of Defense; and the Department of Energy.

Information on land use and land ownership in the Southwest is readily available as noted previously. The critical need, therefore, is for information on the procedures required to obtain a change in the designated use of such land and to actually gain access to or ownership of the 1 ands required. Because of the high percentage of the land owned by the federal government, or which is designated as an Indian reservation, the availability of the land becomes not so much a matter of cost as it is a matter of political negotiations to obtain access. Information must be collected as soon as possible on the actual procedures and policies affecting the use of these lands. 


\section{SECTION 6.0}

\section{INITIAL STRATIFICATION OF THE SOUTHWEST}

The southwestern United States was chosen as the focus of this resource assessment study primarily on the basis of the region's characteristically high levels of insolation. The presumed availability of relatively inexpensive desert land and saline groundwater resources was also influential in the decision.

The region of study, which includes the panhandle of Oklahoma, west Texas, New Mexico, Colorado, Utah, Arizona, Nevada, and southern California, is characterized by diverse terrain and a generally arid or semiarid climate. The topography of the region varies from upland plateaus to rugged mountains and canyons of desert basins and Intermontane valleys. Correspondingly, the climate is also highly variable. The arid conditions and generally high elevations of the region cause large diurnal and annual ranges of air temperatures. Evaporation rates are among the highest in the country.

For the purposes of this preliminary assessment, an extensive network of sha1low microalgae growth ponds was assumed. Exact scale or design was not defined. The economies of scale for chemical plants and petroleum refineries dictate that areas of 1000 acres to 100 square miles, respectively, should be considered. As suggested by Figure 2-1, the ponds would receive their water supply from groundwater resources and would be sized and sited in accordance with the terrain.

The objective of this effort was not to select specific sites for microalgae production, but rather to stratify the southwestern United States into zones of varying suitability for such systems. Actual site selection involves many system-dependent considerations. Future work will examine the areas or zones of greatest suitability for the selection of specific sites.

\subsection{STRATIFICATION PROCESS}

The overlaying of data planes is illustrated in Figures 6-1 and 6-2. Figure $6-1$ is a pictorial representation of multiple land uses overlain with four broad categories of land ownership. These two variables (use and ownership) might ultimately be overlain with water and climate variables as shown in Figure 6-2. The selection of a specific set of variables and resources is, of course, a function of the objectives or purpose of the geographic stratification or compositing task. The parameters shown in Figure 6-2 were used to stratify the Southwest. The procedure employed in combining the data are also task-dependent. McHarg (1969) was one of the first to employ the overlay process. This method has subsequently been employed for many applications such as environmental impact analysis (Turner 1976), selection of routes for highways, power lines, etc., and a geographic market analysis for industrial process heat systems (Turner, Weber, and DeAngelis 1981). 


\title{
Land Ownership
}

\author{
State \\ Private \\ Indian \\ Federal
}

\section{Land Use}

Range

Recreation

Forest

Watershed

Minerals

Military

Oil \& Gas

Coal Industry

Urban

Dryland

Agriculture Irrigated

Agriculture

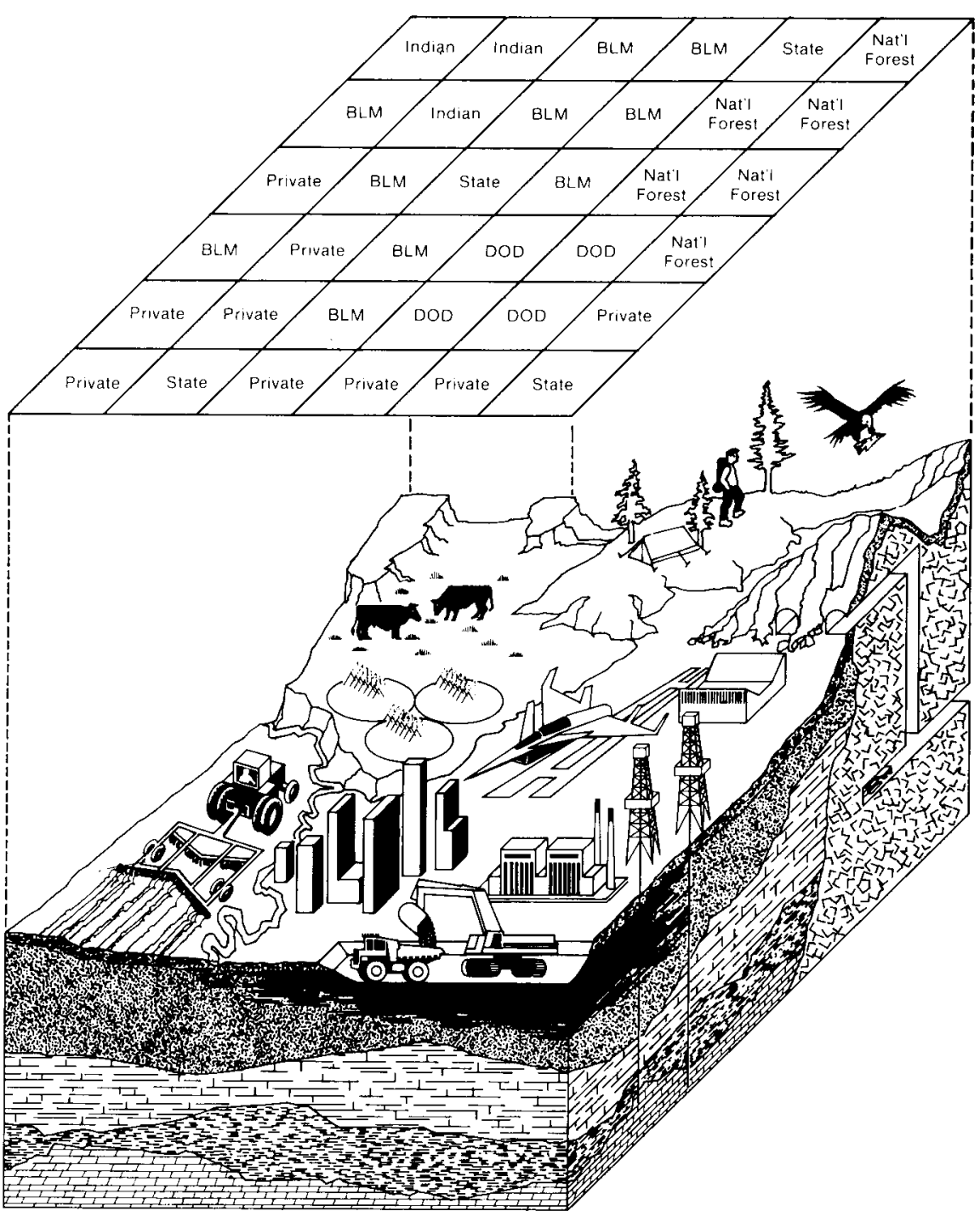

Figure 6-1. Overlay of Possible Land Ownership and Land Use Patterns in the Western United States that Can Be Simulated in a Computer Geographic Information System

The geographic overlay and compositing process is generally performed in four steps:

Step 1 - Application/Resource Systems Study

Step 2 - Overlay Map Production

Step 3 - Digitization of Maps

Step 4 - Preparation of Composite Maps 


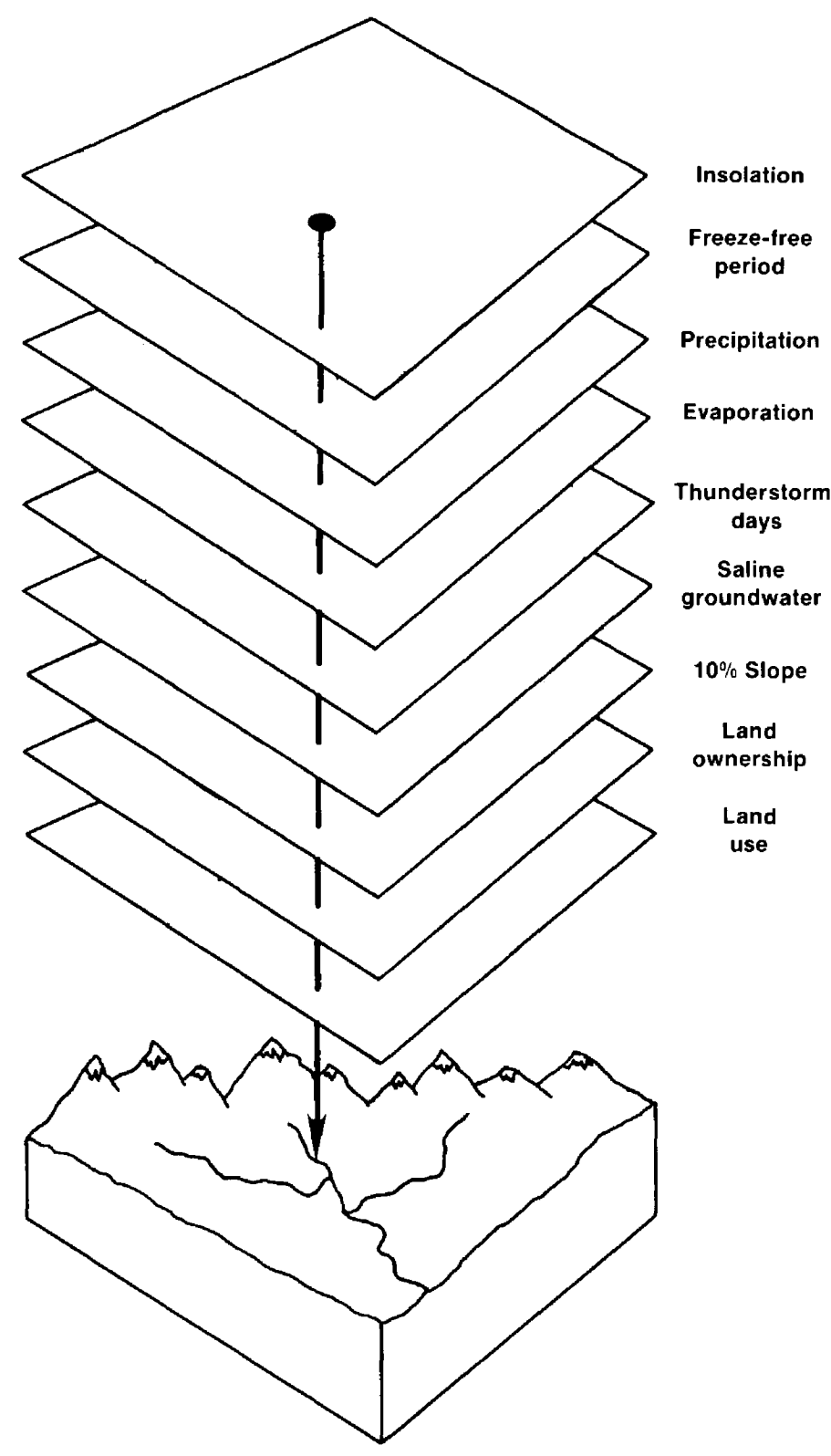

Figure 6-2. Overlay Concept of Figure 6-1 with the Addition of climate and Water Resource Parameters for Resource Stratification
The system study under Step 1 established the application dependency on natural resources and serves to identify resource needs and environmental relationships. Specifically, Step 1 identifies the resources and environmental parameters of interest and defines the data and maps needed to accomplish the task at hand. The results of the studies of microalgae production systems are summarized in Section 2.0 of this report. The land, water, and climate resources of interest are described in detail in Sections $3.0,4.0$, and 5.0 .

Step 2 is conducted in response to Step 1 and entails data collection and the making of maps. Usually, much of the resource and environmental data of interest are already in the form of maps. However, the original maps will likely have different scales and projections that preclude any overlaying operations. Furthermore, some of the maps and other forms of data may require interpretation or transformation to put the data into a format useful for the application at hand. In many instances, the data available are too detailed or have a resolution too fine for the scales at which they will be digitized.

Al1 of the factors noted above were found during Step 2 efforts undertaken to stratify the Southwest. Those mapping efforts are described in detail in Section 6.3.

The third step entails the conversion of the resource data from map formats to a digital form that can be read by a computer. Several digitization procedures are available including a completely manual operation involving a cellular overlay of the maps followed by data entry at a terminal. Completely automatic systems which scan the 
maps with a video camera are also available. The manual process used for this task is described in Section 6.4 .

Step 4, the preparation of composite maps, is itself a multistep process that contains the following steps:

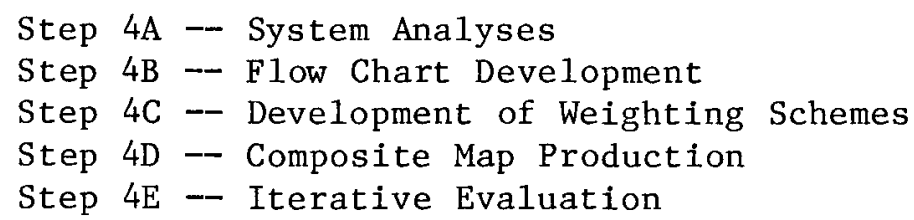

The systems analyses conducted at this point are designed to develop functional relationships between the resource parameters and the application system. Most common1y, one seeks to determine the impact of resources and the environment on construction costs, operation costs, operation efficiency and/or production output, and environmental impact.

Step 4A leads naturally to the development of flow charts (Step 4B) that show how functional relationships can be represented by composites of the resource maps produced in Step 2. Step 4C determines the relative weights to be assigned to resource maps and the values, classes, or other features displayed on the maps. Steps $4 \mathrm{~B}$ and $4 \mathrm{C}$ will determine the accuracy and validity of the compositing process. If sufficient rigor is applied, compositing can be viewed as a mode1-like representation of the functional relationships between the applications system and the resources of interest.

Step 4D carries out the compositing process defined by Steps 4B and 4C. At this point it is possible that Steps 4A, 4B, and/or 4C may need to be repeated to produce accurate maps. The iterative nature of compositing is indicated as Step 4E.

The actual procedures employed and the results of Steps 1 through 4E, as carried out for the stratification of the Southwest, are described in the following sections.

\subsection{MICROALGAE SYSTEMS STUDIES - STEP 1}

Two separate studies of microalgae systems were undertaken for the stratification of the Southwest. Battelle-Columbus undertook a study to identify and prioritize resource parameters important to microalgae production (Vigon et al. 1982). A parallel effort was undertaken at SERI to guide the collection of data for the stratification effort. The Battelle study encompassed nutrient resources and the chemical characteristics of the water resources, whereas the SERI study concentrated on the location and availability of natural resources. The material in Sections $3.0,4.0$, and 5.0 represents the results of SERI's study.

The Battelle results were not directly supportive of the stratification effort, except that some of their findings verified the work at SERI. It was not possible to incorporate their work on $\mathrm{CO}_{2}$ and other nutrient supplies, but future refinements of the stratification should benefit from their efforts. 
Likewise, the chemical criteria they developed for water resources could not be used because of the lack of chemical data in the water resource information available for this project. As specific sites are selected in the future, field data collection will be guided in part by Battelle's work.

The systems studies undertaken by SERI were conducted in parallel with a search for readily available climate, water, and land data. In effect, information needs were combined with information sources to formulate a stratification plan that could be accomplished with available funds and time. Some of the outputs of this parallel effort are the climate, water, and land resource information in Sections 3.0, 4.0, and 5.0. The following section describes in detail the problems and procedures of map overlay production for this task.

\subsection{OVERIAY MAP PRODUCTION - STEP 2}

The objective of this step is the generation of a series of maps of the same region, at the same scale, with the same map projection, and with similar resolutions. These specifications are necessary if each cell in a series of map overlays is to represent the same geographical unit and contain meaningful information at the same level of detail.

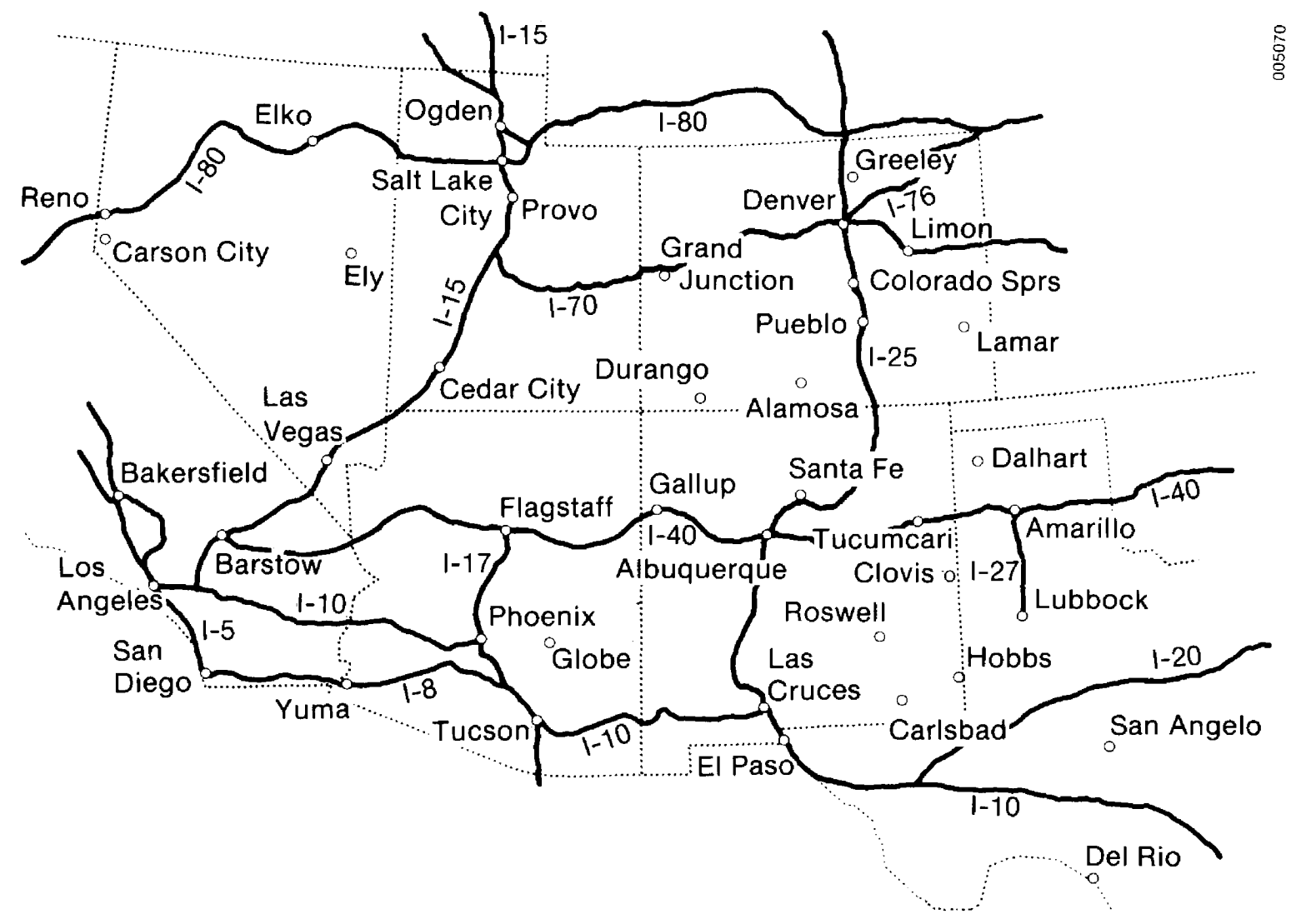

Figure 6-3. Region Included in the Stratification of our Study Area 
The original maps and images were at scales from $1: 500,000$ to $1: 20,000,000$ that had been generated using Alber's Equal-Area, Universal Transverse Mercator, Polyconic, and Lambert Conformal Conic projections. The data thereon were ultimately interpreted, modified, and transferred to a base map at a $1: 2,500,000$ scale with an Alber's Equal-Area projection. Figure 6-3 is a modified version of the base map with major cities and highways added for reference purposes. In this report, the maps of the entire study region have scales varying from $1: 12,500,000$ (e.g., Figure 6-20a) to $1: 20,000,000$ (e.g., Figure 6-4).

The changes in scale were accomplished for the most part through photographic processes. Registration and adjustment for projection effects were accomplished by visual adjustments of polygons at state boundaries. The cartographic equipment needed for projection transformations and precise registration was not available. The problems encountered and procedures used for generating each map are briefly discussed below.

\subsubsection{Climate Maps}

The climate maps generated were:

- Global horizontal insolation

- Freeze-free period

- Precipitation

- Evaporation

- Thunderstorm days.

These annual maps were obtained from the Solar Radiation Energy Resource Atlas of the United States and the Climatic Atlas of the United States. The originals were at a scale of $1: 10,000,000$. The isolines on these maps were transferred to the $1: 2,500,000$ base maps by a pantograph. The only changes made in the maps were the addition or deletion of isolines. Isolines were added and modified slightly for the insolation map, based on additional information not incorporated when SERI prepared the originals. Isolines were deleted from the freeze-free period and evaporation maps to bring them into agreement with the level of detail on the other climate maps and in consideration of the limits of the digitization process described in Section 6.4. The precipitation and thunderstorm day maps were not modified. The climate maps are shown in Figures 6-4 through 6-8.

\subsubsection{Land Resource Maps}

The land resource maps generated were:

- Ten percent slope

- Land use/cover

- Land ownership. 


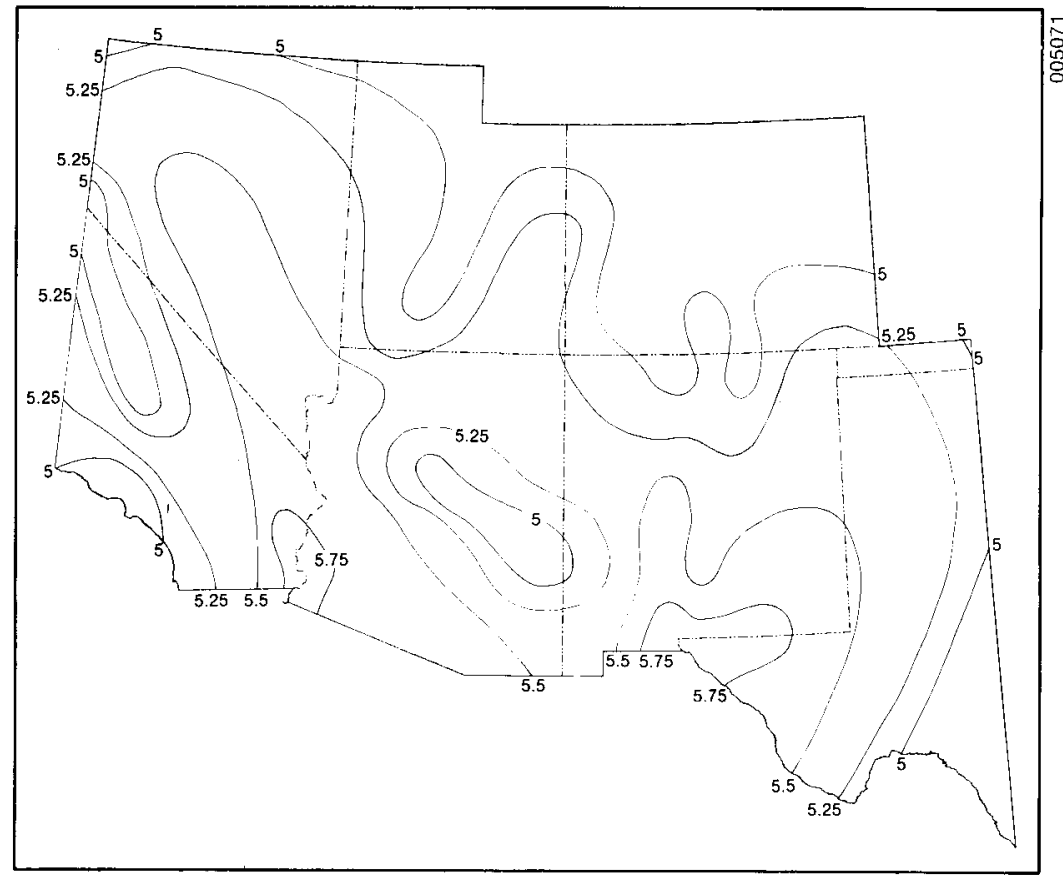

Figure 6-4. Annual Average of the Daily Total Global Horizontal Insolation for the Study Area in $\mathrm{kWh} / \mathrm{m}^{2}$ day

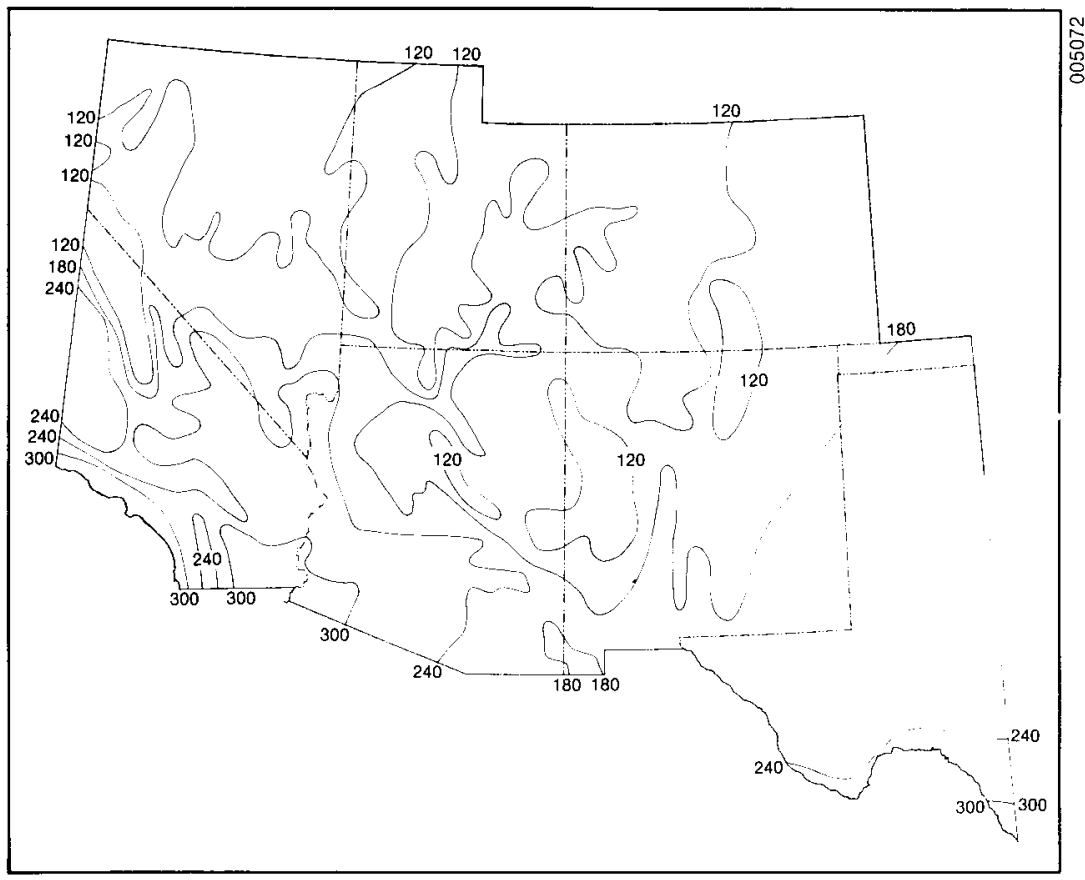

Figure 6-5. Annual Freeze-Free Period for the Study Area in Days 


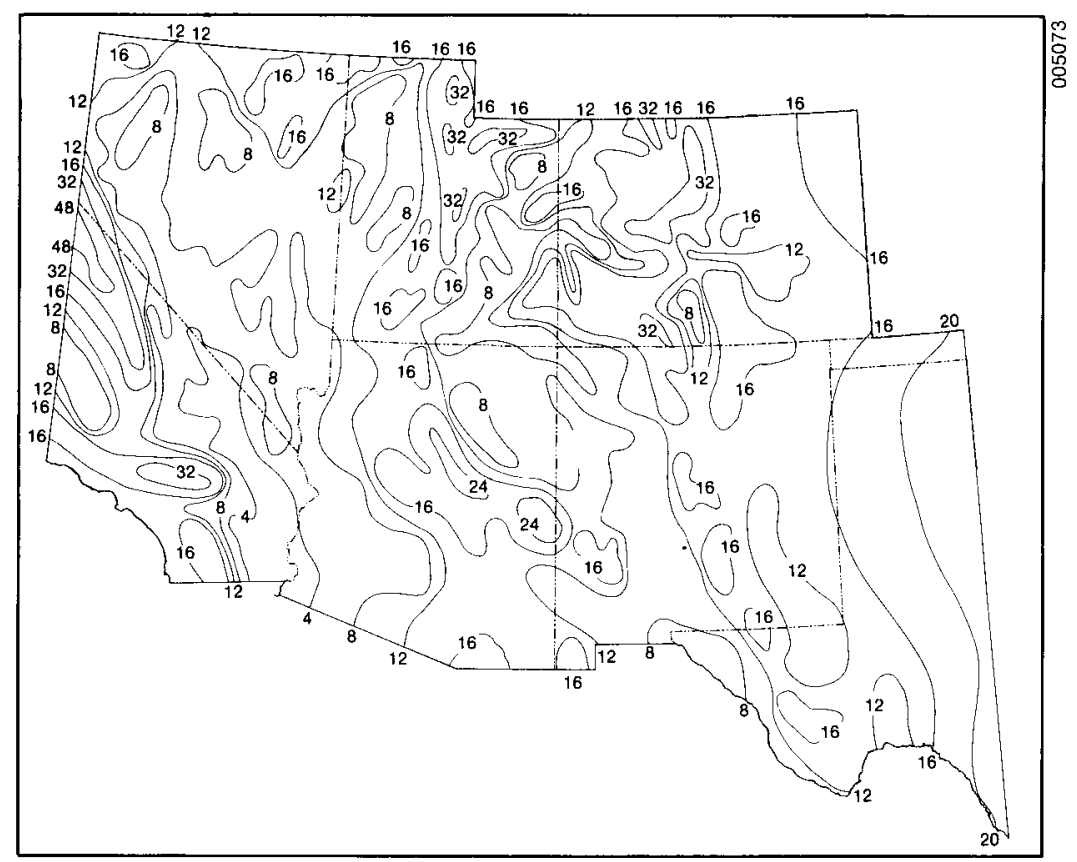

Figure 6-6. Annual Precipitation for the Study Area in Inches

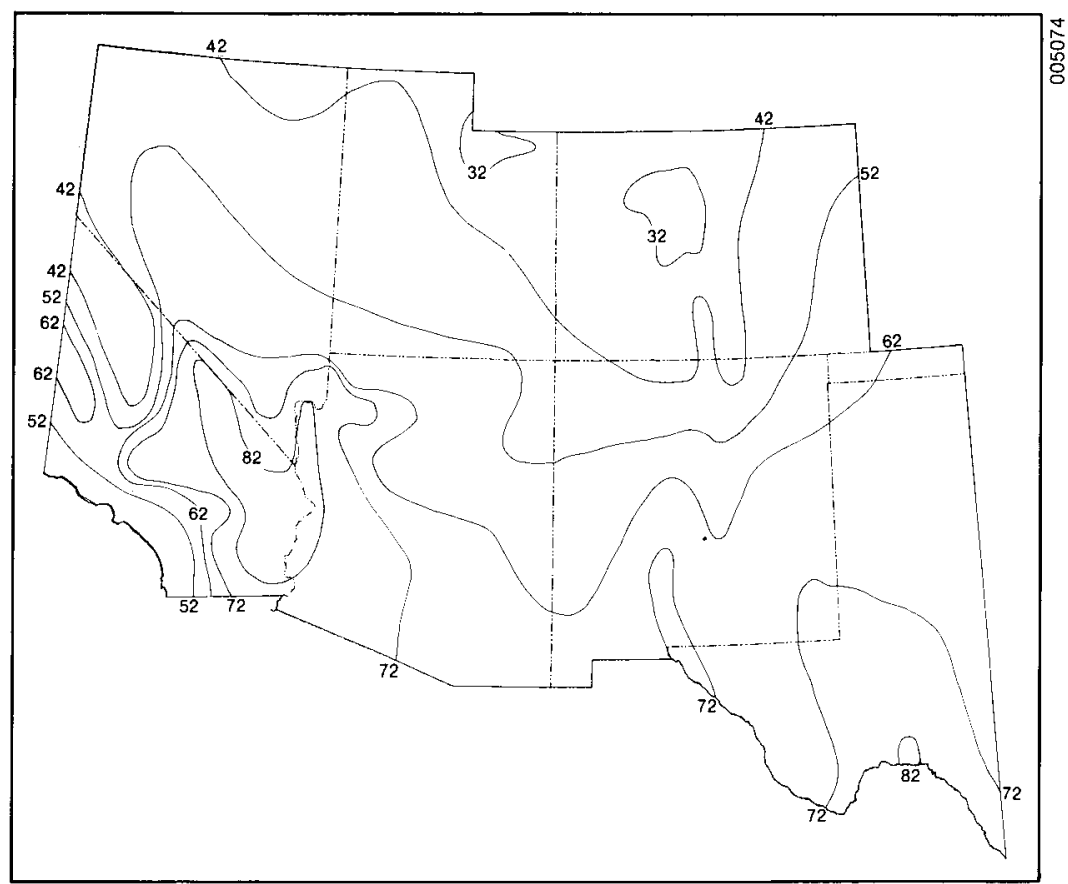

Figure 6-7. Annual Pan Evaporation for the Study Area in Inches 


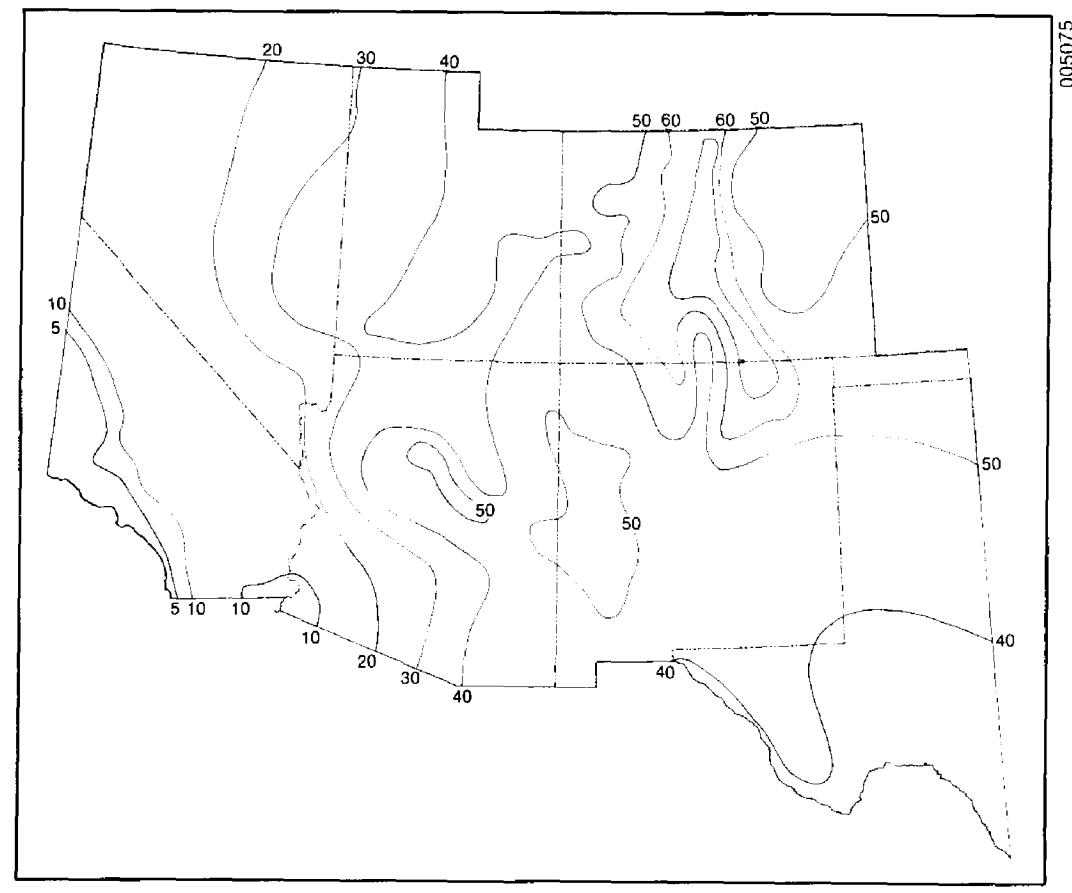

Figure 6-8. Annual Thunderstorm Days for the Study Area (Thunder is heard one or more times on a thunderstorm day.)

Slope maps were not available for most of the Southwest. There are two common means by which they can be generated. If digital elevation data are avai1able, programs such as TOPOGO (Sharpnack and Akin 1969) can be used to compute slope and aspect for each cell of a digital map. The only source of digital terrain data with nationwide coverage is the Defense Mapping Agency, which has digitized the Army Map Service (AMS) Sheets (1:250,000 scale). USGS has initiated the digitization of the $7.5^{\prime}$ quadrangle series $(1: 24,000$ scale) but the job is far from complete. In either case, the cost of computer generation of slope maps for the southwestern United States would have far exceeded our available budget.

The only practical means for generating slope maps for this project was the manual interpretation of elevation contour lines on topographic maps. This was accomplished by using a scale to interpret contour line spacing in terms of slope. State maps at a scale of 1:500,000 were selected for reasons of economy. For similar reasons, it was determined that only the boundary between slopes above and below an arbitrary threshold could be mapped. That threshold was set at $10 \%$ for the following reasons. Below $10 \%$, the construction of ponds will be more or less routine and the increase in excavation costs due to slope will be less than $50 \%$. Above $10 \%$, the cost of excavation increases rapidly (at $15 \%$ the cost is about double that at $0 \%$ ) and the job becomes increasingly complex.

The $10 \%$ slope map that resulted from the above process is shown in Figure 6-9. One must bear in mind that the $500-\mathrm{ft}$ separation between contours on these 


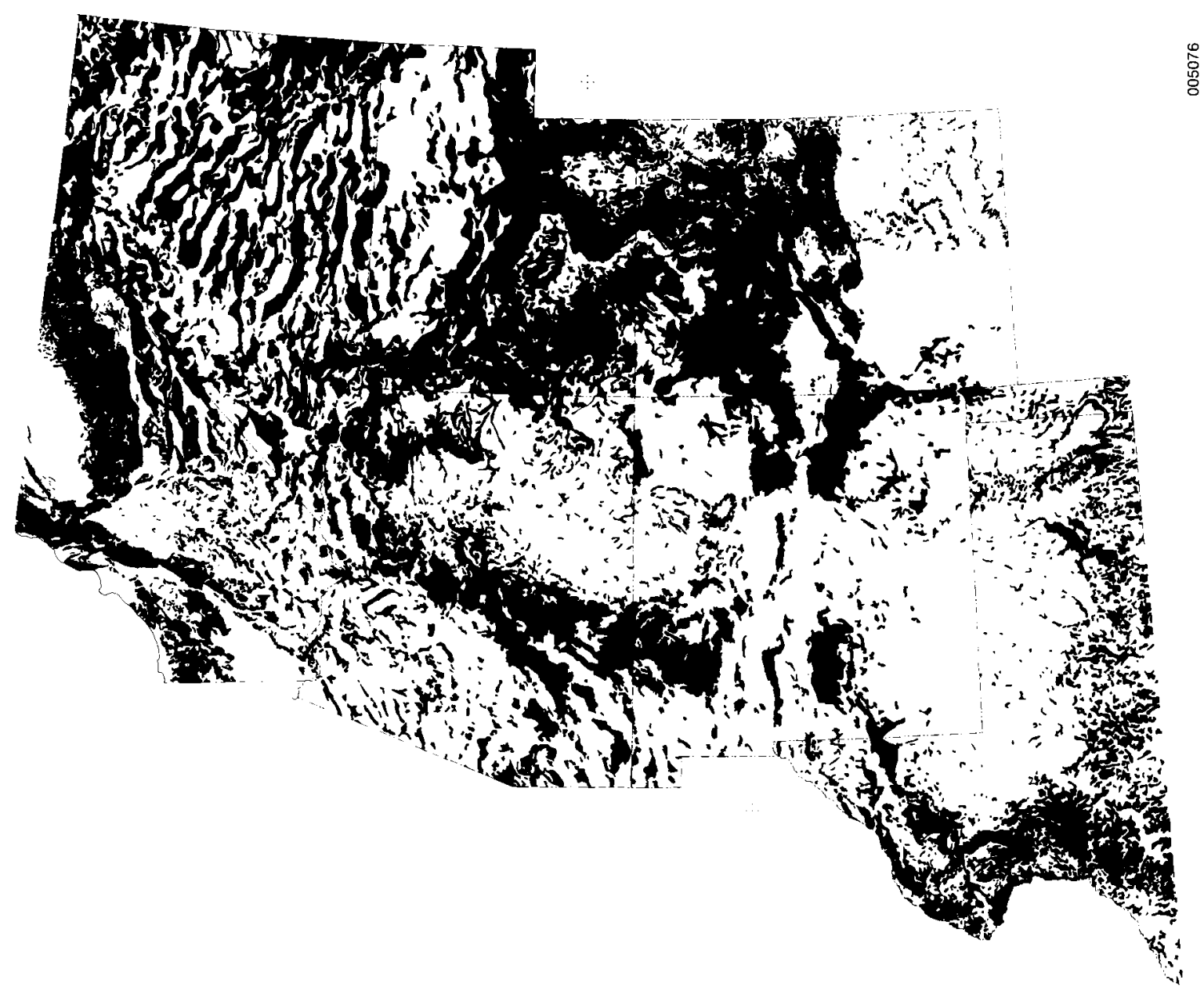

Figure 6-9. Portion of Study Area with a Slope of $10 \%$ or More (dark side)

state maps smooths out minor relief features, thus the area designated as having a slope less than $10 \%$ is probably exaggerated by $30 \%$ to $40 \%$.

Land use/cover maps are also not available for most of the Southwest. USGS has a long-term program to prepare land use/cover maps for the entire nation at a scale of 1:250,000 (same base as AMS sheets). Maps that were available for the Southwest (only 15 of some 100 AMS sheets) were used, but for most of the region the land use/cover information was extracted from Landsat False Color Composite (FCC) prints.

Approximately 130 Landsat FCCs, at a scale of $1: 1,000,000$, were needed to cover the Southwest. These were photointerpreted using a modified classification scheme developed by Anderson et al. (1976). The Anderson classes are given in Table 6-1, along with the classes used by SERI for this task. The classes selected for this task were chosen for the most part because of their significance to the siting and cost of construction of microalgae production systems. However, suitability for interpretation from Landsat FCCs was a prerequisite and matching the task classes to Anderson's scheme will facilitate making improvements in the land use/cover map, as USGS completes more maps in the series. 
Table 6-1. Land Use/Cover Classes

\begin{tabular}{|c|c|c|}
\hline Code & Anderson & SERI \\
\hline 10 & Urban & Urban \\
\hline 11 & Residential & \\
\hline 12 & Commercial & \\
\hline 13 & Industrial & \\
\hline 14 & Transportation etc. & \\
\hline 15 & Industrial complex & \\
\hline 16 & Mixed urban & \\
\hline 17 & Other urban & \\
\hline 20 & Agricultural & Agricultural \\
\hline 21 & Cropland and pasture & Nonirrigated cropland \\
\hline 22 & Orchards etc. & \\
\hline 23 & Feedlots & \\
\hline 24 & Other agricultural land & \\
\hline 30 & Rangeland & Rangeland \\
\hline 31 & Herbaceous & Low biomass \\
\hline 32 & Shrub and brush & High biomass \\
\hline 33 & Mixed range & Mixed \\
\hline 40 & Forest Land & Forest Land \\
\hline 41 & Deciduous & Deciduous \\
\hline 42 & Evergreen & Evergreen \\
\hline 43 & Mixed forest & Mixed forest \\
\hline 50 & Water & Water \\
\hline 51 & Streams and canals & \\
\hline 52 & Lakes & Lakes \\
\hline 53 & Reservoirs & Reservoirs \\
\hline 54 & Bays and estuaries & \\
\hline 60 & Wetland & Wetland \\
\hline 61 & Forested & \\
\hline 62 & Nonforested & \\
\hline 70 & Barren Land & Barren Land \\
\hline 71 & Dry salt flats & Dry salt flats, etc. \\
\hline 72 & Beaches & \\
\hline 73 & Sandy areas & \\
\hline 74 & Bare rock & \\
\hline 75 & Strip mines, etc. & \\
\hline 76 & Transitional & \\
\hline 77 & Mixed barren 1 and & \\
\hline 78 & & Other barren land \\
\hline 80 & Tundra & \\
\hline 81 & Shrub and brush & \\
\hline 82 & Herbaceous & \\
\hline 83 & Bare ground & \\
\hline
\end{tabular}


Table 6-1. Land Use/Cover Classes (Concluded)

\begin{tabular}{clc}
\hline Code & \multicolumn{1}{c}{ Anderson } & SERI \\
\hline 84 & Wetland & \\
85 & Mixed tundra & \\
90 & Perennial Snow or Ice & Alpine \\
91 & Perennial snow & \\
92 & Glaciers & \\
\hline
\end{tabular}

Note: Level I classes are printed bold face.

Level II classes are in normal print.

The cost significance of the land use/cover classes is related primarily to land acquisition. For example, a11 urban lands will be too expensive to consider for this application; therefore, no attempt was made to map the Level II classes. The semiarid and arid climates of the western United States make the availability of irrigation water a primary factor in determining land costs. Hence, for this task, the general Agricultural Class 20 was used for all agricultural lands except those in which a majority of the acreage was apparently not under irrigation. Nonirrigated crop lands were designated Class 21 and represent the cheaper agricultural regions.

Rangelands and forest lands were classified to Level II for general interest, not because these classes are likely to affect cost or suitability. Watercovered regions and wetlands are not suitable for microalgae sites and are mapped for the purpose of excluding these regions. Under the barren lands class, the "dry salt flats" actually designate any bright and featureless region with little or no vegetative cover. All other barren lands had to be groupqed in one class since the Anderson classes are difficult if not impossible to recognize on Landsat images. Finally, since any tundra or perennial snow or ice region is unsuitable for microalgae production, these classes were grouped together and designated as alpine.

In some instances the Level I classes were marked on the maps when Level II interpretations were impossible. For the most part, rangeland, forestland, water, and barren land were mapped at Level II. The user must combine these into Level I classes if their application warrants.

We could not evaluate the accuracy of the interpretations of the Landsat images except for those regions where USGS Land Use maps were available. The qualitative evaluation done at those locations indicated that the interpretations were quite accurate for at least the Level I classes. Figure 6-10 shows the full detail of the information extracted from Landsat for New Mexico.

Land ownership maps were obtained from BLM for all states except Texas and Oklahoma. These BLM "Land Status Maps" were created in 1979 at a scale of 1:500,000 (except California at 1:750,000) with a Lambert Conformal Conic projection. These maps have a resolution of 120 acres, two orders of magnitude better than the 12,455 -acre cell created by the digitization process used on 


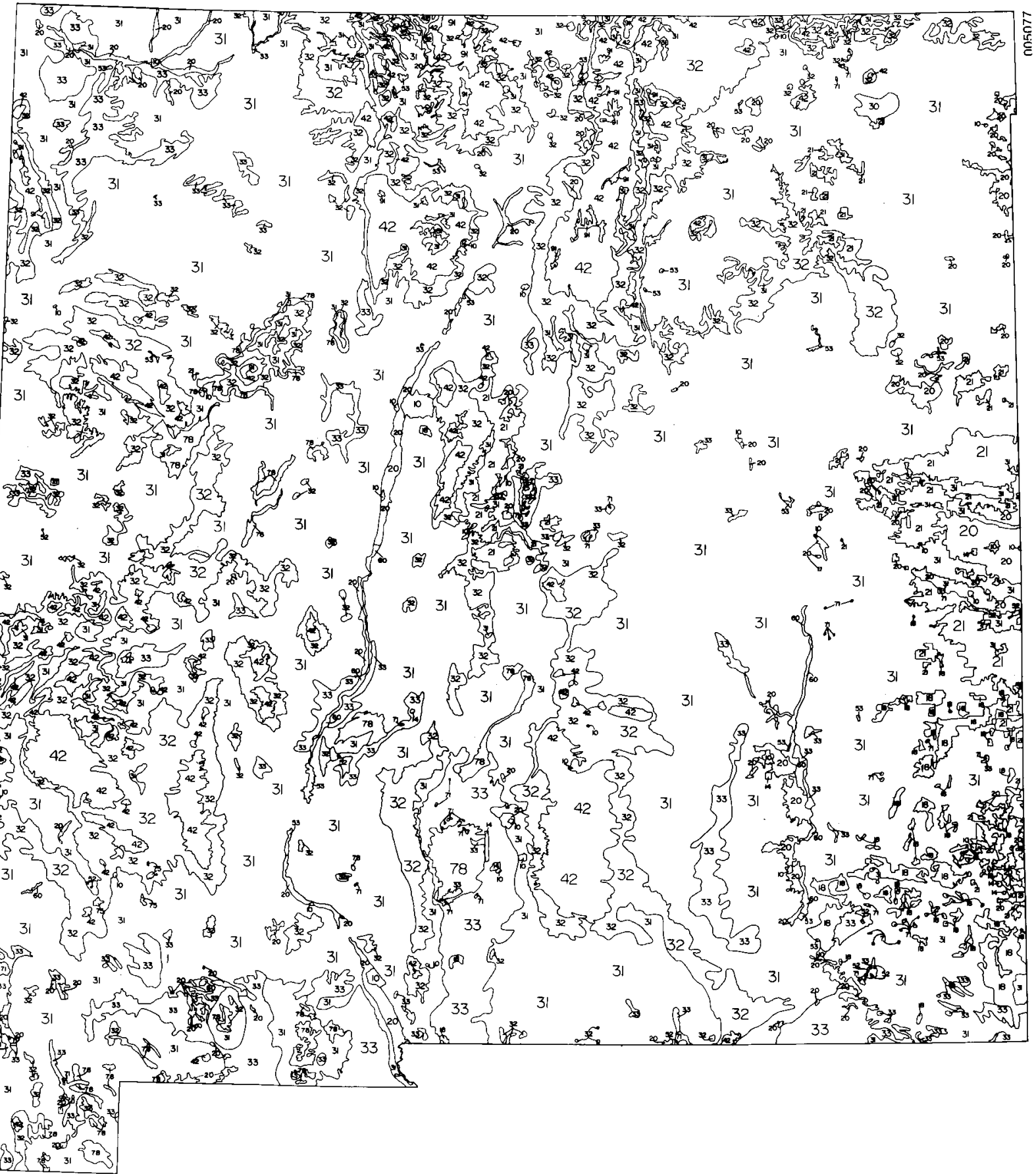

Figure 6-10. Land Use Map of New Mexico Generated by Photointerpretation of $1: 1,000,000$ Scale False Color Composites of Landsat Images. (See Table 6-1 for number codes.) 
this project. A 120-acre resolution was needed by BLM to accurately display the checkerboard ownership patterns created by federal and state ownership of lands in the western states. A typical pattern is shown in Figure 6-11 for the region around Carlsbad, N. Mex. Each township (36 sections) covers an area of 23,040 acres. This is contrasted with our digitization cel1 of 12,455 acres, one of which is randomly located on Figure 6-11.

Therefore, the use of the BLM Land Status Maps required a degradation of resolution. This was accomplished by drawing boundaries around more or less homogeneous regions larger than a township. A single dominant ownership for these polygons was designated whenever one class represented $2 / 3$ or more of

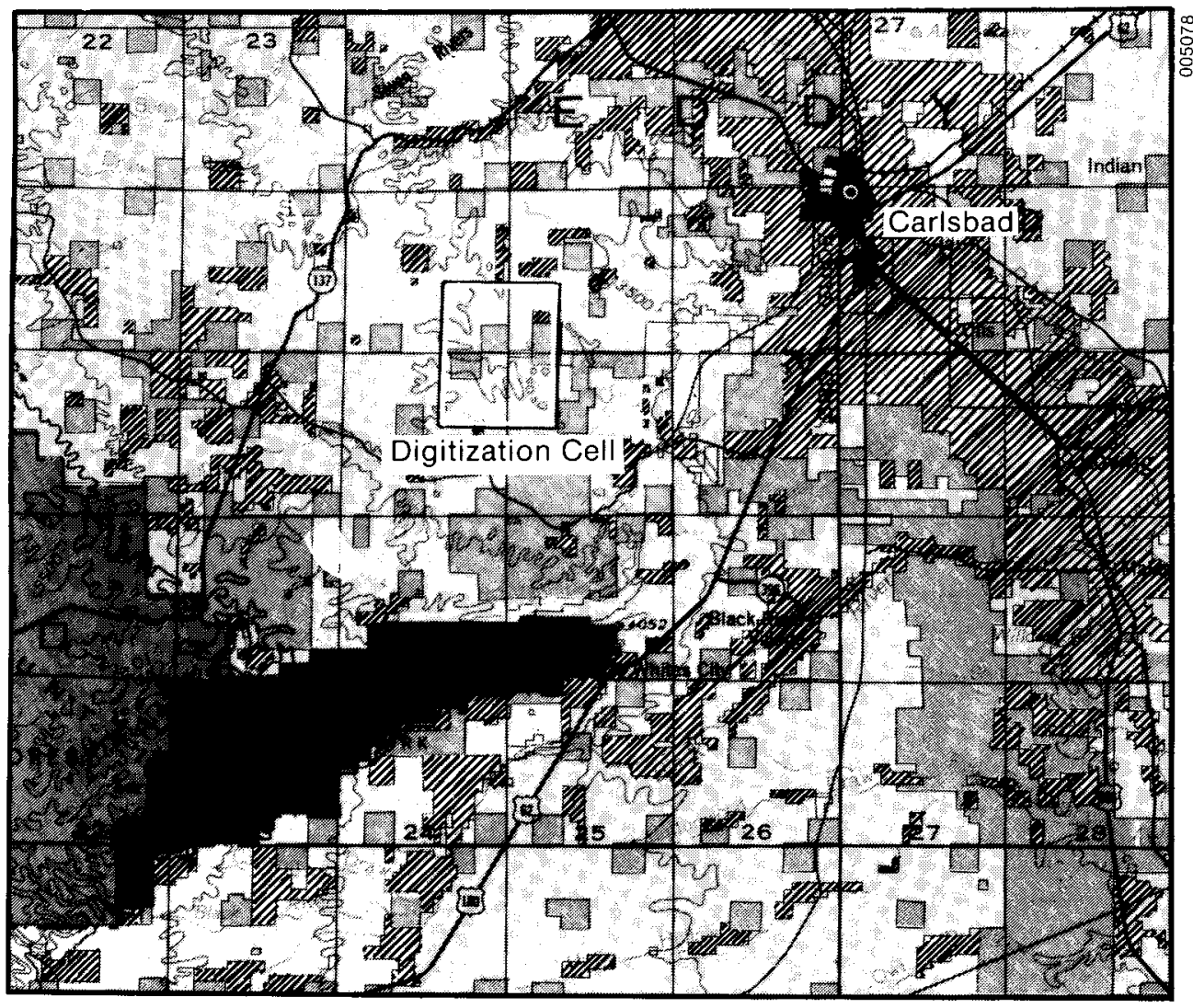

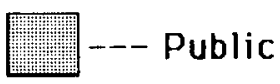

--- State

--- National Forest

--- Private

National Parks \& Monuments
Scale $1: 500,000$

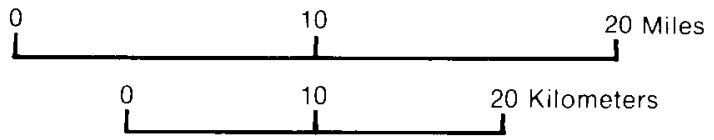

1 inch equals approximately 8 miles

Figure 6-11. Portion of the BLM Land Status Map of New Mexico Showing the Checkerboard Patterns of Public, State, and Private Ownership 
the area. A mixed class was designated whenever no one class was dominant in a region. The various combinations of mixed classes included public/state, private/state, private/public, public/state/private, and some combinations including Indian (reservation) ownership. Because of the complex mixtures found, all combinations were combined into a single mixed (M) class. A listing of the ownership classes used is given in Table 6-2. The resultant polygon map for the state of New Mexico is shown on Figure 6-12.

With the exception of military facilities, state and national parks, and wildlife refuges, west Texas and the Oklahoma panhandle are privately owned. Maps of these areas were generated from data obtained from a variety of sources.

\subsubsection{Water Resource Maps}

The only readily available, compatible map data for mineralized groundwater resources of the Southwest was that prepared by Feth et a1. (1965). This nationwide compilation of data came from many sources in 34 states. Published reports and unpublished records were obtained by Feth from federal, state, and local agencies. The largest single contributor was USGS.

The character, reliability, and usefulness of the data displayed on Feth's maps can be summarized by the following statements:

- Only the uppermost zone of mineralized water was mapped according to its occurrence at depths of $0-500 \mathrm{ft}, 500$ to $1000 \mathrm{ft}$, and greater than $1000 \mathrm{ft}$.

- The available data were grouped into the following categories of mineral concentrations:

$$
\begin{array}{r}
1,000-3,000 \mathrm{ppm} \\
3,000-10,000 \mathrm{ppm} \\
10,000-35,000 \mathrm{ppm} \\
>35,000 \mathrm{ppm}
\end{array}
$$

Table 6-2. Land Ownership Classes

\begin{tabular}{ll}
\hline Code & Class \\
\hline B & Public land (BLM) \\
S & State lands \\
P & Private lands \\
M & Mixed (mixture of public, state, and private) \\
I & Indian reservations \\
A & Military reservations \\
F & National forests and grasslands \\
N & National parks and monuments \\
W & Wilderness areas \\
E & Department of Energy (e.g., Nevada test site) \\
U & Urban land (developed) \\
\hline
\end{tabular}




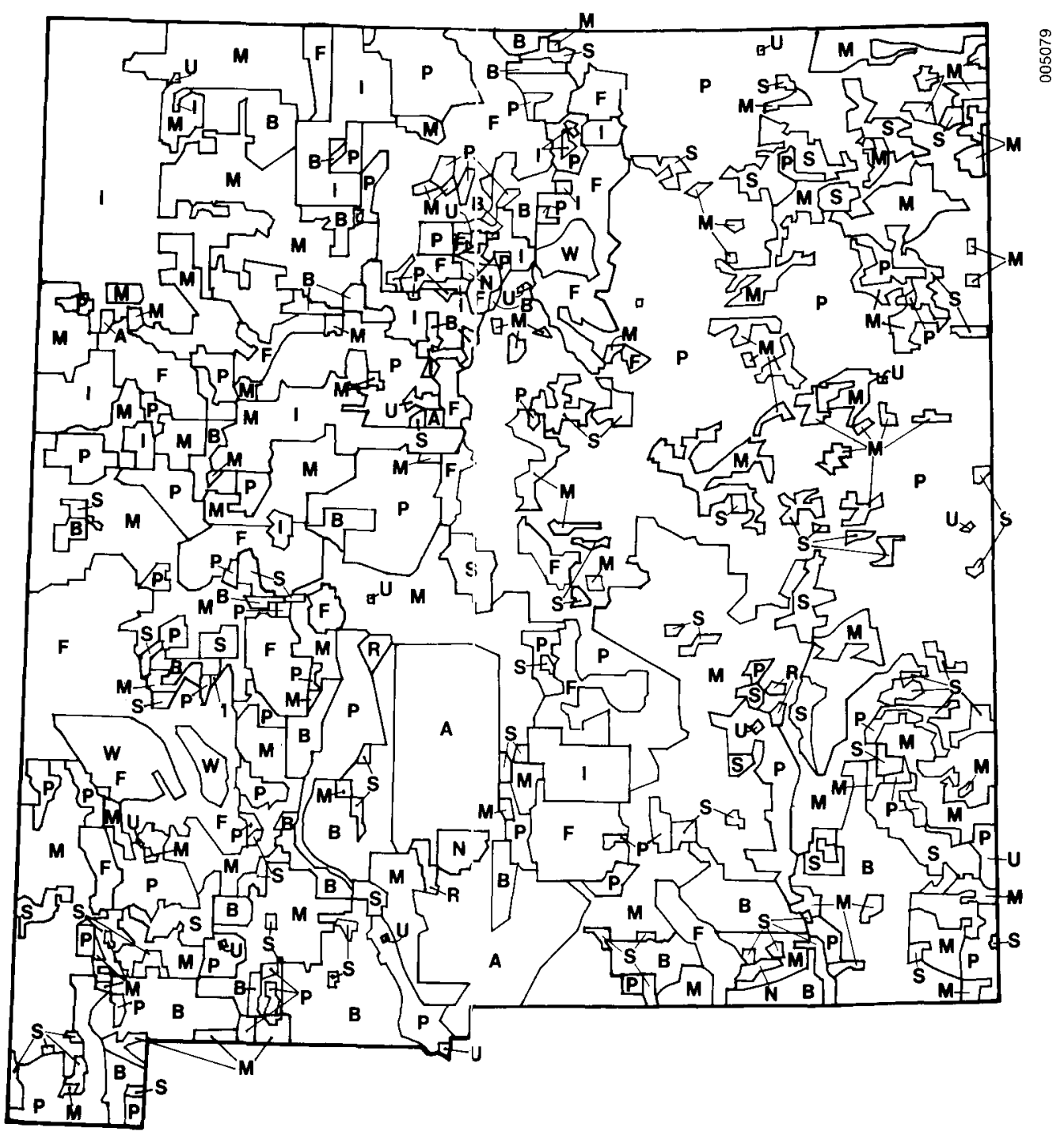

Figure 6-12. Polygon Map of Land Ownership Patterns in New Mexico. (See Table 6-2 for class codes.)

- The information was derived primarily from data of opportunity, obtained from wells being drilled for purposes other than exploration for mineralized water. Thus, the sampling was not statistically designed.

- It is not feasible to estimate volumes of available mineralized water on the basis of these data. Up to this time (1965), mineralized water was only a liability and estimations of yield were not even considered. Seldom have performance tests been made on saline-water aquifers.

- Data obtained during the past 20 years are not included. Hence, the maps do not show water resources discovered during the last two decades. 
Overall one must conclude that water resource information is seriously deficient and represents a major weakness in this attempt to stratify the Southwest into zones of suitability for microalgae production.

More detailed and up-to-date information was found for some regions, but only Feth's map provided uniform data for the entire Southwest. Hence, mapmaking for water resources was limited to redrawing Feth's map at a scale of $1: 2,500,000$ from a scale of $1: 3,168,000$. Figure 6-13 shows the polygon map of saline water resources for the Southwest.

As noted above, Feth's map included water resources with salinities between 1000 and $3000 \mathrm{ppm}$. These were not transferred to the polygon map for this project (see Figure 6-13) since water with this level of mineralization is used for irrigation, livestock, and occasionally for human consumption. On the basis that these water resources would not be readily available for microalgae production systems, they were eliminated from further consideration. In retrospect, this was a questionable decision since competition for resources is very complex and should not be decided in such a preemptive manner. The areas affected by this decision include all of west Texas and all of New Mexico except for the southwest corner ( $15 \%$ of the land area) and the mountainous region in the north-central part of the state ( $10 \%$ of the land area). In the other states, the 1000-3000 ppm resources are mostly confined to sma11 zones surrounding water resources with higher salinities. The users of the resultant stratification maps should keep this in mind. However, one should also be reminded that the mapping of these resources in New Mexico and West Texas is probably due in large measure to the extensive exploration for oil and minerals in these regions. As noted by Feth (1965), ". . the areas

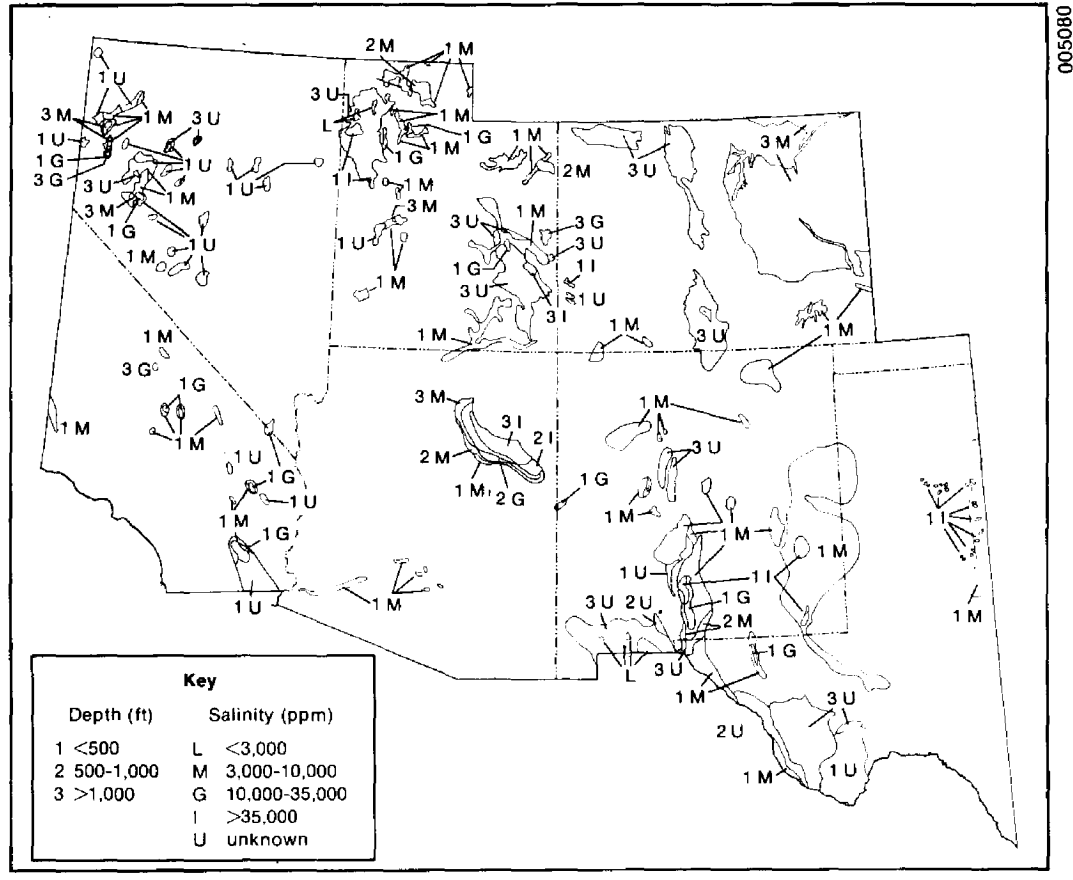

Figure 6-13. A Saline Groundwater Map of the Study Area Based on Data of Opportunity from Feth et al. 1965 (Considered to be incomplete.) 
presently left blank on sheet 1 may be shown to have producible supplies of mineralized water. Sheet 1 thus represents the incomplete state of knowledge in 1964."

\subsection{DIGITIZATION OF MAPS - STEP 3}

The digitization of the polygon maps was carried out by Geometronics International, Inc. using a manual procedure. The polygon maps were overlaid with a clear mylar grid of cells. Each cell was 1/8-in. $\times 1 / 10-i n$. in size, corresponding to the space occupied by computer printer symbols when the printer is set for 8 lines/in. (normal single space typing is 6 lines/in.). The mylar grids were registered to each map such that the numbered columns and rows represented the same location on all maps. The grids were coded by writing in symbols at polygon boundaries, which were entered into the computer by key punch (termina1) operators. The computer software interpreted the codes such that a class or value symbol was assigned to each cell within polygon boundaries. The resultant data sets were then used to generate computer maps at the same scale as the polygon maps. This completed the digitization process.

\subsubsection{Climate Maps}

The 1:2,500,000 climate maps were digitized without modification. Figure 6-14 provides a side-by-side comparison of the polygon and digital freeze-free period maps. Very little information was lost during the digitization of the climate maps.

\subsubsection{Land Resource Maps}

Unfortunately, a great deal of information was lost in the process of digitizing slope, land use, and ownership maps. The polygon slope map has a resolution on the order of 1000 acres. Considerable detail was lost, therefore, when the map was digitized using a cell size of 12,455 acres as shown by the side-by-side comparison of the polygon and digital maps shown in Figure 6-15.

The land use maps generated from Landsat images also have a resolution of about 1000 acres. Furthermore, much of the detail on these maps, as shown on Figure 6-10, could not be effectively used in the stratification process. For example, there was no information available from which cost differences could be obtained for the Level II classes of rangeland and forest land. Therefore, a decision was made to digitize only those land use classes for which weights could be assigned for compositing. Furthermore, most forest lands and all alpine lands in the Southwest lie in regions having slopes exceeding $10 \%$. It seemed unnecessary, therefore, to digitize forest and alpine lands since these areas would already be given a low suitability on the basis of slope. In the final analysis, the land use classes shown on Table 6-3 were digitized.

The loss of land use information due to class truncation and reduced resolution is evident when one compares the polygon map for New Mexico (Figure 6-10) 

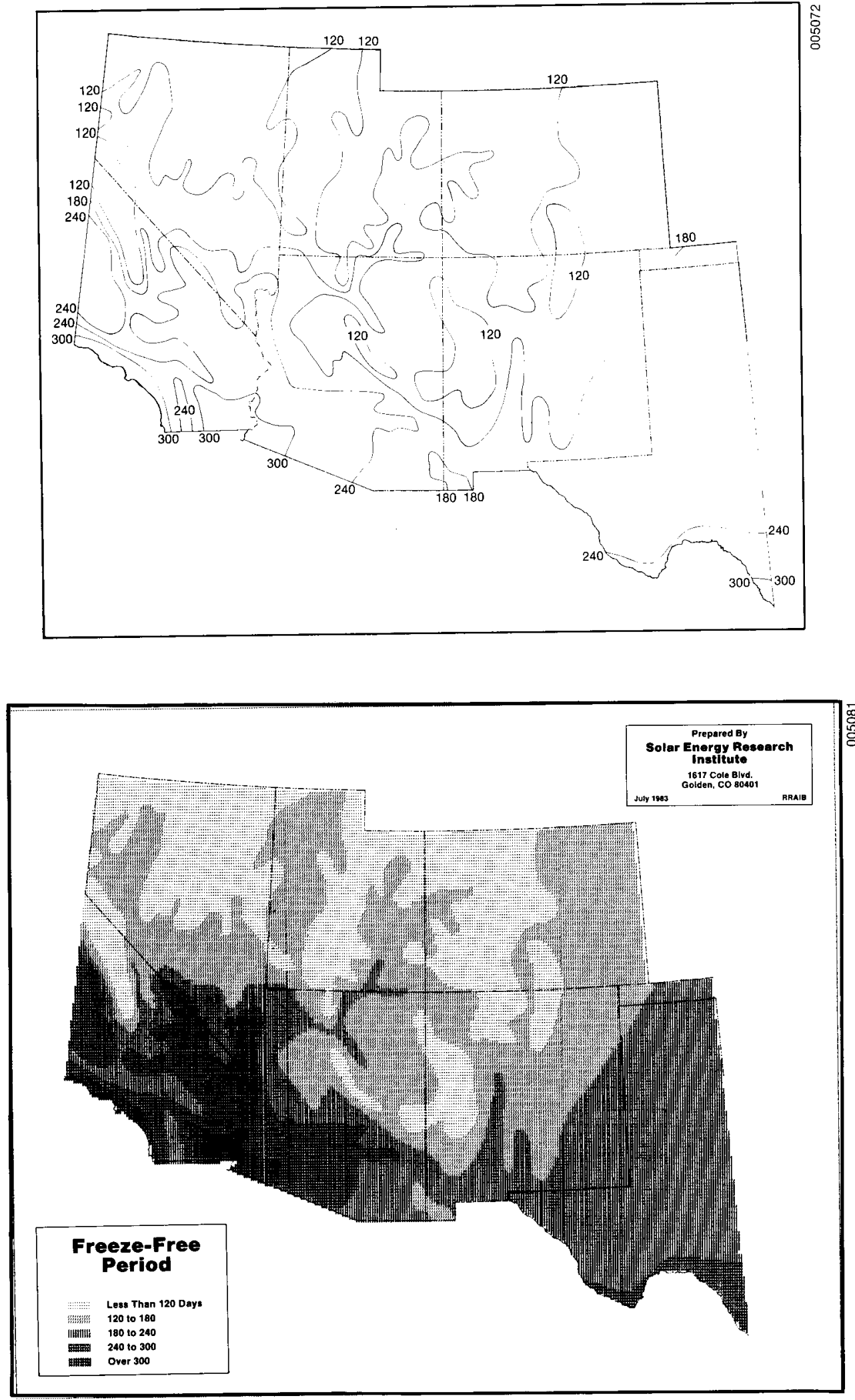

Figure 6-14. Polygon and Digital (Line Printer) Versions of the Freeze-Free Period Maps for the Study Area (negligible loss of information) 

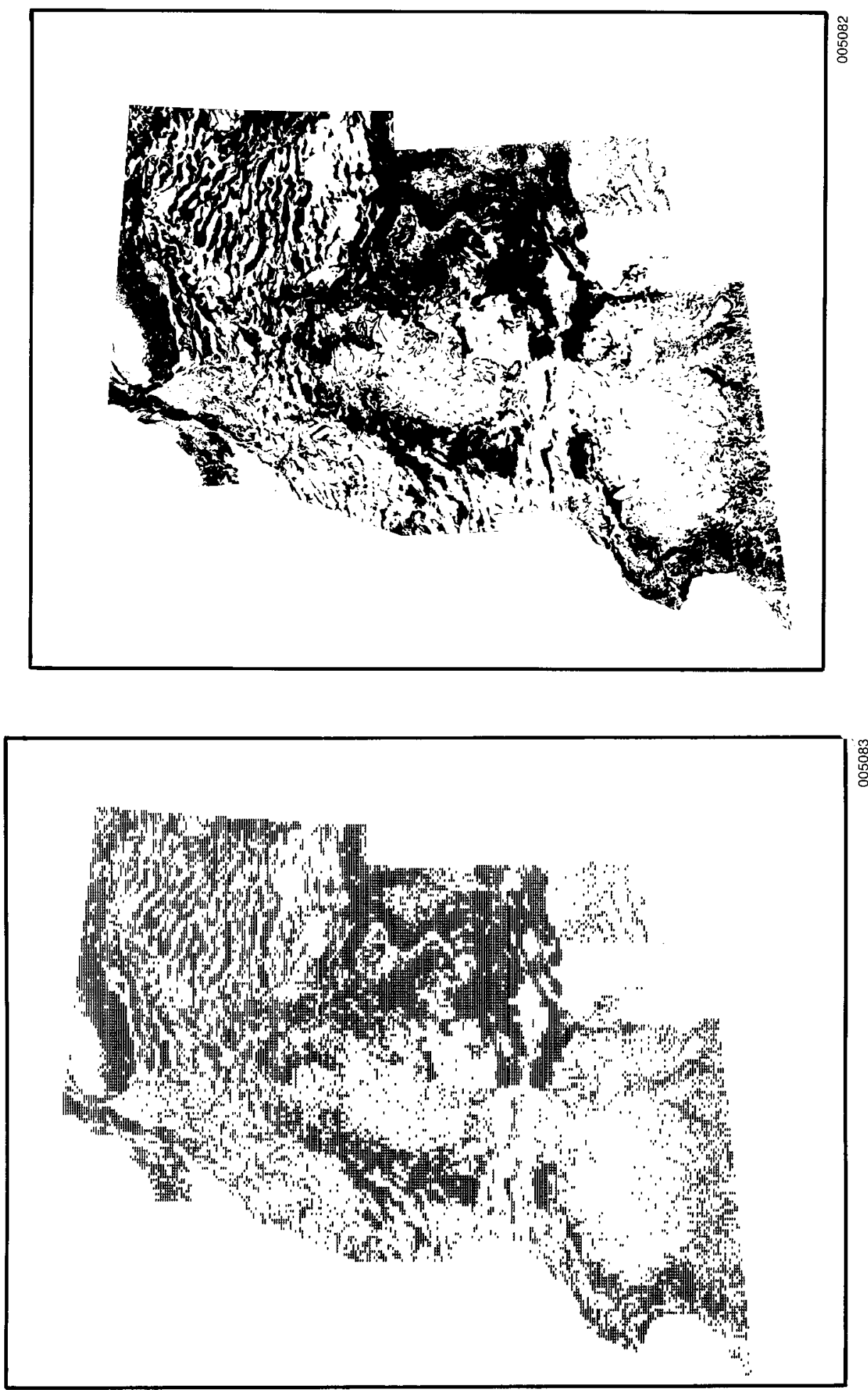

Figure 6-15. Polygon and Digital (Line Printer) Versions of the $10 \%$ Slope Map for the Study Area (considerable loss of detail during digitization) 


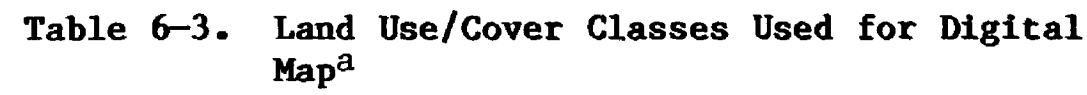

\begin{tabular}{ll}
\hline Code & \multicolumn{1}{c}{ Class } \\
\hline 10 & Urban \\
20 & Agricultural (irrigated) \\
30 & Rangeland (includes dry cropland) \\
52 & Lakes and reservoirs \\
60 & Wetlands \\
71 & Dry salt flats, etc. \\
\hline
\end{tabular}

$a_{B o l d}$ face type indicates Level $I$ class, and normal print indicates Level II class.

with the digital map shown on Figure 6-16. Note that although this information was lost for the initial stratification effort discussed earlier, the information is still available to the Microalgae Program in the form of $1: 1,000,000$ scale maps of each state, having all the detail shown in Figure 6-10. This information could be used for future refinements of the stratification or for actual site selection in areas having suitable conditions as determined by this initial effort.

The land ownership map could have been digitized in its original polygon format, but the cost of reproducing all of the detail of these maps (see Figure 6-12) could not be justified. For example, one cannot determine the relative costs of public, state, and private lands without examining specific plots and discussing acquisition with the individuals or offices responsible for the lands. Therefore, it was not possible to determine the suitability of these lands when stratifying the entire Southwest. On this basis, public, state, private, and mixed lands were grouped into a single ownership class for digitization. Similarly, it was determined that national parks and monuments and wilderness areas would be unavailable for this application and could be grouped together for the stratification. This left a class composed of Indian reservations, military reservations, and Department of Energy lands. Since urban areas were identified on the land use maps, it was not necessary to digitize this information from the land ownership maps. In the final analysis, only three classes of land ownership were digitized. These are defined on Table 6-4.

The loss of land ownership information through the processes of Steps 2 and 3 is illustrated in Figure 6-17, which shows the original BLM ownership map compared with the polygon and digital formats generated on this project for a small part of New Mexico. The digital land ownership map for the entire Southwest is shown in Figure 6-18. It is similar to the land use map, although much of the land ownership information collected was not used for the initial stratification. That information is still available for future work, including site selection. 


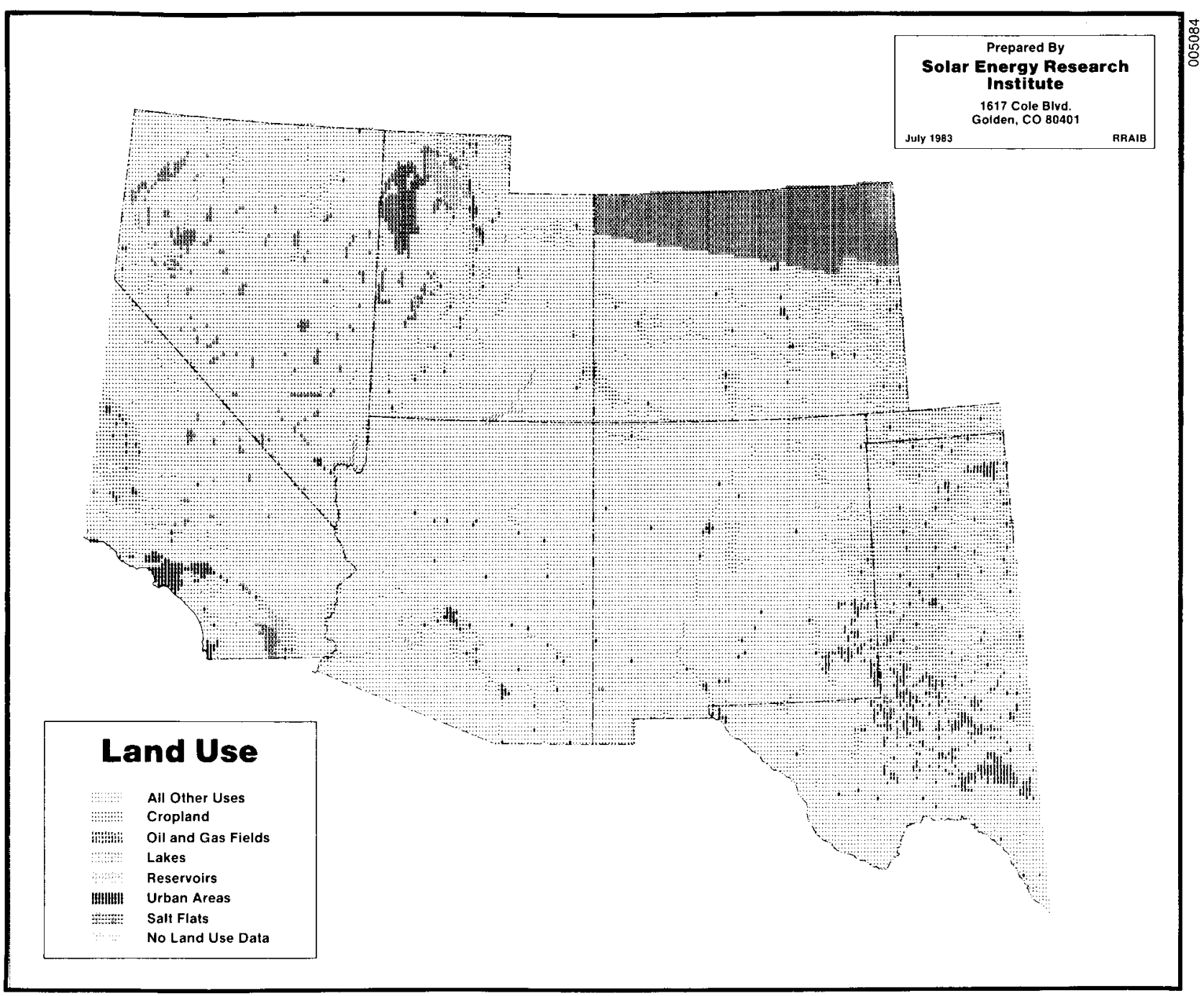

Figure 6-16. Digital Version of the Land Use Map of the Study Area. (A comparison of New Mexico on this map with Figure 6-10 indicates a great loss of information during digitization.)

Table 6-4. Land Ownership Classes for Digital Map

\begin{tabular}{lll}
\hline Code & \multicolumn{1}{c}{ Class } & \multicolumn{1}{c}{ Description } \\
\hline B & Suitable & Public, state, and private lands \\
Less Suitable & Indian, military, and DOE lands \\
& Not Suitable & Parks, monument, and wilderness
\end{tabular}




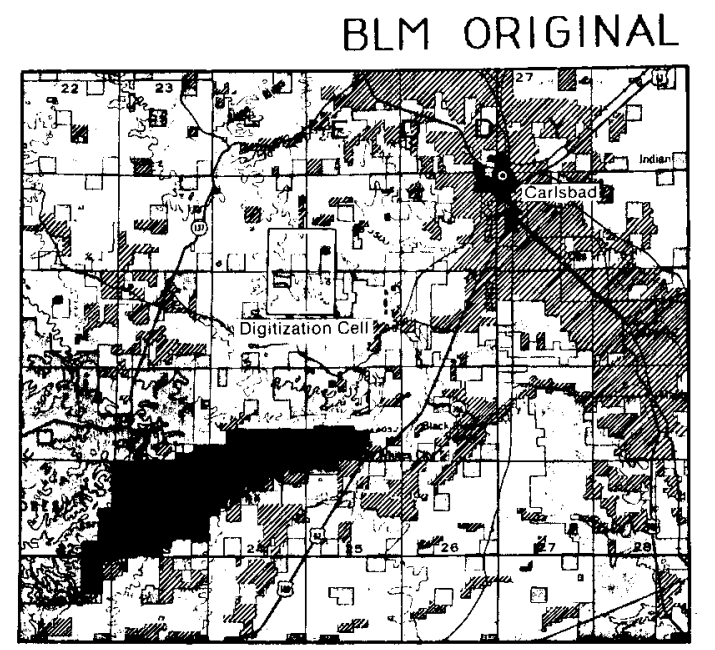

B--- Public Lands

F -- National Forests

M--- Mixed (Public, State, Private)

d--- National Parks \& Monuments

P--- Private Ownership

$\mathbf{S}^{---}$State Lands

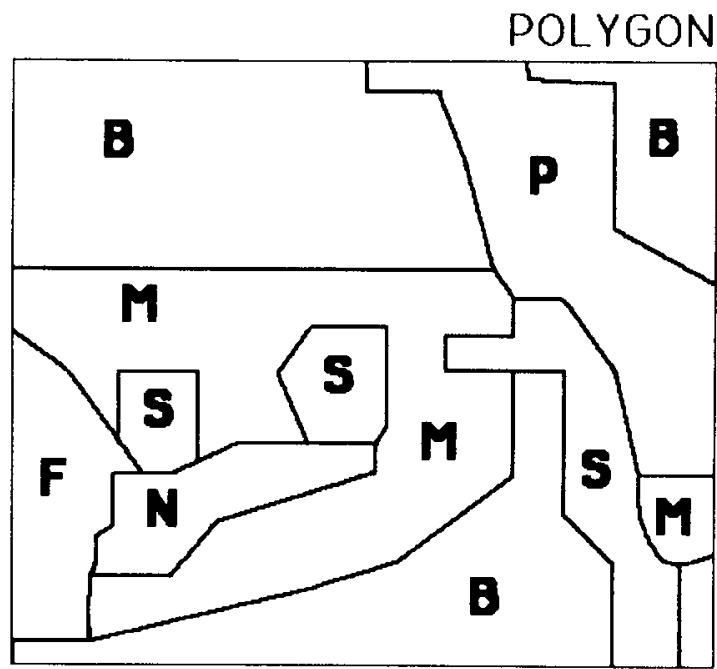

\section{DIGITAL}

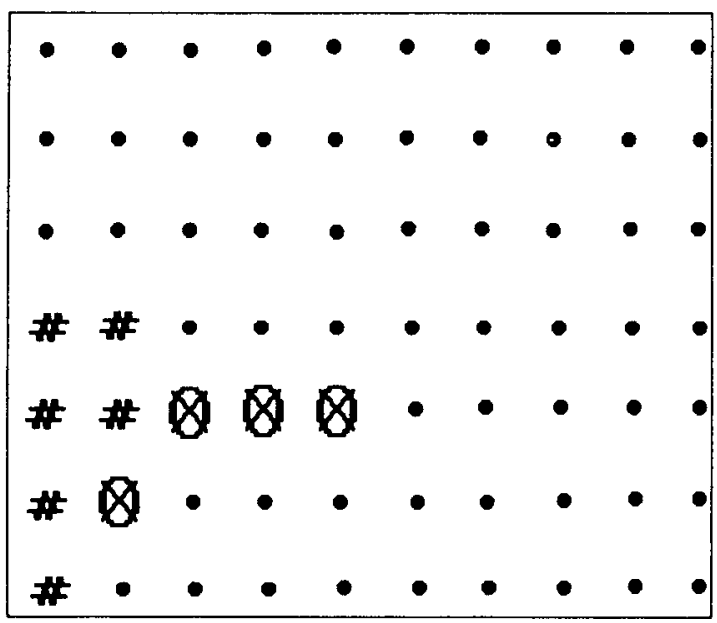

- -- Suitable (Public, State, Private)

\#--- Less Suitable (Indian, Military, Forest)

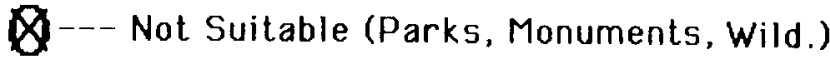

Figure 6-17. Progressive Loss of Information Illustrated by Original, Polygon, and Digital Land Ownership Maps for a Small Region in Southern New Mexico (Scales of $1: 1,000,000$ ) 


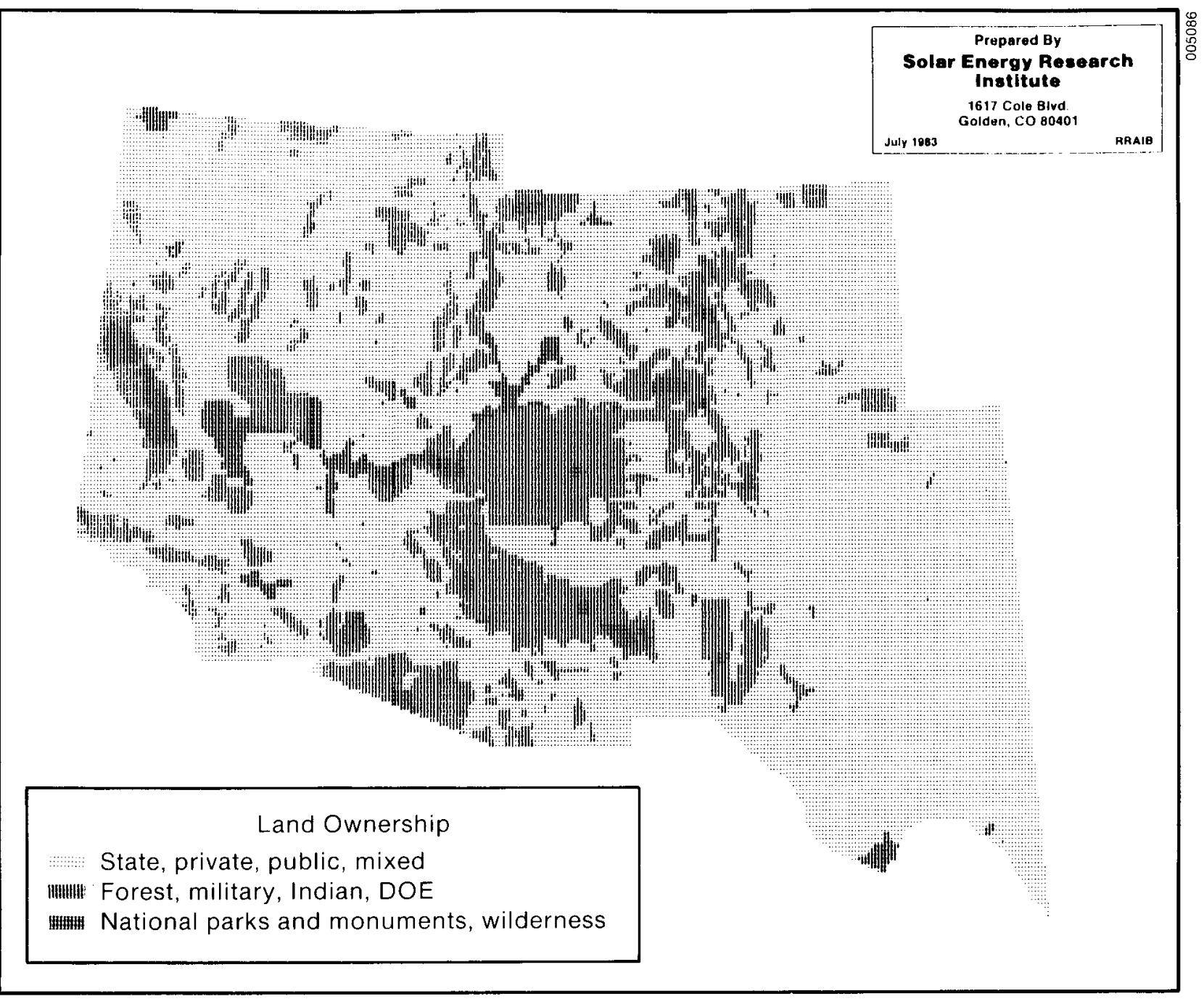

Figure 6-18. Digital (Line Printer) Map of Land Ownership for the Study Area

\subsubsection{Water Resource Maps}

Very little information was lost in the process of digitizing the water resource map. Some of the areas mapped by Feth were too small to accurately depict with 12,455 acre cells, but this was the only difficulty encountered. It was determined, however, that the effects of water salinity and depth on the cost and operational characteristics of microalgae production systems were quite different (see Section 6.5.3). For this reason, separate salinity and depth maps were prepared during the digitization process. These maps are not shown here since they do not represent any change in information content from the polygon map shown in Figure 6-13. 


\subsubsection{Summary}

The digitization process produced essentially a one-for-one transfer of information from the polygon maps for climate and water resources. Furthermore, as will be discussed in the following section, all of the climate and water data, but not the land resource data, were effectively used in the compositing process.

Some information was lost from the slope and land use maps as a result of the degradation of resolution. However, the greater loss of information resulted from our inability to use all of the information on the land use and ownership maps. Land information was discarded because of our inability to use it to determine suitability of one region compared to another. Given more funds and time or a smaller region, all of the land use and land ownership data collected could be used.

Therefore, the initial stratification has served its purpose--that of limiting the area of future investigations. Furthermore, all of the detailed information collected for land resources will be an excellent source of data for those investigations.

\subsection{COMPOSITING THE MAPS FOR THE SOUTHWEST - STEP 4}

Most of the systems analyses to be described below were actually performed prior to the digitization of the polygon maps. These systems analyses made it clear that not all of the land resounce information collected could be used for compositing and stratifying the Southwest. This resulted in the simplification of the digitization process and the saving of much time and money.

\subsubsection{Systems Analyses - Step 4A}

These analyses were organized under efforts to determine climate, land, and water resource effects on microalgae production systems in terms of

- Construction costs

- Operating costs

- Production efficiency.

The effects of water, land, and climate resource variables on construction costs were easier to evaluate than the effects on operating costs and production efficiency. MPS designs and operating procedures were too poorly defined to permit accurate estimates of resource impacts on operations and production. Nevertheless, rough estimates were needed to assign weights to resource parameters for the compositing process.

\subsubsection{Factors Affecting Construction Costs}

C1imate. In the Southwest, climate should have little effect on construction costs unless the ponds are covered to reduce evaporation losses. There were 
no costs available for structures designed to cover ponds such as those being considered for microalgae production. Structures for which costs are available include greenhouses, swimming pools, and temporary hangars. Typical costs are given below:

\begin{tabular}{lr}
\hline Cover Type & Cost \\
\hline Greenhouse, commercial, 5000 ft ${ }^{2}$ & $\$ 22 / \mathrm{ft}^{2}$ \\
Greenhouse, geodesic dome-plexiglas, 48 ft diameter & $\$ 15 / \mathrm{ft}^{2}$ \\
Hangar, circular-steel frame-plastic cover, 80 ft diameter $\begin{array}{c}\$ 16 / \mathrm{ft}^{2} \\
\text { Pool cover, air-inflated including blowers and heaters }\end{array}$ & \begin{tabular}{l}
$\mathrm{ft}^{2}$ \\
\hline
\end{tabular}
\end{tabular}

The $\$ 6 / \mathrm{ft}^{2}$ cost for an inflated pool cover is the average of two estimates of $\$ 3$ and $\$ 9$. This equates to $\$ 261,360$ per acre and far exceeds allowable cost. On the basis of this estimate, other systems analyses will assume an open system unless noted otherwise.

Land Acquisition. In general, the cost of land will be determined by current land use and development pressures. Development pressure is a function of growth rate and distance from expanding population centers. Typical land costs for the Southwest are

Irrigated cropland
Dry cropland
Rangeland
Forest land

$\$ 3000$ per acre
300 per acre
100 per acre
1000 per acre

The high cost of private forest lands is caused by recreational development throughout the Southwest. Forest productivity is too low to generate such land values from timber harvests. The value of land that is less than 30 miles from urban developments is uniformly high regardless of the current land use.

Government-owned land (state and federal) may or may not be available for purchase. Nevertheless, lease costs should be proportional to the value of the land. Hence, these lands were given the same value as similar private lands for comparative purposes. Indian reservation lands were valued similarly.

Hater Acquisition. The cost of obtaining water will be determined by the following factors:

- Current water use

- Existing water rights 
- Depth to aquifers

- Distance to sources.

For this analysis it was assumed that the saline waters of interest have had no previous use and have not been previously claimed. Water acquisition costs are determined, therefore, by the cost of wells, pipelines, and pumps. Distribution of the water between the ponds was not included as a water acquisition cost.

Wel1 costs will be a function of water demand, aquifer depth, and aquifer or well production capacity. Battelle-Columbus estimated that water demand will be

Covered system - $2 \mathrm{gpm} / \mathrm{ha}$ or $2900 \mathrm{gpd} / \mathrm{ha}$

Open system - $7 \mathrm{gpm} / \mathrm{ha}$ or $10,000 \mathrm{gpd} / \mathrm{ha}$

(Units are gallons/min/hectare or gallons/day/hectare.)

These values assume annual evaporation of about 55 inches, negligible seepage (limited by plastic liners if necessary), and $75 \%$ reduction in evaporation for the covered system. Since the USGS map of mineralized water resources used a production capacity of $10,000 \mathrm{gpd}$ as a threshold of significance for saline water resources (Feth et al. 1965), any resource shown on the map is capable of supplying a 1-ha system from one well. In many areas production capacities of millions of gallons per day are indicated, which means that one well could supply water for a system 100 ha or more in size.

Aquifer depths are categorized on the USGS map in ranges of 0-500 feet, 5001000 feet, and greater than 1000 feet. Therefore, we11 costs were estimated for depths of 250, 750, and 1500 feet. Well drilling costs are a function of well diameter, well depth, and the rock types through which the well is drilled. Typical costs for drilling a 4- to 6-in.-diameter well range from $\$ 15 / \mathrm{ft}$ for shallow wells $(<300 \mathrm{ft})$ to over $\$ 30 / \mathrm{ft}$ for deep wells $(>2000 \mathrm{ft})$.

The size and cost of pumps are also functions of well depth since the energy required to lift the water is significant. Assuming each well will supply water to a 50-ha (123-acre) pond, the required annual average flow is $350 \mathrm{gal} / \mathrm{min}$ or $0.78 \mathrm{ft}^{3} / \mathrm{s}$.

The power to lift water is given by

$$
\text { horsepower }=\frac{\mathrm{w} Q \mathrm{~h}_{\mathrm{e}}}{500} \text {, }
$$

where

$$
\begin{aligned}
\mathrm{w} & =\text { the specific weight of water }\left(62.4 \mathrm{lb} / \mathrm{ft}^{3}\right) \\
\mathrm{Q} & =\mathrm{flow}\left(\mathrm{ft}^{3} / \mathrm{s}\right) \\
\mathrm{h}_{\mathrm{e}} & =\text { the lift head }(\mathrm{ft}) .
\end{aligned}
$$


The power to lift the water for the three depths of interest and the estimated pump costs are

\begin{tabular}{lrr}
\hline $\begin{array}{c}\text { Depth } \\
(\mathrm{ft})\end{array}$ & hp & $\begin{array}{c}\text { Cost } \\
(\$)\end{array}$ \\
\hline 250 & 22 & 7,000 \\
750 & 66 & 15,000 \\
1,500 & 132 & 30,000 \\
\hline
\end{tabular}

The following costs are for 25,75 , and $150 \mathrm{hp}$ pumps installed in the wells. The total cost for well drilling, pump, and pump installation for 50 ha is estimated to be

\begin{tabular}{cccc}
\hline $\begin{array}{c}\text { Depth } \\
(\mathrm{ft})\end{array}$ & $\begin{array}{r}\text { Drilling Cost } \\
(\$)\end{array}$ & $\begin{array}{c}\text { Pump } \\
\text { Installation } \\
(\$)\end{array}$ & $\begin{array}{c}\text { Total } \\
(\$)\end{array}$ \\
\hline 250 & 3,750 & 7,000 & $\$ 10,000$ \\
750 & 16,875 & 15,000 & 31,875 \\
1,500 & 45,000 & 30,000 & 75,000 \\
\hline
\end{tabular}

If the wells cannot be located directly beneath the ponds, a pipeline will be required to transport the water to the site. Construction costs consist of trenching, pipe, and pipe laying. For a trench $4 \mathrm{ft}$ deep, the typical excavation and back fill costs will be $\$ 4 / 1$ inear $\mathrm{ft}$ or $\$ 21,100 / \mathrm{mile}$. PVC pipe (6-in. diameter rated at $160 \mathrm{psi}$ ) costs $\$ 3 / \mathrm{ft}$ or $\$ 15,800 / \mathrm{mile}$. Laying the pipe will cost about $\$ 2 / \mathrm{ft}$ or $\$ 10,500 / \mathrm{mile}$. The total cost for a 6-in. water line will be about $\$ 47,400 / \mathrm{mile}$. It was assumed that for the short distances involved, no additional pumping will be required to overcome friction losses.

Pond Construction. Costs for pond construction are separated into excavation and grading costs. Construction of a 20-m-wide pond with embankments 2-m wide by $1-\mathrm{m}$ high will require a $20-\mathrm{cm}$ excavation on level terrain. Volume excavated per unit area is $2000 \mathrm{~m}^{3} /$ ha (1058 $\mathrm{yd}^{3} /$ acre). 
On a slope the construction could be similar to the following diagram:

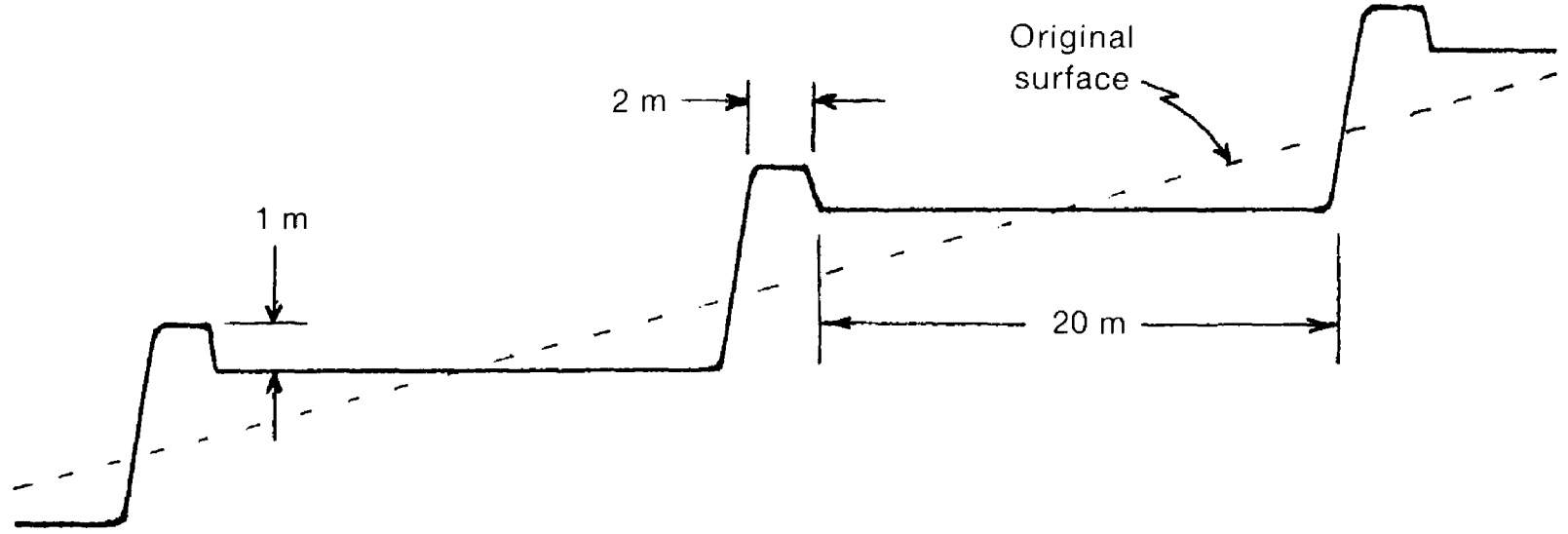

(Vertical relief exaggerated)

The total material excavated for various slopes is

\begin{tabular}{lcc}
\hline \multirow{2}{*}{$\begin{array}{c}\text { Slope } \\
(\%)\end{array}$} & \multicolumn{2}{c}{ Volume Excavated } \\
\cline { 2 - 3 } & $\mathrm{m}^{3} / \mathrm{ha}$ & $\mathrm{yd}^{3} / \mathrm{acre}$ \\
\hline 0 & 2,000 & 1,090 \\
1 & 2,250 & 1,320 \\
3 & 2,750 & 1,460 \\
5 & 3,250 & 1,720 \\
10 & 4,500 & 2,380 \\
15 & 5,750 & 3,040
\end{tabular}

Construction costs include excavation and fill (15 $\mathrm{yd}^{3}$ scraper) at $\$ 2 / \mathrm{yd}^{3}$ and fine grading (bottom and embankments) at $\$ 3,000 /$ acre. These amounts are used in the following table to show the construction costs for various slopes.

\begin{tabular}{ccc}
\hline $\begin{array}{c}\text { Slope } \\
(\%)\end{array}$ & $\begin{array}{c}\text { Excavation and Fill } \\
(\$ / \text { acre })\end{array}$ & $\begin{array}{c}\text { Total } \\
(\$ / \text { acre })\end{array}$ \\
\hline 0 & 2,120 & 5,120 \\
1 & 2,640 & 5,640 \\
3 & 2,920 & 5,920 \\
5 & 3,440 & 6,440 \\
10 & 4,760 & 7,760 \\
15 & 6,080 & 9,080 \\
\hline
\end{tabular}


Road Construction Costs. The construction of roads to service a facility could become a major cost factor. Typical road construction costs are noted below:

Base ( 12 in. deep $-24 \mathrm{ft}$ wide)
Grave1 ( 6 in. deep $-24 \mathrm{ft}$ wide)
Macadam ( 4 in. thick $-24 \mathrm{ft}$ wide)

Tota1
$\$ 70,000 / \mathrm{mile}$ $23,000 / \mathrm{mile}$ $\frac{112,000 / \mathrm{mile}}{\$ 205,000 / \mathrm{mile}}$

Hence, the distance to existing road networks and the size of the system being serviced by a road become important factors for site selection. For example, a 10-mile road to service a 1000-acre facility will add $\$ 2,050 /$ acre $\left(\$ 0.05 / \mathrm{ft}^{2}\right)$ to the construction costs. A 50-mile road to a remote area would be prohibitive for a system this size. Obviously these costs will be higher in rough terrain where cut and fill costs will be added to the base costs given above.

Summary of Construction Costs. A comparison of the various construction costs for a "nominal" uncovered system will serve to indicate their relative significance. The nominal system will have the following characteristics:

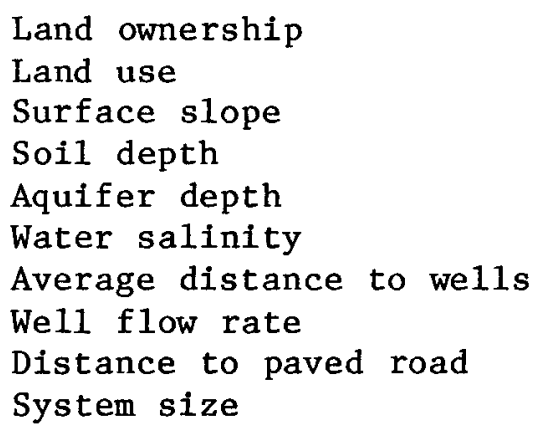

Estimated construction costs per acre and per square foot are

\begin{tabular}{lrr}
\hline \multicolumn{1}{c}{ Item } & \$/acre & \$/ft \\
\hline Land acquisition & 300 & 0.007 \\
Water acquisition (rights) & 0 & 0.000 \\
Wells and pumps & 260 & 0.006 \\
Pipeline & 380 & 0.009 \\
Pond construction & 6,000 & 0.138 \\
Road construction & 1,025 & 0.024 \\
\multicolumn{1}{c}{ Total construction } & 7,965 & 0.184 \\
\hline
\end{tabular}

It is clear from these figures that pond and road construction and the effect of slope on these costs will be prime factors in the selection of specific sites. Also, note that land acquisition costs will be minimal until irrigated 
agriculture and higher valued land uses become involved. Hence, the use of dryland or rangeland will likely be preferred to barren remote lands because of the road system that usually accompanies agricultural land uses. Road construction costs could become a limiting factor for systems installed in truly remote areas.

WARNING - The zero cost of water rights acquisition is based on an assumed zero value of highly saline water. This is not unreasonable considering the current expense associated with disposal of unwanted saline water entering the Colorado River and saline water collected at geothermal power plants. However, the growing interest in various industrial uses of saline water and the possible impact of saline water usage on fresh water supplies raises the possibility of significant water rights cost. For example, water rights in Colorado cost from $\$ 500$ to $\$ 3,000$ per acre-foot. An uncovered pond system uses approximately 4.5 acre-feet per year. The cost of water acquisition, therefore, could become a dominant cost factor.

\subsubsection{Factors Affecting Operating Costs}

The factors that control operating costs for a microalgae production system have been documented by CSO International Inc. (1978) and Dynatech R/D Company (1978). These factors are labor, maintenance and supplies, electrical power, and nutrients. The two largest costs are labor and electrical power. of these, only electrical power will be significantly affected by natural resources. Electrical power is used for pumps, paddle wheels to mix the microalgae culture, and for blowers to deliver carbon dioxide to the ponds. CSO and Dynatech indicate that approximately $80 \%$ of the electric power costs will be required for pumping water. There are no indications whether these cost estimates include the cost of lifting the water from a subsurface aquifer prior to delivery to the ponds. It appears that the estimates of pumping costs are based on delivery of water to the ponds, pumping required for harvesting, and return flow to the ponds after harvesting. If this is the case, the actual electric power required for pumping could easily be twice the figures shown in these reports, since a power equal to that specified would be required to lift the water $400 \mathrm{ft}$, a reasonable distance.

On this basis, aquifer depth becomes a very important and perhaps dominant factor in the operating costs for MPS facilities using saline groundwater resources. Furthermore, the evaporation rate will determine the amount of water that has to be lifted and delivered to the ponds. These two climate and water resource parameters will have a direct and major effect on operating costs. Water salinity could also affect operating costs since the initial salinity of the water will determine the amount of blowdown water that must be provided to maintain salinity within the range required by the microalgae. If precipitation can be used effectively to reduce the demand for make-up water, this will directly reduce operating costs. The occurrence of thunderstorms will increase operating costs if the high winds that usually accompany such storms cause damage to the earth works or cause contamination requiring drainage and resupply of water to the ponds. In summary, aquifer depth, water salinity, evaporation, precipitation, and thunderstorm days will all affect operating costs. 


\subsubsection{Factors Affecting Production Efficiencies}

The growth rate and daily production of microalgae will be affected by the intensity of the photosynthetically active radiation, and the $\mathrm{CO}_{2}$ and nutrient concentrations. The annual production will be directly affected by the length of the growing season and the period of time that the ponds are out of operation for maintenance, cleaning, etc. Severe storms, therefore, could reduce the annual productivity of the system.

Climate and operational information required to estimate pond temperature and the effect of climate on pond temperature was not available. Therefore, the only natural resource parameters whose effect on annual production could be estimated were solar radiation and the length of the growing season. The length of the growing season was estimated to be proportional to the freezefree period for which climate information was available. It was assumed that a linear relationship would exist between freeze-free period and annual production period.

It was also assumed that a linear relationship would exist between insolation levels and annual production. This was based on the hypothesis that the photosynthetic process is taking place from the surface down to a depth where the average insolation drops below 150 calories $/ \mathrm{cm}^{2}$-day. The rate and effectiveness of mixing affects this assumption, which essentially assumes a static and equal density of microalgae at all depths from the surface to the bottom of the ponds. On this basis, variation in insolation governs the depth at which microalgae growth takes place. Although these assumptions could be grossly in error, their effect on the stratification of the Southwest will be minor since only a $10 \%-15 \%$ variation in annual insolation is observed for this region. On the other hand, freeze-free periods vary greatly, from less than 100 days to greater than 300 days.

\subsubsection{Flow Chart Development - Step 4B}

Based on the results of the systems analysis just described, the flow chart shown in Figure 6-19 was developed for the compositing process. The first step in preparing a climate suitability map involved the development of a relative productivity map from the composite of insolation and freeze-free period and the development of a make-up water map from the composite of precipitation and evaporation. This step could have been eliminated by combining all five climate parameters in one composite to generate climate suitability. However, the maps of relative productivity and make-up water are informative in their own right.

The first step in preparing a water suitability map involved the separation of salinity and depth data from the original saline groundwater map, which actually was carried out during the map production step. The compositing of land resource parameters did not require a comparable step.

The second step in the compositing process called for the development of individual climate, water, and land suitability maps. These intermediate results are useful for several reasons. First, each of the resultant maps provides informative and very different kinds of suitability data of value to 


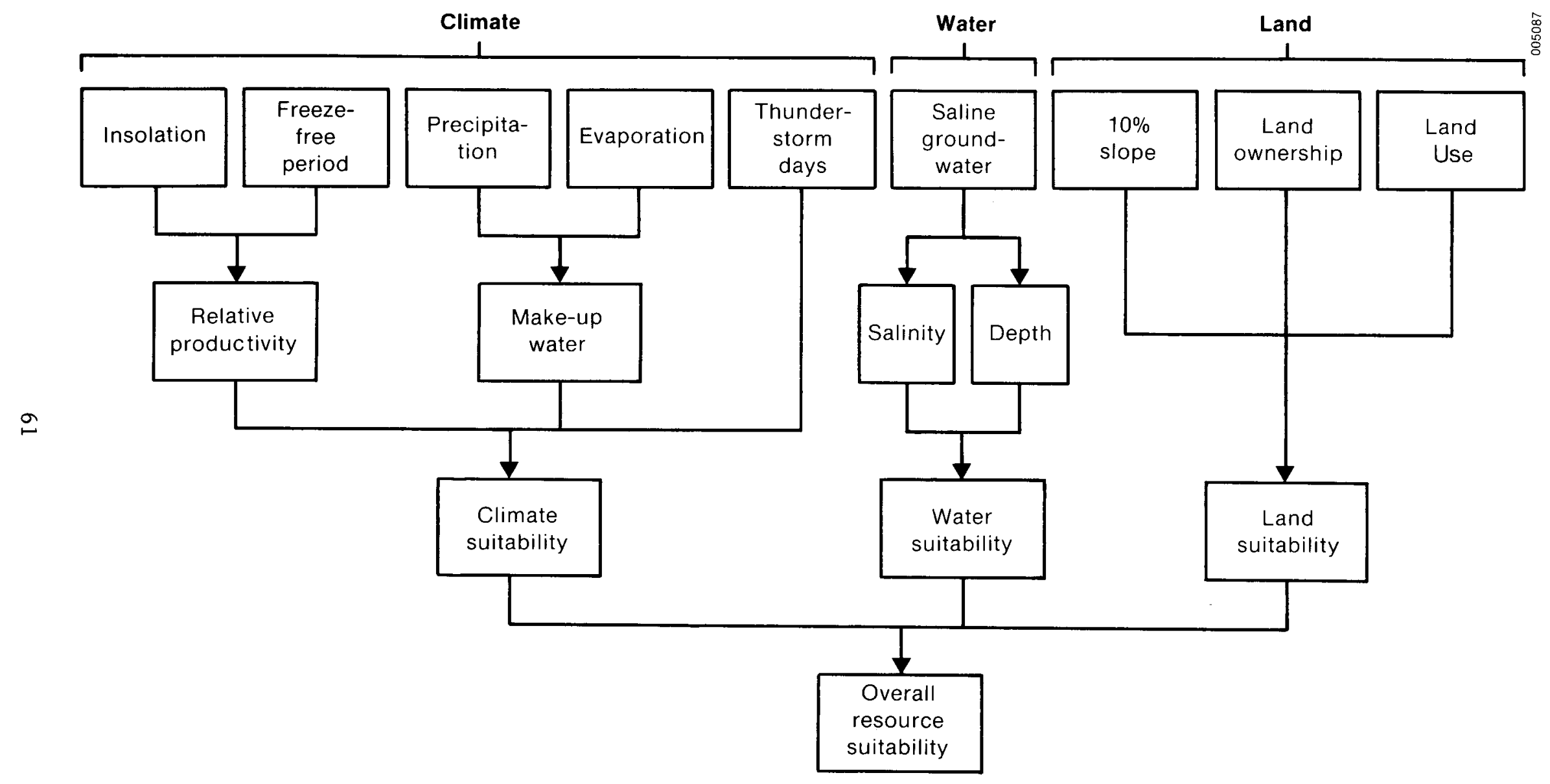

Figure 6-19. The Map Compositing Process Used to Stratify the Southwest into Zones of Relative Suitability for Microalgae Production of Biomass 
the future development of microalgae systems. Furthermore, the quality and reliability of the climate, water, and land data were quite different, making it desirable to present the resultant composite maps separately. Finally, by generating the separate suitability maps it was much easier to observe the effect of changes in the weights given to each of the original nine parameters.

Obviously, the final overa11 resource suitability map could have been developed from a single composite using all of the original nine parameters. The development of the weighting scheme would have been very difficult, however, and the resultant information would have been much less.

\subsubsection{Development of Weighting Schemes - Step 4C}

The generalized map analysis planning system (GMAPS) developed by A. K. Turner of Geometronics International Inc. in Golden, Colo., was employed for the compositing process. The procedure utilized by GMAPS involves a system of internal and external weights for combining the information contained in the baseline parameter maps. Internal values or weights (integers between 0 and 99) are assigned to parameter values (e.g., precipitation) or map categories (e.g., land use categories) for each map involved in the production of each composite to reflect the relative importance of each value or category. External weights (0-99) are assigned to each map to reflect the relative importance of each resource parameter or intermediate map product.

The assignments of internal and external weights were based to the extent possible on the analysis of system construction costs, operational costs, and biomass productivity as discussed in section 6.5.1. In many instances, this objective procedure could not be employed and the assignment of weights became more or less subjective. In order to reduce the subjectivity, a computer program was developed to test alternative weighting schemes. In effect, this program identified the characteristics of the final suitability classes and revealed the effect of changing both internal and external weights. This program was especially useful in defining land suitability classes (see Section 6.5.6).

\subsubsection{Composite Map Production - Steps 4D and 4E}

The process of generating composite maps is accomplished by performing a weighted addition of the integer values assigned to each cell of each map employed in the composite process. The composite map, therefore, consists of a range of numerical values resulting from the weighted sum of the values on the original maps. The final decision-making process consists of the assignment of numerical ranges to designate the classes to be displayed on the composite map. These ranges could be assigned in any manner desired depending on the purpose of the composite and the information to be conveyed. They could vary from uniformly sized ranges giving equal value to the entire range of numerical sums or they could be highly skewed to represent an exponential function. Ideally, this assignment of ranges should be based on a quantitative and objective evaluation of the final use for which the composite map has been generated. The assignment of ranges for each of the composites generated on this project is discussed in the following subsections. 


\subsubsection{C1imate Suitability Composite}

As indicated in Figure 6-19, the first composite generated was a combination of insolation and freeze-free period maps to produce a relative productivity map of the southwestern United States.

Figure 6-20 defines the computation used to form the composite, provides a diagram of the statistical distribution of the five productivity classes, and presents a map of the geographic distribution of the five classes. As noted previously, the assumption was made that annual productivity will be linearly related to both insolation and freeze-free period. Therefore, the internal values used in the compositing process were linearly related to insolation and freeze-free period values. The external weights were assigned such that insolation and freeze-free period were given equal importance for the calculation of relative productivity. In effect, this was accomplished by normalizing the freeze-free period and insolation values as indicated in Figure 6-20b.

The five productivity classes represent different proportions of the total range of composited values as indicated by the width of the bars on the distribution plot. The variable widths were chosen to limit the most productive areas to a small percentage of the total area. The acreage of each class can be computed by multiplying the percentages by the total area in the region. The impact of freeze-free period and insolation on productivity is obvious when one compares Figure 6-20a with Figures 6-4 and 6-5.

The second composite, make-up water, was computed directly by subtracting precipitation from evaporation. This resulted in nine ranges or categories of make-up water as shown in Figure 6-21. Note that blank or white areas on the map require no make-up water; in other words, annual precipitation either equals or exceeds annual evaporation. Computation and statistical distribution information are given on Figure 6-21b.

The climate sultability composite was generated by combining relative productivity with make-up water and severe storms (thunderstorm days). Since make-up water (pumping costs) will 1ikely represent about 50\% of the operating costs, and since relative productivity can be directly related to total revenue, productivity was given twice the weight of make-up water. Both were linearly related to climate suitability. Thunderstorm days were also linearly related to climate suitability on the basis that loss in productivity and damage to the facilities will be the same for each thunderstorm occurrence. Thunderstorm occurrence was arbitrarily assigned a weight equal to $30 \%$ of the weight given to make-up water. The computation of climate suitability and the resultant composite map and statistics are all given on Figure 6-22. This composite is probably the most meaningful and accurate of all the composite maps.

\subsubsection{Land Suitability Composite}

The generation of a land suitability composite was the most complex and most subjective of all the composites. The final assignments of weights to individual categories of land use, land ownership, and gradient or slope are 


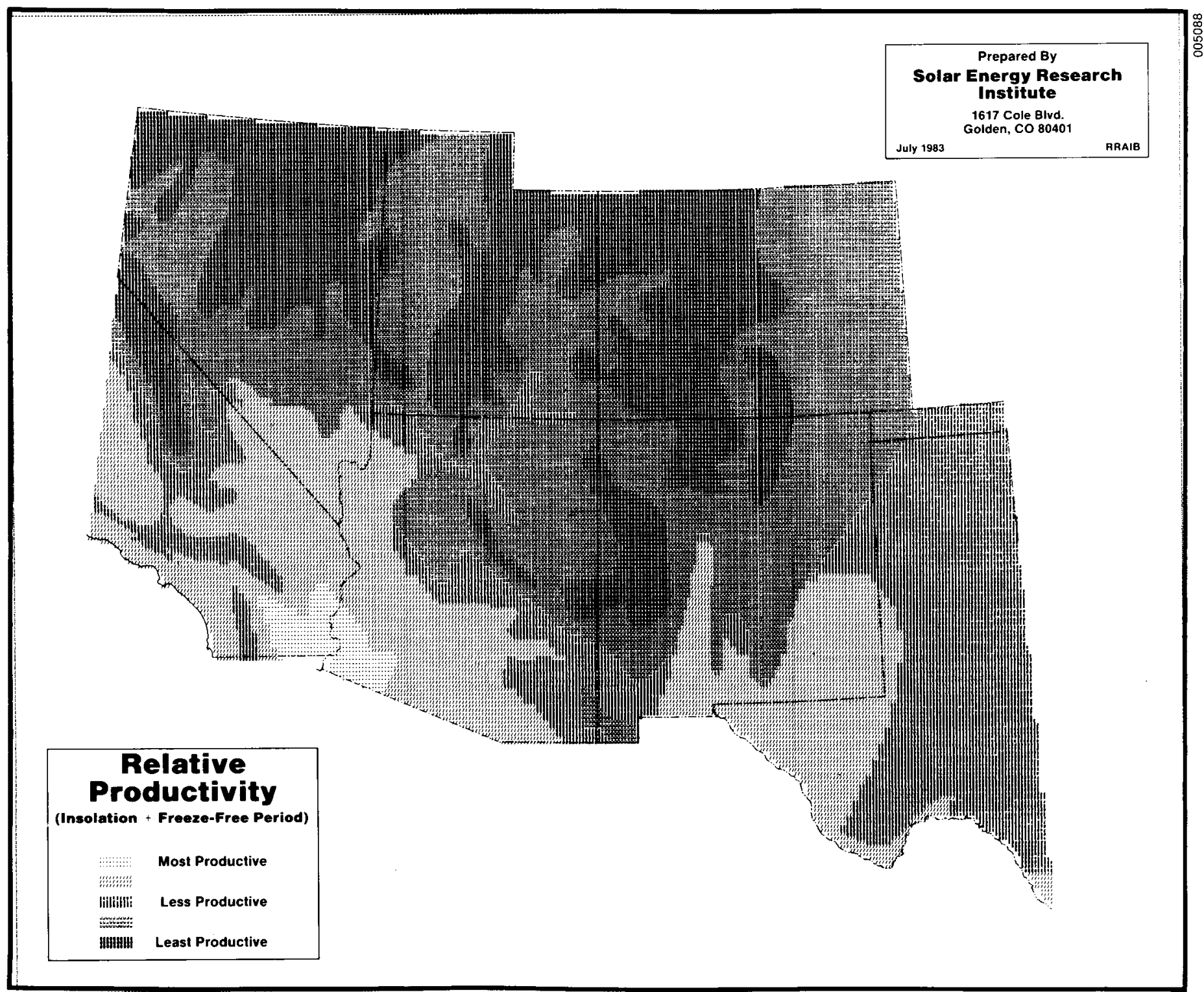

Figure 6-20a. Estimated Relative Productivity of Shallow Pond Microalgae Production Systems in the Study Area 


\section{Computation}

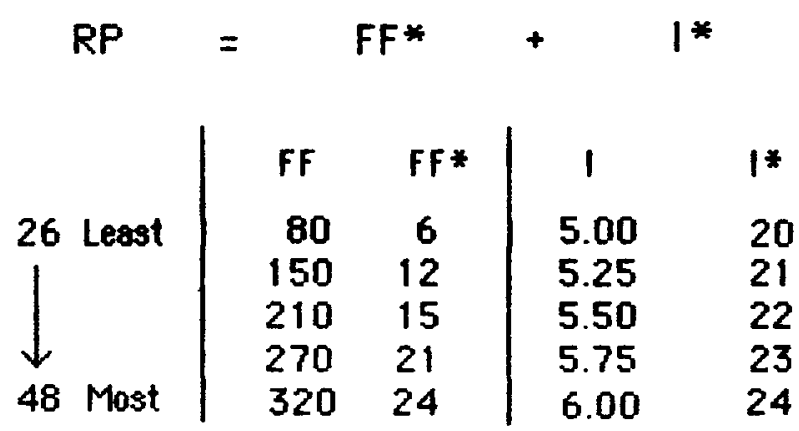

FF - Freeze Free Period (days)

FF* - Normalized Yalues of FF

1 - Insolation-Ann. Mean (Kwh/day)

I* - Hor malized Volues of I

RP - Unitless Yalues of Relative Productivity

Notes:

(1) This computation assumes s linear relationship between freeze - free period, insolation and annual productivity.

(2) Total area in the region defined by the map is $1.898 \times 10^{8}$ hectares or $4.689 \times 10^{8}$ acres.
Distribution

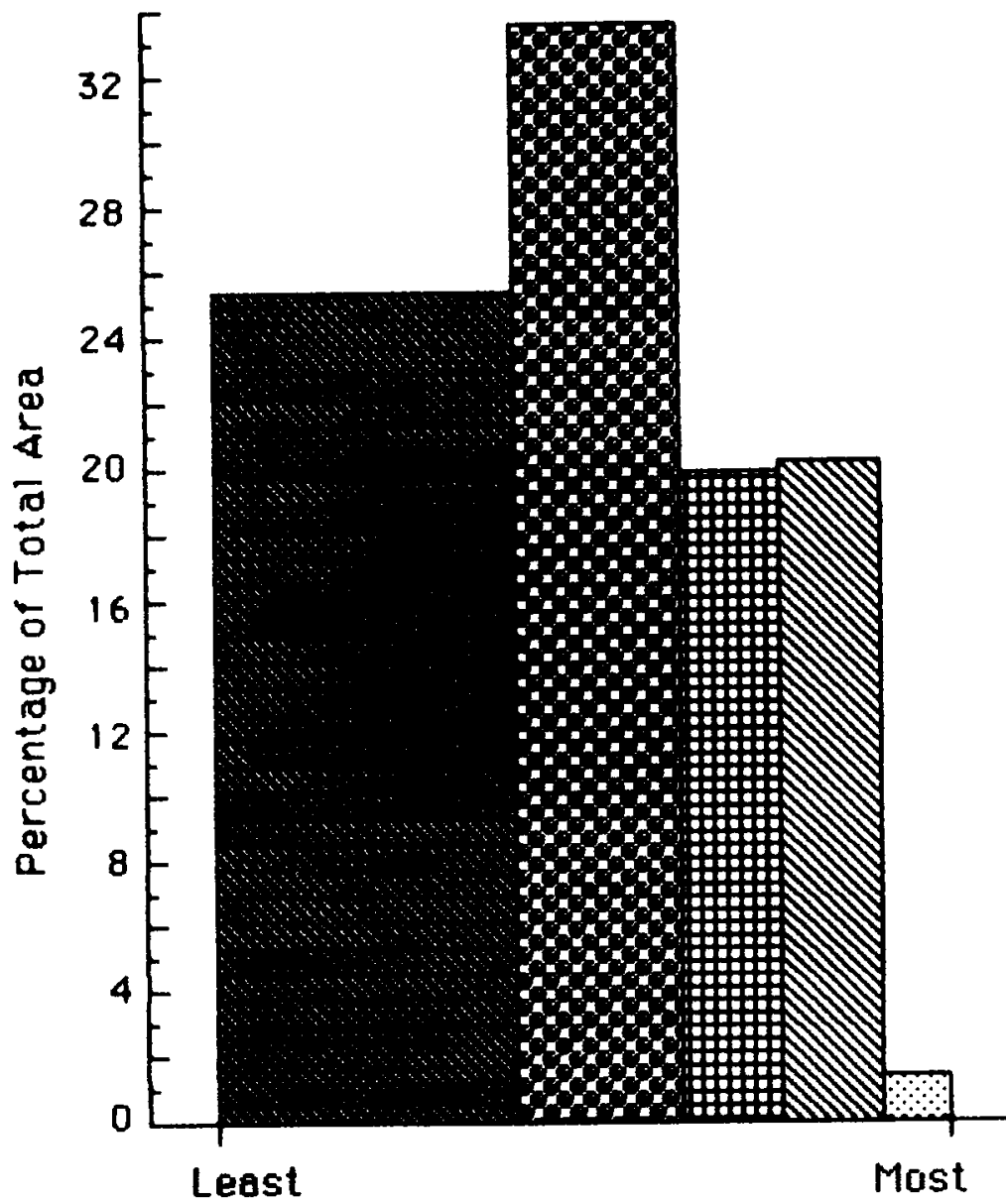

Relative Productivity

Figure 6-20b. Computations Performed in the Compositing of Insolation and Freeze-Free Period Maps to Generate the Relative Productivity Map; Also Bar Graph with Relative Productivity and Proportionate Occurrence of Each Class 


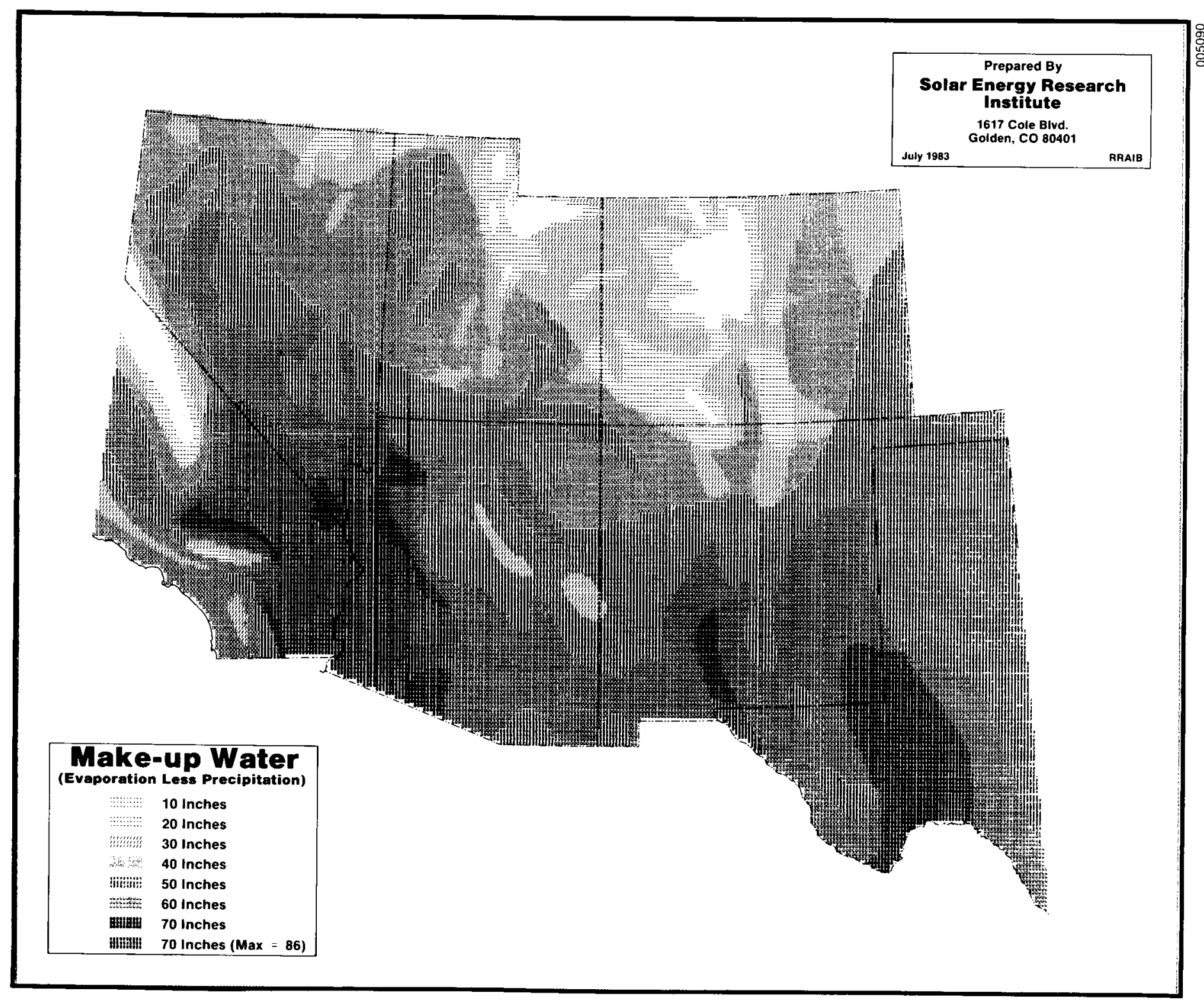

Figure 6-21a. Estimated Make-Up Water Required to Maintain a Constant Water Level in Shallow, Uncovered Ponds in the Study Area 


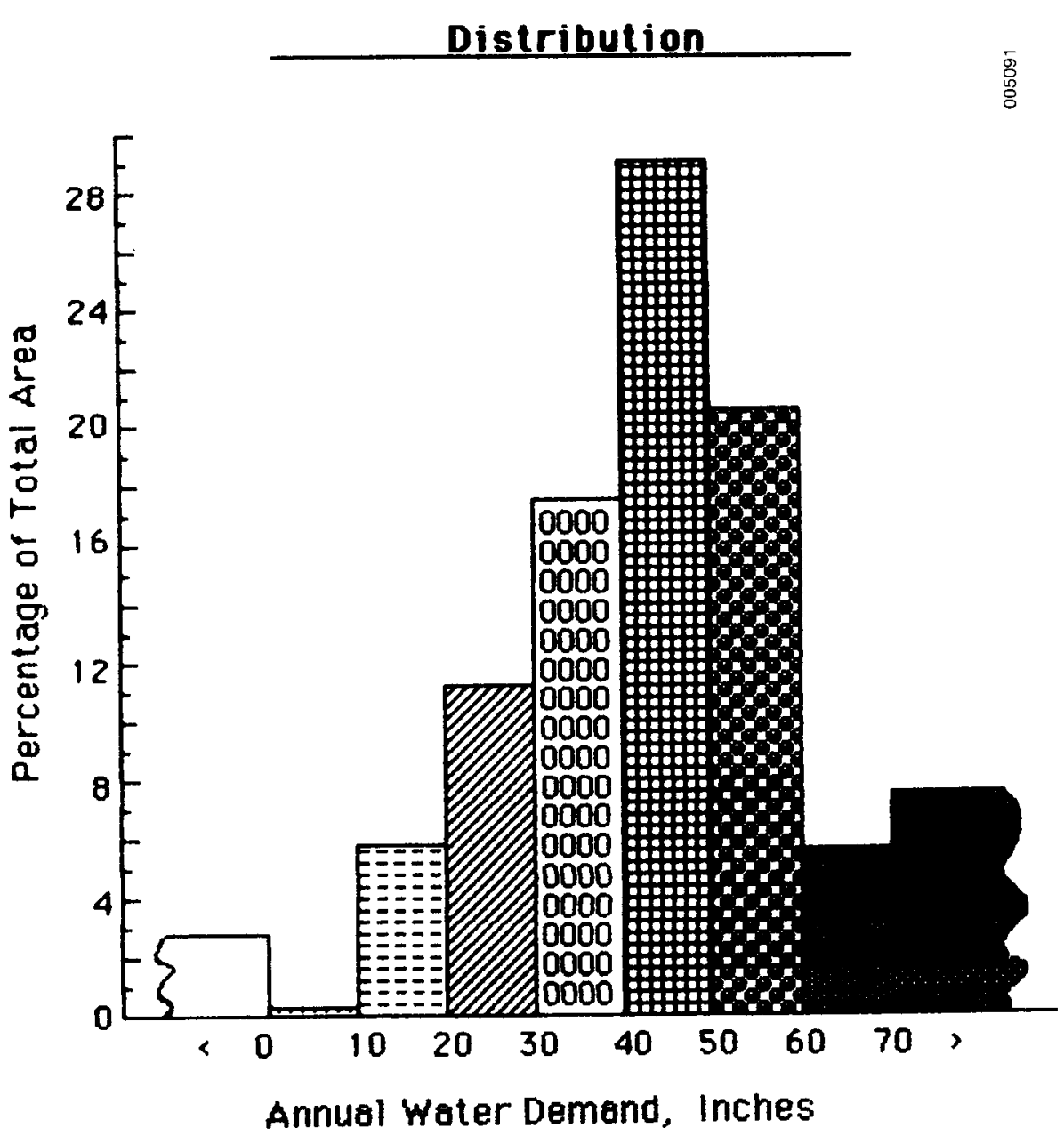

Figure 6-21b. Computations Performed in the Compositing of Precipitation and Evaporation Maps to Generate the Make-Up Water Map; Also Bar Graph Depicting the Proportionate Occurrence of Each Make-Up Water Class

(1) The ranges of MUW, E, \& $P$ which are observed in the Southwest are indicsted above.

(2) Total ares in the region defined by the map is $1.898 \times 10^{8}$ hectares or $4.689 \times 10^{8}$ acres.

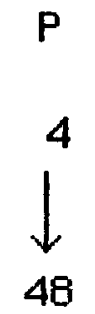

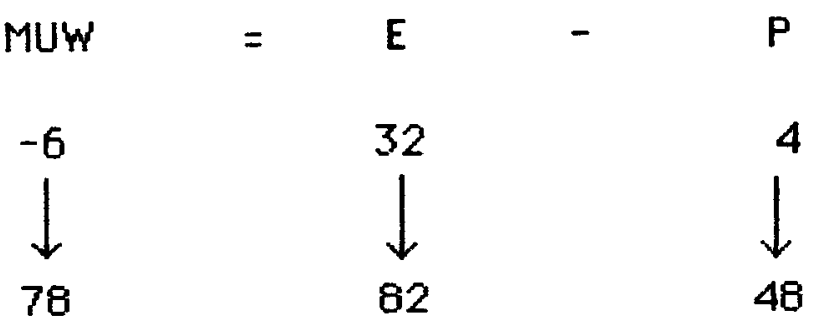

$$
\begin{aligned}
& \text { MUw - Moke-Up water (in/yr.) } \\
& E \text { - Evaporation (in./yr.) } \\
& P \quad \text { - Precipitotion (in./yr.) }
\end{aligned}
$$

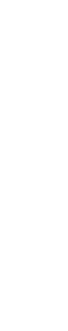




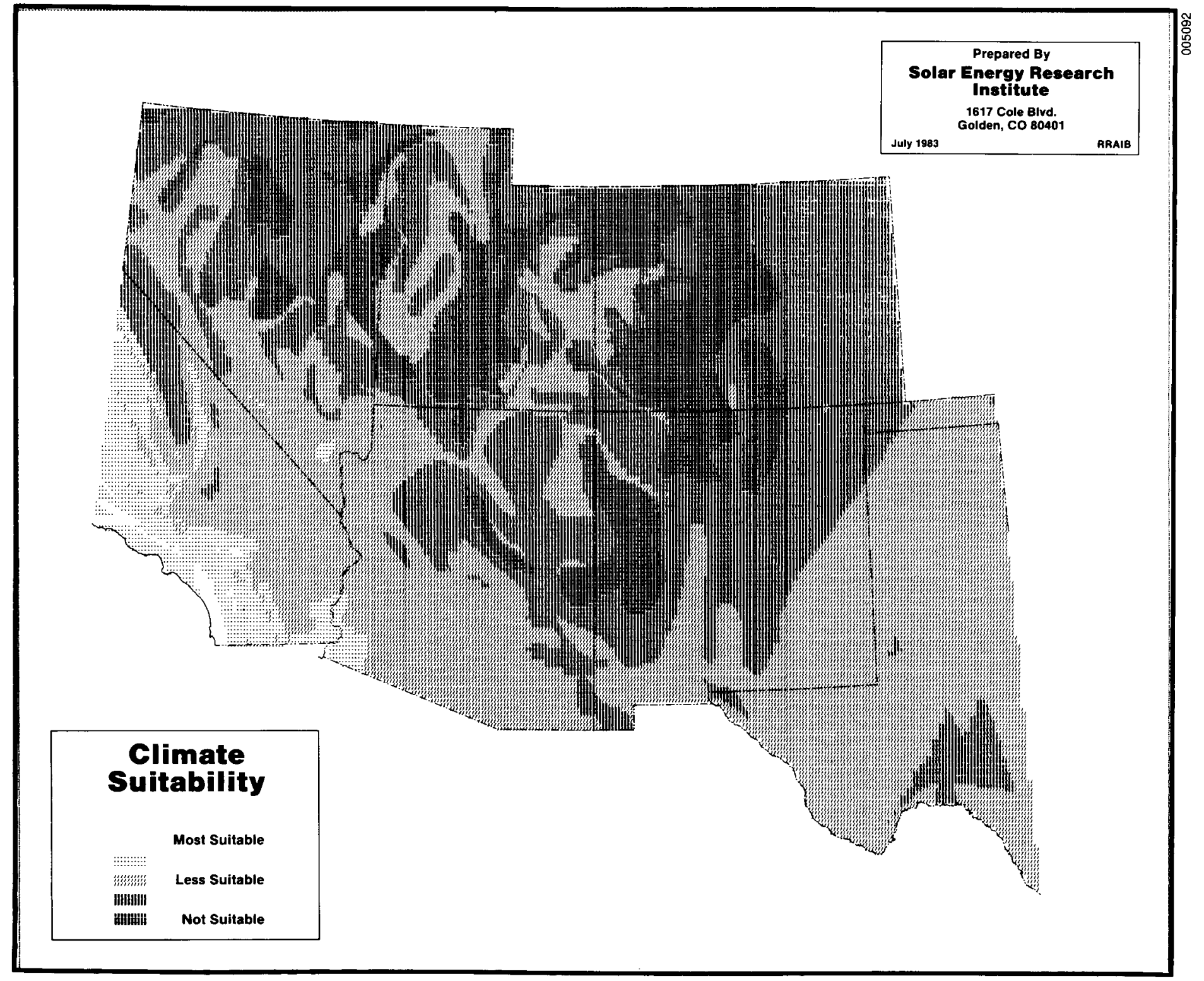


Computations

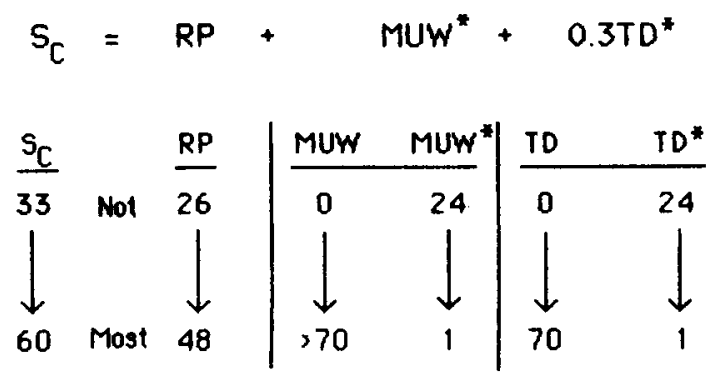

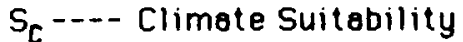
RP-.-- Relative Productivity MUW -- Make Up Woter MUW - Normalized MUW TD*--- Normalized TD

\section{Notes:}

(1) Suitobility factors are all relative and unitless. Furthermore, they do not represent magnitudes of change; $i$.e., the most suitable class could represent more or less than the difference in numbers generated by the compositing process.

(2) Total area in the region defined by the mop is $1.898 \times 10^{8}$ hectores or $4689 \times 10^{8}$ acres.

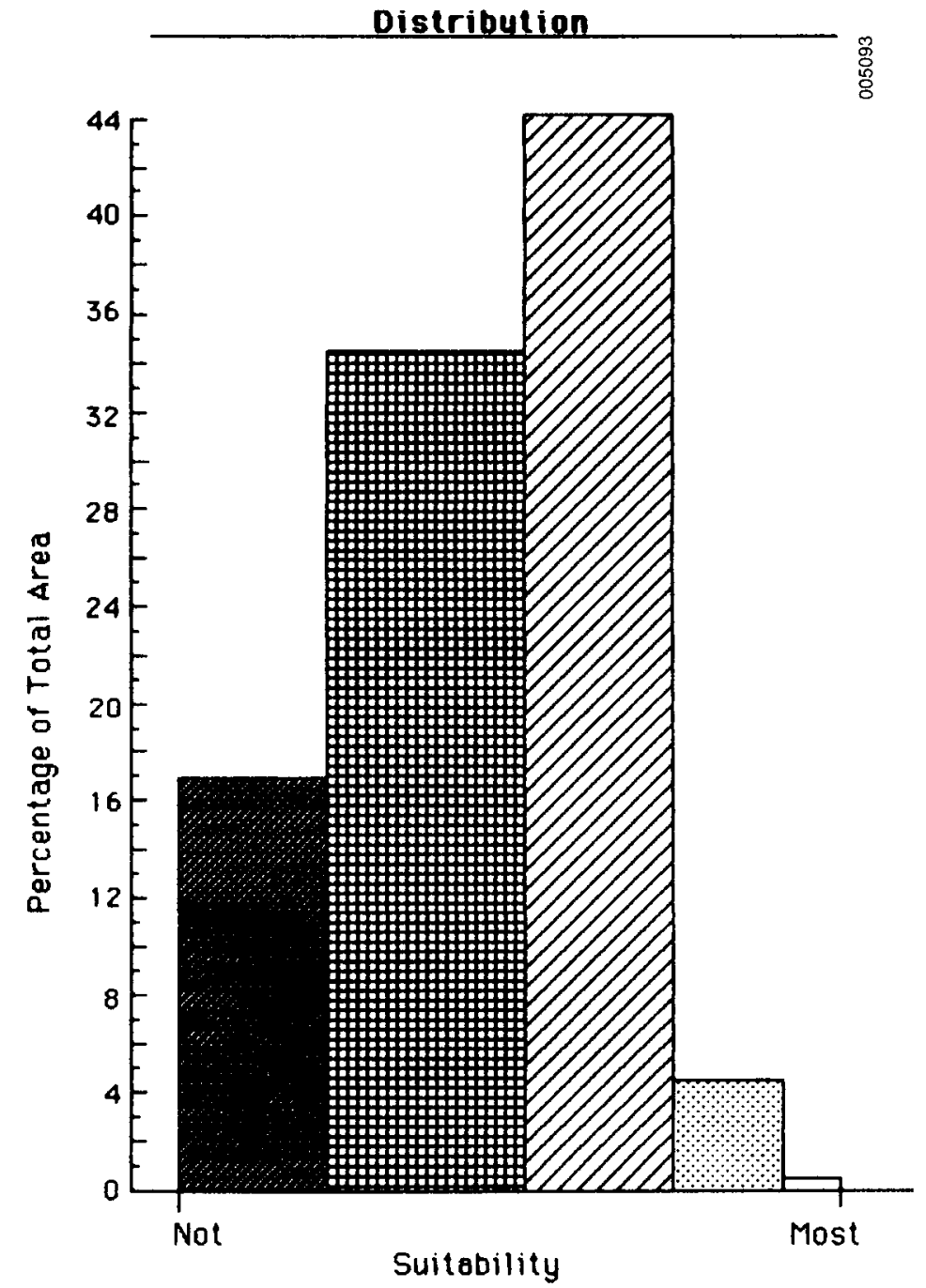

Figure 6-22b. Process Employed to Combine Relative Productivity, Make-Up Water, and Thunderstorm Day Maps to Generate the Climate Suitability Map; Also Bar Graph of Relative Suitability and Proportionate Occurrence of Each Class 
given on Figure 6-23b. The more suitable the land resource category, the greater was the assigned weight. The most suitable land use category, salt flats etc., included any flat nonvegetated region that had dry 1 ake bed features. The "other" category included rangeland and dryland farming. Although generally consistent with expected acquisition and construction costs, the magnitude of the weights was arbitrary and designed to create the clusters of land classes indicated on the distribution chart for land suitability. Note that the most suitable land resource class consists only of salt flats, rangeland, and dry land, under public, state, or private ownership, with a slope of less than 10\%. The second class includes only public, state, or private gas and oil fields with less than $10 \%$ slope. This class was selectively separated from the others by a careful assignment of class ranges because of the significance of these fields as potential $\mathrm{CO}_{2}$ resources (Amirijafiri et al. 1980). Also note that the first three classes exclude any land having a slope greater than $10 \%$.

As evidenced by the map of Figure 6-23a and the bar chart of Figure 6-23b, land suitability is much less restrictive than climate suitability. This is in part the result of the grouping of ownership classes but is probably an accurate representation of the arid and semiarid lands of the Southwest.

\subsubsection{Water Suitability}

The water suitability map shown in Figure $6-24 \mathrm{a}$ is not a composite but is simply a map of depth to saline water resources. Because of uncertainty regarding the accuracy of the digitized salinity map, it was not included in the mapping of water suitability. In the final analysis, this may not represent much loss of information since the assignment of weights to salinity values had not been established because of opposing considerations. Increasing salinity will likely reduce the demand for such water, but at the same time increase the blow-down water needed to maintain proper salinity levels in the ponds. The effect of salinity on acquisition and operating costs is therefore difficult to assess at this time, and it is probably best that salinity data were not included in any of the composites.

Water depth, on the other hand, will directly effect both construction and operating costs. On this basis, water depth was considered to be linearly related to water suitability. The depth categories used by Feth et al. (1965) made the establishment of linearly related water categories impossible. Hence, each class of water depth was assigned as given on Figure 6-24b. The resultant map and distribution chart seem to indicate that water resources may be the limiting factor in locating MPS facilities in the Southwest. In actuality, this may simply reflect the absence of information on saline water resources.

\subsubsection{Overall Suitability Composites}

Two final or combined composites were prepared. One was formed by combining land and climate suitability maps. Water was excluded because of the questions surrounding the water resource data. In particular, the sparsity of the data and its "data of opportunity" character make one hesitate to give the 
water suitability map much weight. Therefore, the climate/land suitability composite is probably more significant than the overall suitability map, which included water suitability.

Both composites were generated by adding the class numbers ( 1 to 5 ) that were assigned to the flve suitability classes of the climate, land, and water suitability maps. Basically, therefore, these overall composites show the congruence of the individual suitability classes. One cannot give significance to the magnitude of the final composite values. Rather, they simply provide an ordering of suitability classes. Similar to placement in a race, first and fifth places can be very close together or far apart. Also, the separation between classes can be quite different. For this reason, the width or range of values for each final class were set to achieve a more or less symmetrical distribution with smaller percentages (populations) for the most and least suitable classes.

The results for these two final composites are shown in Figures $6-25$ and 6-26. They clearly show the stratification of the Southwest into zones of relative suitability, which will guide future resource studies and site selection efforts. 


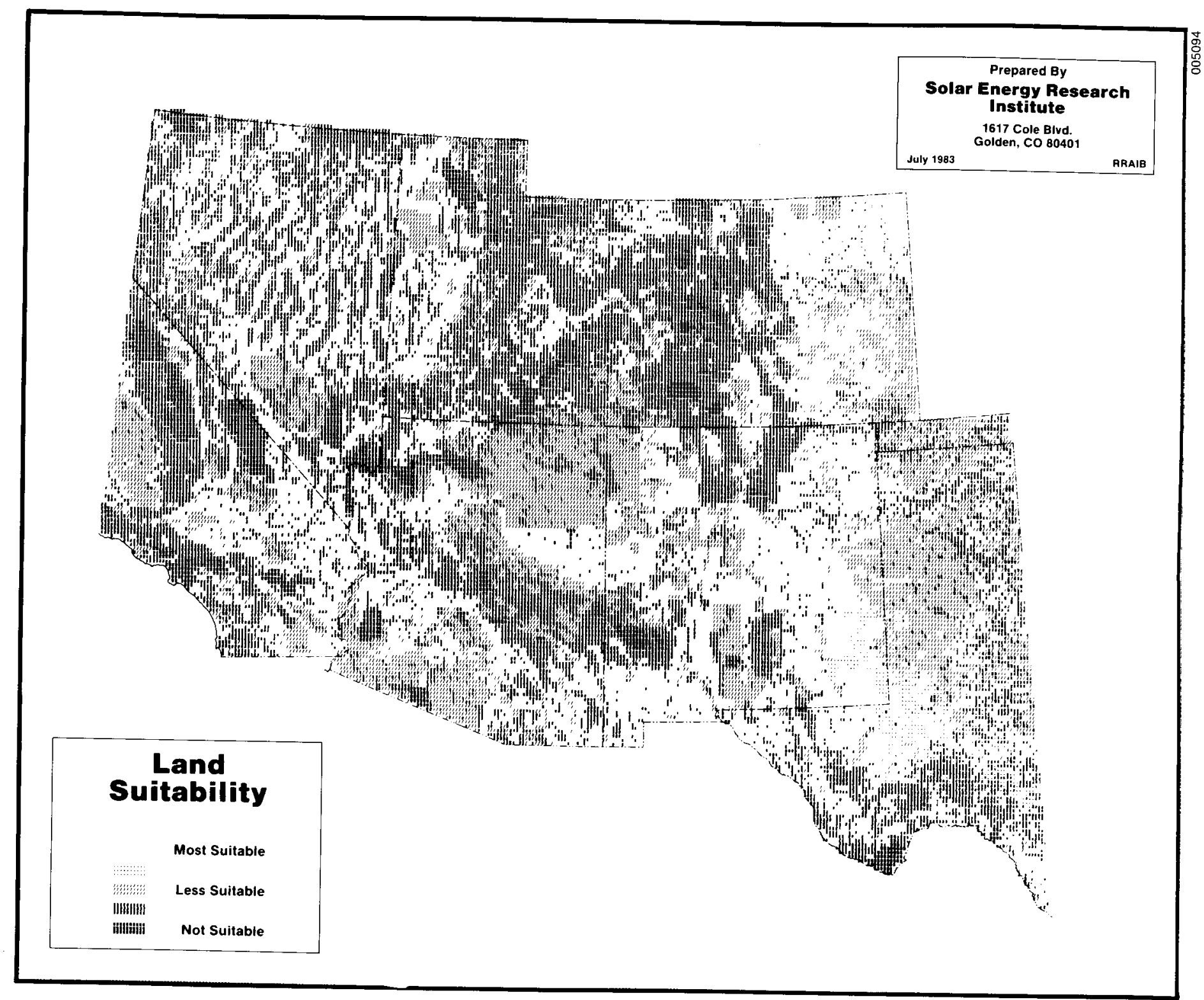

Figure 6-23a. Zones of Relative Suitability for Microalgae Biomass Production Based on the Availability and Suitability of Land Resources 
Computotion

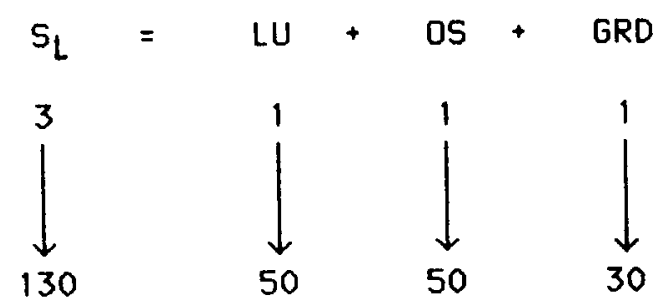

S- - - Solt flots et al . - . - . - - 50

0-.-Dther - . - . - ...... 25

G- - - Dil \& Gos Fields-.... 10

C-.-Cropland-......... 2.5

L- - - Lokes ond Reseryoirs-- - 1 and Mixed

Indian Reser. \& DOE
Land Use (LU)

Ownership(오)

1-- - Public, Stote, Privote - - 50

2-- - Natl. Forest, Military, - 10

3-- - Notl. Parks, Wilderness, - - 1

Wildlife Refuge, et ol.

Gradient (GRD), Slope

(-.- Less than 10\%-..... 30

>-. Greoter then 10\%.....

Notes:

(1) The weights ( 1 to 50 ) for the lond parameters are based on objective estimates of their effects on ocquisition and construction costs (see text). The

symbols in each bar on the frequency

distribution chart identify the make - up

of the five Land Suitability Classes,

i.e. Sis are Salt Flats under Public,

State. Private or Mixed ownership with

orodient or slope less than los $4.689 \times 10^{8}$ ocres.
Distribution

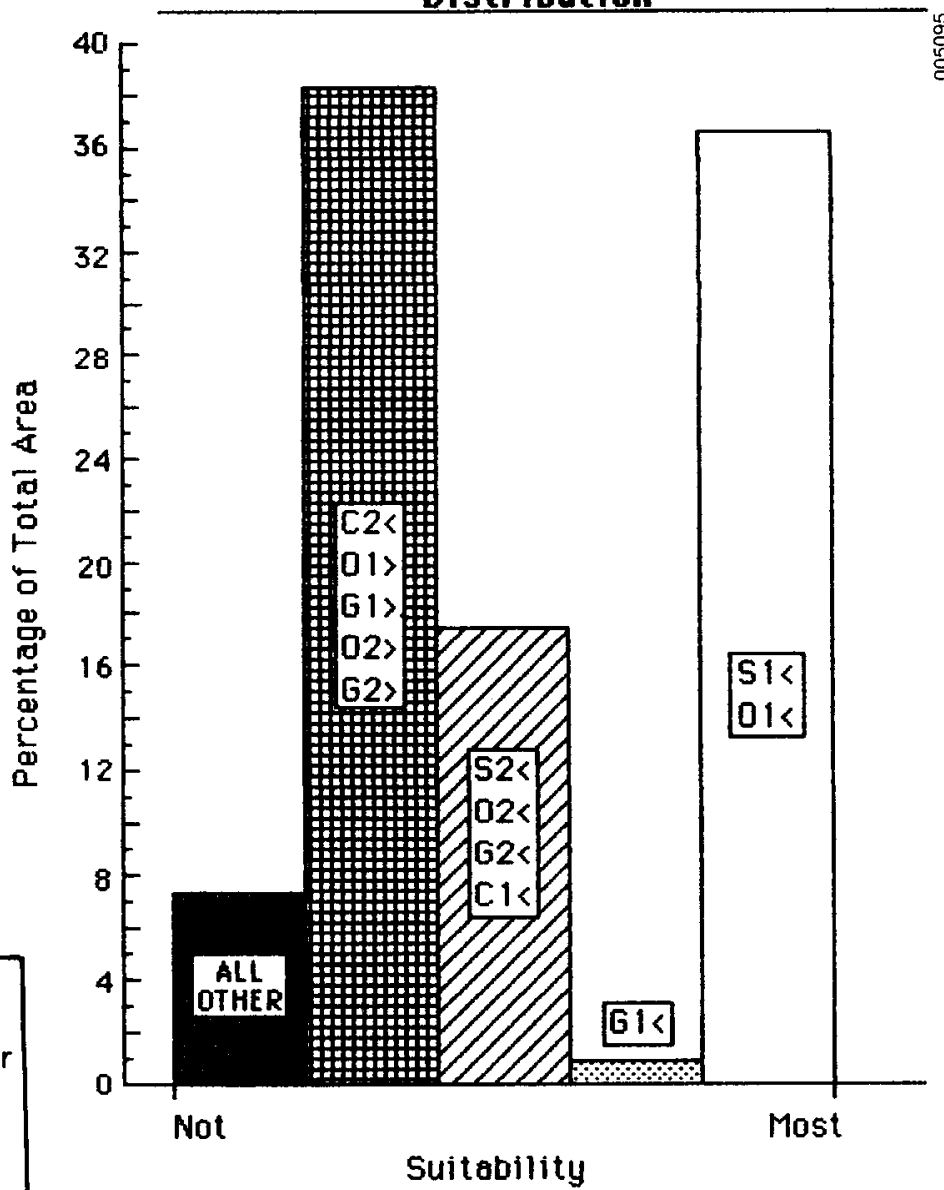

Total area in the region defined by the mop is $1.898 \times 10^{8}$ hectores or

Figure 6-23b. Process Employed to Combine Land Use, Land Ownership, and Gradient (10\% S1ope) Maps to Generate the Land Suitability Map; Also Bar Graph Defining Types of Land Parcels and Proportionate Occurrence of Each Class 


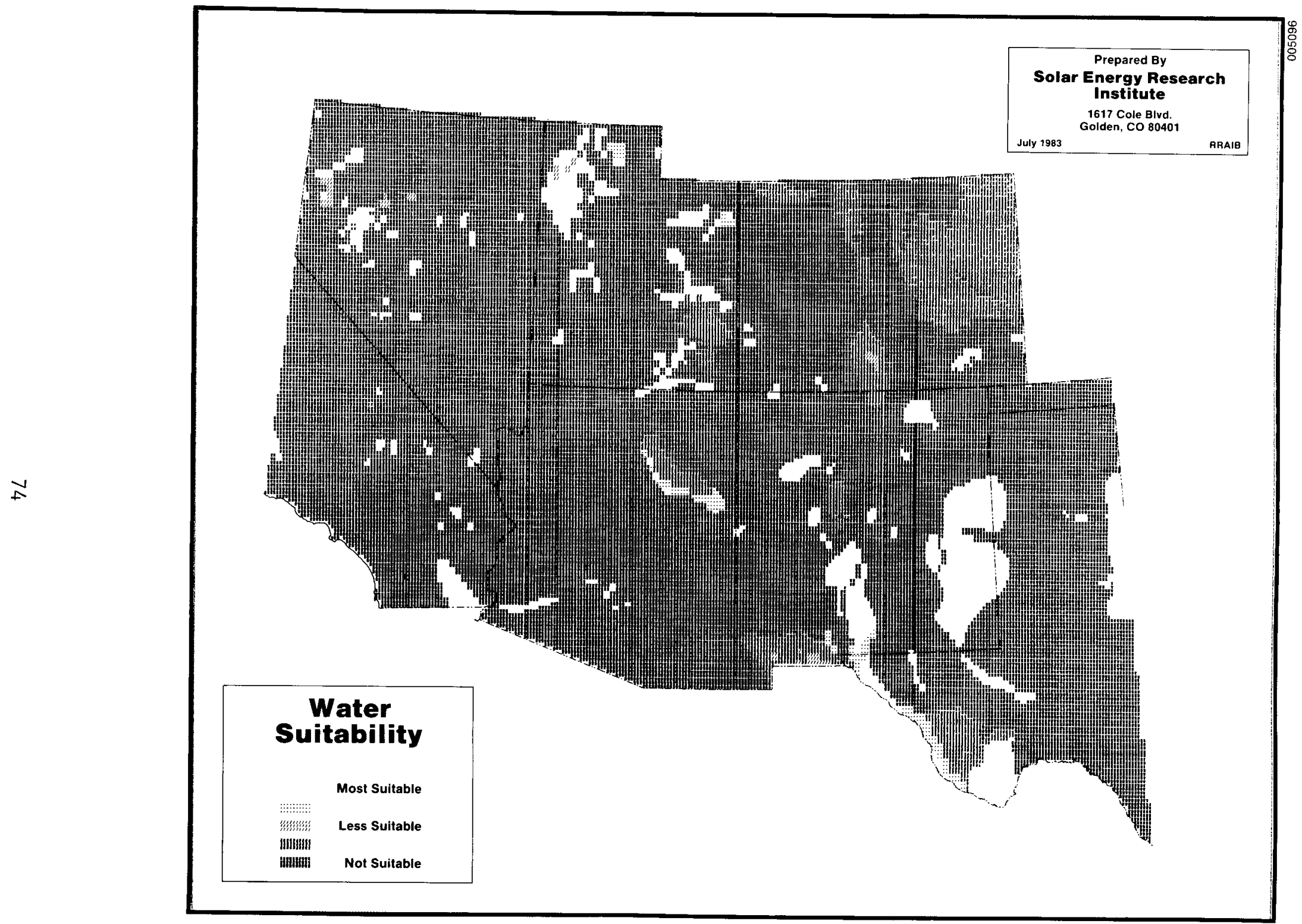

Figure 6-24a. Zones of Relative Suitability for Microalgae Biomass Production Based on the Depth to Saline Groundwater 


\section{Computotion}

$\begin{array}{lll}S_{W} & = & \text { Depth to Groundwater } \\ 1 & -- & \text { No Known Groundwater } \\ 2 & -- & >1000 \mathrm{ft} \\ 3 & -- & 0-1000 \mathrm{ft} \\ 4 & -- & 500-1000 \mathrm{ft} . \\ 5 & -- & <500 \mathrm{ft} .\end{array}$

Notes: (1) Solinity dato were not incor porated in the computation of water suitability ( see text for explanation).

(2) An approximate linear relationship is established bewtween depth and water suitability.

(3) Total oree in the region defined by the map is $1.898 \times 10^{8}$ hectores or $4.689 \times 10^{8}$ scres.
Distribution

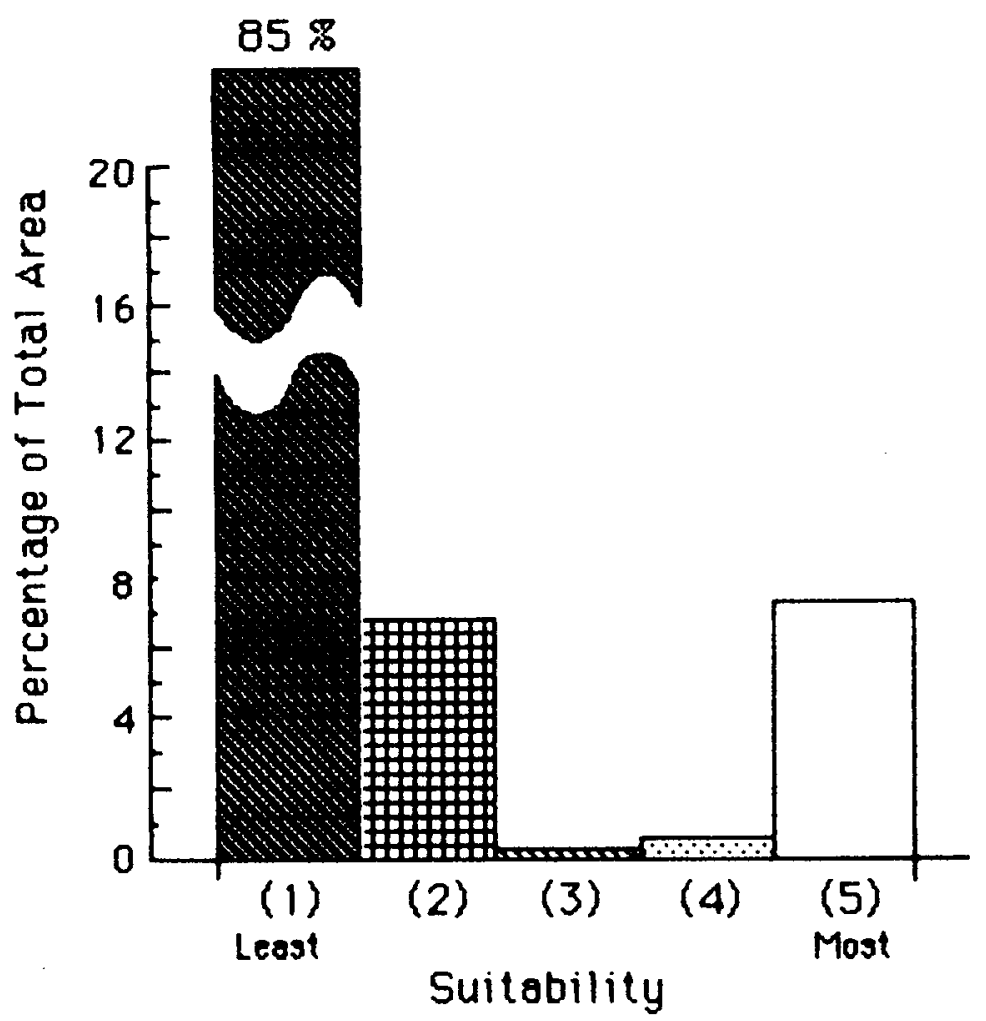

Figure 6-24b. Assignment of Each Depth Class to a Suitability Class and the Proportionate Distribution of Each Class 


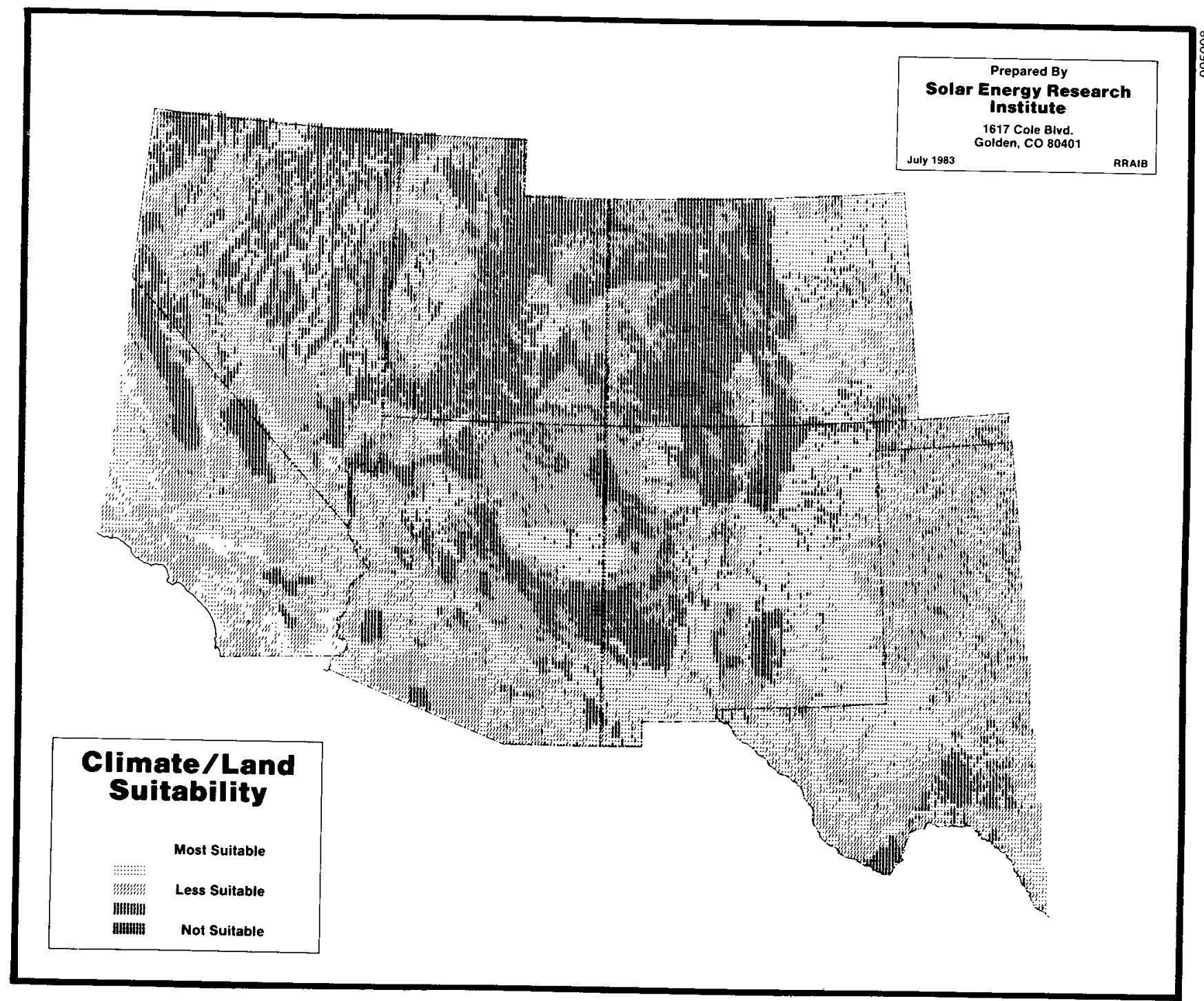

Figure 6-25a. Zones of Relative Suitability for Microalgae Biomass Production Based on a Compositing of the Climate and Land Suitability Maps 


\section{Computation}

\begin{tabular}{|c|c|c|c|}
\hline $\mathrm{s}_{\mathrm{Cl}}$ & $=$ & $s_{c}$ & + \\
\hline 2 & Not & 1 & \\
\hline 10 & Most & 5 & \\
\hline
\end{tabular}

Notes:

(1) Suitobility foctors are oll relotive and unitless. Furthermore, they do not represent magnitudes of change; i. e., the most suitable cless could represent more or less than 5 times the suitobility of the least (not) suitable closs.

(2) Total area in the region defined by the mep is $1.898 \times 10^{8}$ hectores or $4.689 \times 10^{8}$ acres.

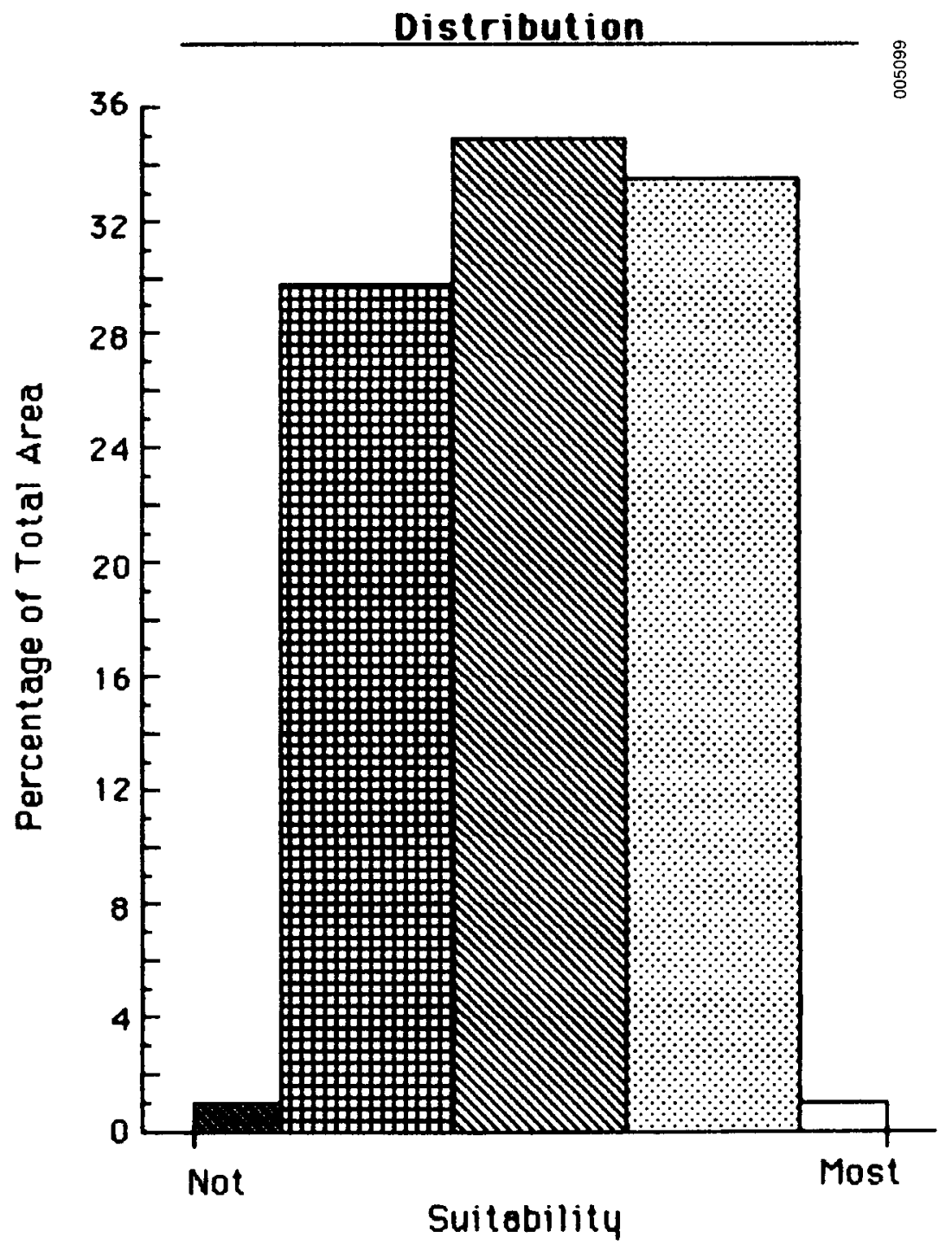

Figure 6-25b. Process Employed to Combine Land and climate Suitability Maps to Generate the Climate/Land Suitability Map; Also Bar Graph Showing Relative Suitability and Proportionate Occurrence of Each Class 




Figure 6-26a. Zones of Relative Suitability for Microalgae Biomass Production Based on a Compositing of Climate, Land, and Water Suitability Maps 


\section{Computation}

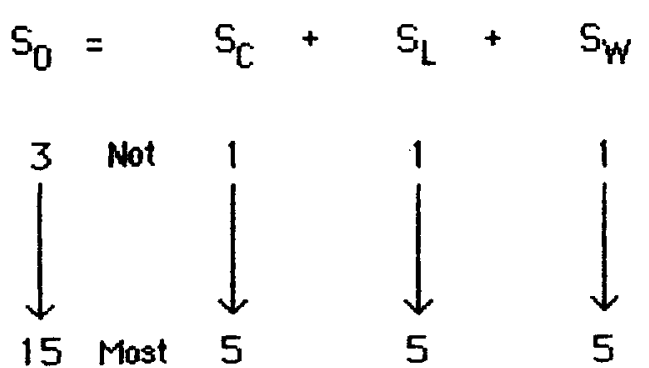

Notes:

(1) Suitability factors are all relative and unitless. Furthermore, they do not represent magnitudes of change ; i. e., the most suitable class could represent more or less than 5 times the suitability of the lesst (not) suitable class.

(2) Total ares in the region defined by the map is $1.898 \times 10^{8}$ hectares or $4.689 \times 10^{8}$ acres.

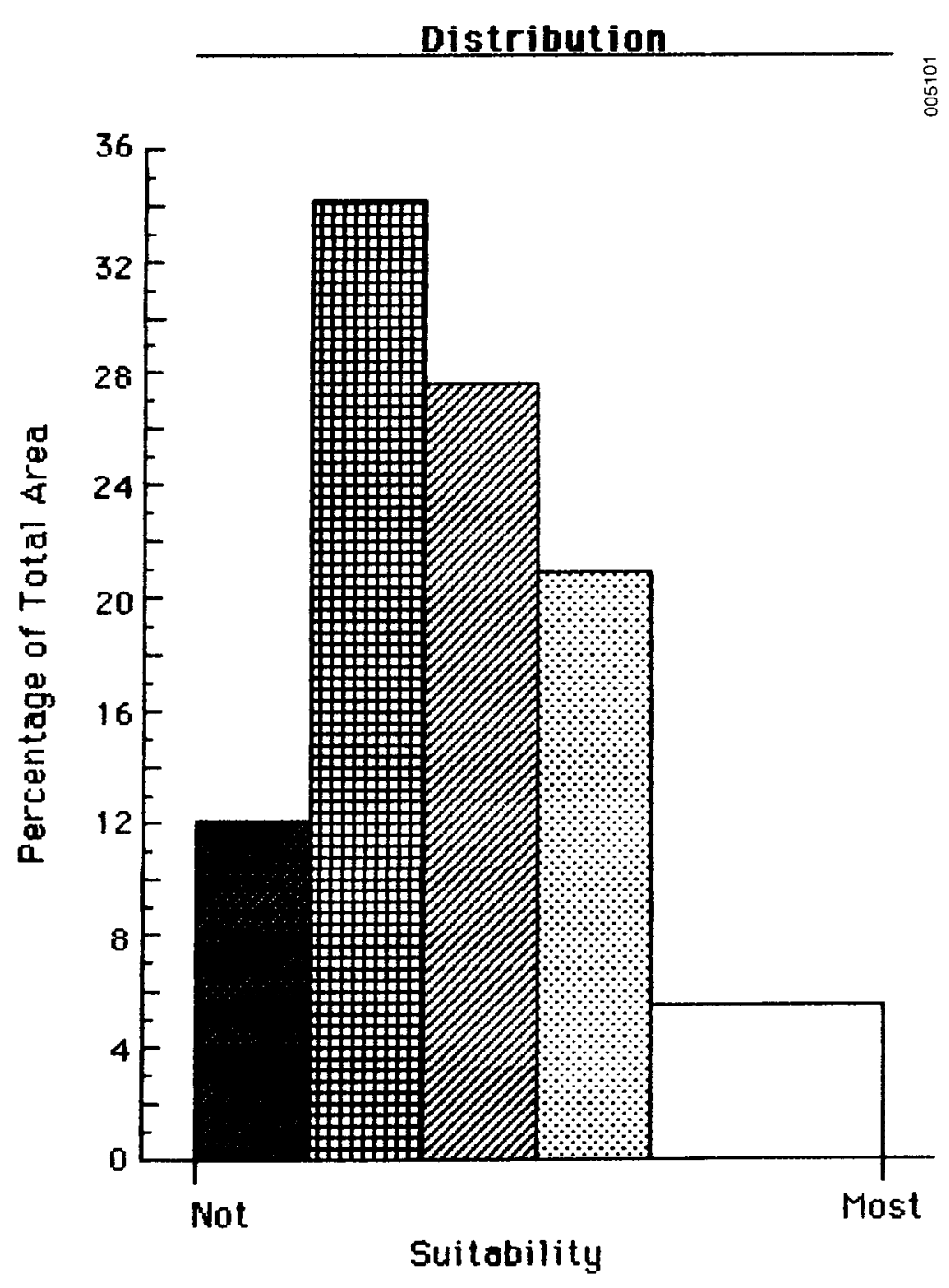

Figure 6-26b. Process Employed to Combine Climate, Land, and Water Suitability Maps to Generate the Overall Suitability Map; Also Bar Graph Depicting the Total Suitability and Proportionate Occurrence of Each Class 


\section{SECTION 7.0}

\section{PLANS FOR FUTURE ASSESSMENTS, STRATIFICATION, AND SITE SELECTION}

Plans for future work should be developed with the following important considerations in mind.

1. The saline groundwater data for the southwestern United States must be considered lacking in geographic coverage, inadequate regarding aquifer yield and water salinity data, deficient regarding supporting geologic strata information, and generally suspect and inadequate for the design and siting of aquatic biomass production systems. This lack of reliable information is the direct result of the lack of interest in this resource in the past. All of the data available are data of opportunity, collected haphazardly with no regard for consistent measurements and data reporting formats.

2. The slope information generated under this project is based on an arbitrary suitability boundary, established for a slope of $10 \%$. A range of slopes should be mapped prior to the refinement of the stratification process and prior to site selections. Both the vertical and horizontal resolutions of the 1:500,000 scale maps used to generate the slope map are inadequate for site selection.

3. The climate data, though of good quality, relate directly to the growth of plants above the surface of the earth. Models must be developed to relate available climatological and meteorological data to the growth environment of shallow ponds containing microalgae cultures. Furthermore, the national resolution of the climate data is inadequate for site selection purposes. State and county level data must be obtained where available; if such data are not available, measurement programs will be required.

4. In order to complete the initial stratification within the time and monies alloted, land ownership and land use classes were combined into broad categories. Furthermore, the digitization employed resulted in a 10:1 degradation in the spatial resolution of the original data. In this instance, the original work was done at scales of $1: 500,000$ and $1: 1,000,000$. All of the original information has been retained for future work.

5. The geographic information system employed for the stratification processing was developed in the 1960s. The use of more sophisticated interactive computer systems could greatly improve both the scientific value and the quality and usefulness of the output products.

6. The weights assigned to the various parameters employed in this initial stratification were based on a cursory analysis necessitated by lack of information, time, and money. A great deal of additional work will be required to develop weighting factors that are truly representative of the relative importance of the parameters employed.

7. Water law and environmental law could easily become the dominant factors detering or prohibiting the construction and operation of large-scale aquatic biomass production systems. Because of the nature of these 
systems, and the lack of previous use of saline water resources, we have virtually no understanding of the nature and magnitude of the problems that may be encountered. History suggests that pioneering ventures into water and environmental legal domains involve time measured not in months but in years. Therefore, initial research to understand this legal maze should be undertaken at the earliest possible date.

8. The 12,455-acre cells employed in the initial stratification will be inadequate for anything except the selection of regions for work at a higher resolution. Those areas of prime suitability should be subjected to resource assessment and stratification procedures at a scale of $1: 500,000$ or $1: 1,000,000$ that would use cell sizes of 500 or 2,000 acres, respectively. This will be required to obtain any credible designation of areas for experimental or production sites. Eventually, of course, one must anticipate work at a scale of 1:24,000 for actual site design and engineering. 


\section{SECTION 8.0}

\section{REFERENCES}

Amirijafiri, B., et al., 1980, Alternative Concepts for Supplying Carbon Dioxide for Enhanced Oil Recovery Projects, DOE/MC/8333-1, Morgantown, WV: Morgantown Energy Technology Center.

Anderson, James R., Ernest E. Hardy, John T. Roach, and Richard E. Witwer, 1976, "A Land Use and Land Cover Classification System for Use with Remote Sensor Data," Geological Survey Professional Paper 964, Washington, DC: USGPO, $28 \mathrm{pp}$.

Benemann, J. R., and L. P. Raymond, 1981, An Examination of Aquatic Biomass Production, Report prepared for the Solar Energy Research Institute, Golden, C0, 139 pp.

CSo International Inc., 1978, Cost Analysis of Microalgae Biomass Systems, HCP/T1605-01, available from NTIS, Springfield, VA, 98 pp.

Dynatech R/D Company, 1978, Cost Analysis of Aquatic Biomass Systems, HCP/ET-4000-78/1, available from NTIS, Springfield, VA, $255 \mathrm{pp}$.

Fegeas, Robin G., Robert W. Claire, Stephen C. Gupti11, K. Eric Anderson, and Cheryl A. Hallam, 1983, "Land Use and Land Cover Digital Data," Geological Survey Circular 895-E, Alexandria, VA: U.S. Geological Survey, 21 pp.

Feth, J. H. et al., 1965, "Preliminary Map of the Conterminous United States Showing Depth to and Quality of Shallowest Ground Water Containing More than 1,000 Parts per Million Dissolved Solids," Hydrologic Investigations Atlas HA-199, U.S. Geological Survey, 31 pp.

Goldman, Joel C., 1979, "Outdoor Algal Mass Cultures--I. Applications," Water Research, Vol. 13, pp. 1-19.

McHarg, I. M., 1969, Design with Nature, Garden City, NY: Natural History Press.

Prickett, T. A., and C. G. Lonnquist, 1971, "Selected Digital Computer Techniques for Groundwater Resource Evaluation," Illinois State Water Survey Bulletin 55, 62 pp.

Sharpnack, D. A., and G. Akin, 1969, "An Algorithm for Computing Slope and Aspect from Elevations," Photogrammetric Engineering, Vol. 35, pp. 247-248.

Shelf, G., and C. J. Sorder, editors, 1980, Algae Biomass, Elsevier/NorthHolland Biomedical Press.

Solar Energy Research Institute (SERI), 1981, Solar Radiation Energy Resource At las of the United States, SERI/SP-642-1037, Golden, CO: Solar Energy Research Institute, $178 \mathrm{pp}$. 
Trescott, P. C., G. F. Pinder, and S. P. Larson, 1976, "Finite-Difference Mode1 for Aquifer Simulation in Two Dimensions with Results of Numerical Experiments," Techniques of Water Resources Investigations of the U.S. Geological Survey Book 7, Chap. C1., $116 \mathrm{pp}$.

Turner, A. Keith, 1976, "Computer Aided Environmental Impact Analysis, Part I," MER19 \#2. Golden, CO: Colorado School of Mines.

Turner, A. Keith, Joseph C. Weber, and Michael DeAngelis, 1981, A Geographic Market Suitability Analysis for Low- and Intermediate-Temperature Solar IPH Systems, SERI/TR-733-1194, Vo1 I., Golden, CO: Solar Energy Research Institute, $126 \mathrm{pp}$.

U.S. Department of Commerce (USDC), 1977, Climatic Atlas of the United States, Asheville, NC: Department of Commerce, NOAA, $80 \mathrm{pp}$.

Vigon, B. W., M. F. Arthur, L. G. Taft, C. K. Wagner, E. S. Lipinsky, J. H. Litchfield, C. McCandlish, and R. Clark, 1982, Resource Assessment for Microalga1/Emergent Aquatic Biomass Systems in the Arid Southwest. Report prepared for the Solar Energy Research Institute, Golden, C0, 119 pp. 


\begin{tabular}{|c|c|c|}
\hline $\begin{array}{l}\text { Document Control } \\
\text { Page }\end{array}$ & \begin{tabular}{|l|l|} 
1. SERI Report No. & 2. NTIS Accession No. \\
SERI/TR-215-2484 & \\
\end{tabular} & 3. Recipient's Accession No. \\
\hline \multirow{3}{*}{\multicolumn{2}{|c|}{$\begin{array}{l}\text { 4. Title and Subtitle } \\
\text { Resource Evaluation and Site Selection for Microalgae } \\
\text { Production Systems }\end{array}$}} & 5. Publication Date \\
\hline & & November 1984 \\
\hline & & 6. \\
\hline \multicolumn{2}{|c|}{$\begin{array}{l}\text { 7. Author(s) Eugene L. Maxwel], A. Gray Folger, } \\
\text { Susan E. Hogg }\end{array}$} & 8. Performing Organization Rept. No. \\
\hline \multirow{2}{*}{\multicolumn{2}{|c|}{$\begin{array}{l}\text { 9. Performing Organization Name and Address } \\
\text { Solar Energy Research Institute } \\
1617 \text { Cole Boulevard } \\
\text { Golden, Colorado } 80401\end{array}$}} & 10. Project/Task/Work Unit No. \\
\hline & & $\begin{array}{l}\text { 11. Contract (C) or Grant (G) No. } \\
\text { (C) } \\
\text { (G) }\end{array}$ \\
\hline \multirow{2}{*}{\multicolumn{2}{|c|}{ 12. Sponsoring Organization Name and Address }} & $\begin{array}{l}\text { 13. Type of Report \& Period Covered } \\
\text { Technical Report }\end{array}$ \\
\hline & & 14. \\
\hline \multicolumn{3}{|l|}{ 15. Supplementary Notes } \\
\hline \multicolumn{3}{|c|}{$\begin{array}{l}\text { 16. Abstract (Limit: } 200 \text { words) Climate, land, and water resource requirements of microalgae } \\
\text { production systems (MPS) were examined relative to construction costs, operating } \\
\text { costs, and biomass productivity. The objective was the stratification of the south- } \\
\text { western United States into zones of relative suitability for MPS. Maps of climate } \\
\text { (insolation, freeze-free period, precipitation, evaporation, thunderstorm days), } \\
\text { land (use/cover, ownership, slope), and water (saline groundwater) resource param- } \\
\text { eters were obtained. These maps were transformed into digital overlays permitting } \\
\text { the cell-by-cell compositing of selected resource parameters to form maps repre- } \\
\text { senting relative productivity, make-up water, climate suitability, land suitability, } \\
\text { water suitability, and overall suitability. The Southwest was selected for this } \\
\text { study because of its high levels of insolation, saline water resources, and large } \\
\text { areas of relatively low valued land. The stratification maps cannot be used for } \\
\text { the selection of specific sites because of their low resolution (12,455-acre cells). } \\
\text { They can be used to guide future resource studies and site selection efforts, how- } \\
\text { ever, by limiting these efforts to the most suitable regions. Future efforts } \\
\text { should concentrate on saline water resources, for which only limited data are } \\
\text { currently available. }\end{array}$} \\
\hline \multicolumn{3}{|l|}{$\begin{array}{l}\text { 17. Document Analysis } \\
\text { a. Descriptors Alg } \\
\text { Productivity }\end{array}$} \\
\hline \multicolumn{3}{|l|}{ c. UC Categories } \\
\hline \multicolumn{3}{|l|}{61} \\
\hline \multirow{2}{*}{\multicolumn{2}{|c|}{$\begin{array}{l}\text { 18. Availability Statement } \\
\text { National Technical Information Service } \\
\text { U.S. Department of Commerce } \\
5285 \text { Port Royal Road } \\
\text { Springfield, Virginia } 22161\end{array}$}} & $\begin{array}{c}\text { 19. No. of Pages } \\
100\end{array}$ \\
\hline & & $\begin{array}{r}\text { 20. Price } \\
\text { A05 }\end{array}$ \\
\hline
\end{tabular}

